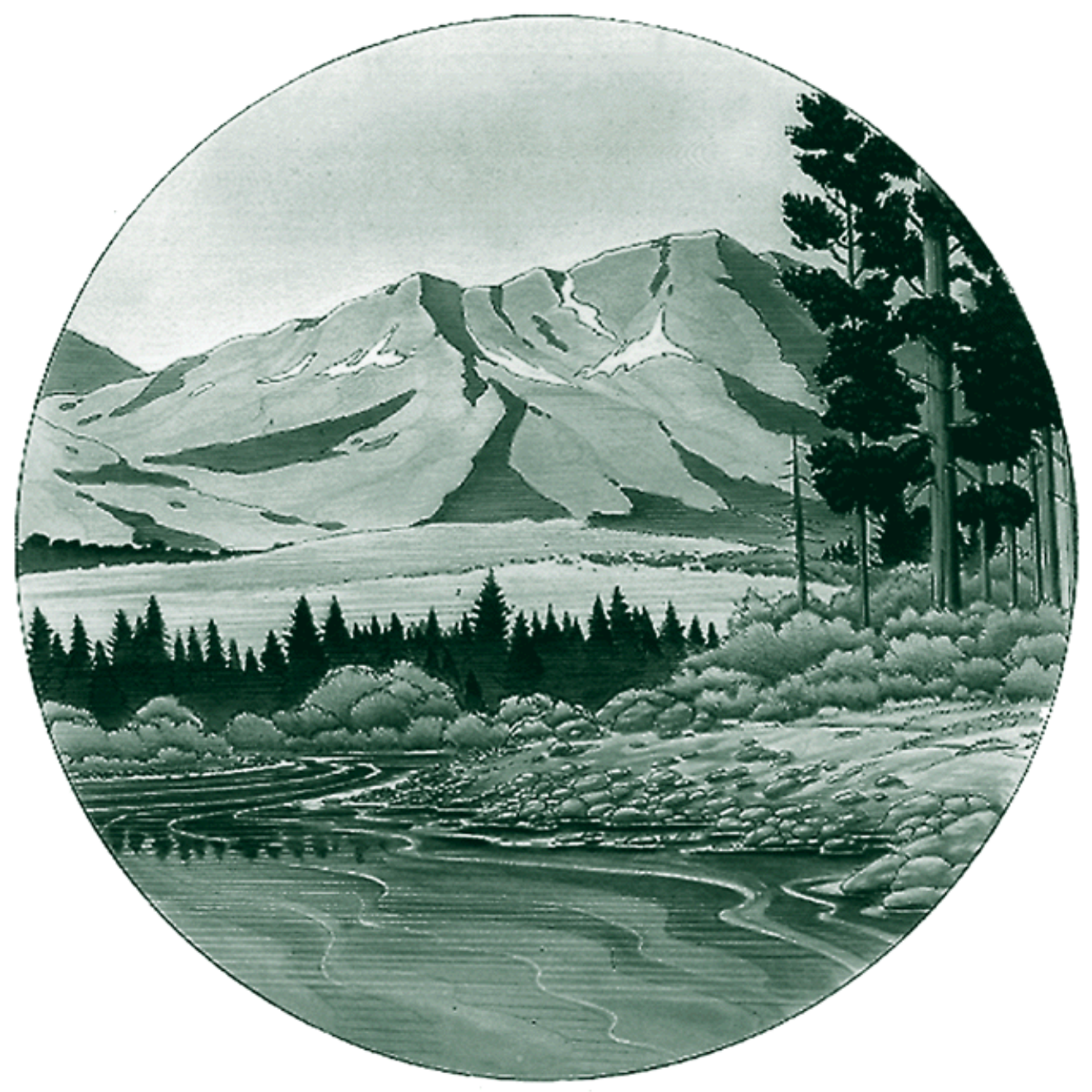


This report was funded by the Bonneville Power Administration (BPA), U.S. Department of Energy, as part of BPA's program to protect, mitigate, and enhance fish and wildlife affected by the development and operation of hydroelectric facilities on the Columbia River and its tributaries. The views of this report are the author's and do not necessarily represent the views of BPA.

This document should be cited as follows:

S. L. Blanton, McMichael, G. A., Neitzel, D. A., Pacific Northwest National Laboratory, 1999, Annual Report 1998 to Bonneville Power Administration, Portland, OR, Contract DE-AI79-86BP62611, Project 86118, 68 electronic pages (BPA Report DOE/BP-62611-15)

This report and other BPA Fish and Wildlife Publications are available on the Internet at:

\section{http://www.efw.bpa.gov/cgi-bin/efw/FW/publications.cgi}

For other information on electronic documents or other printed media, contact or write to:

Bonneville Power Administration Environment, Fish and Wildlife Division

P.O. Box 3621

905 N.E. 11th Avenue

Portland, OR 97208-3621

Please include title, author, and DOE/BP number in the request. 


\title{
Washington Phase II Fish Diversion Screen Evaluations in the Yakima River Basin, 1998
}

\author{
Prepared by: \\ S.L. Blanton \\ G.A. McMichael \\ D.A. Neitzel \\ Pacific Northwest National Laboratory \\ Richland, Washington \\ Prepared for: \\ U.S. Department of Energy \\ Bonneville Power Administration \\ Environment Fish and Wildlife \\ P.O. Box 3621 \\ Portland, Oregon 97208-3621 \\ Project Number 86-118 \\ Task Order DE-AT79-9430373BPA \\ Contract Number DE-AI79-86BP62611
}

December 1999 
[left blank with purpose] 


\section{Contents}

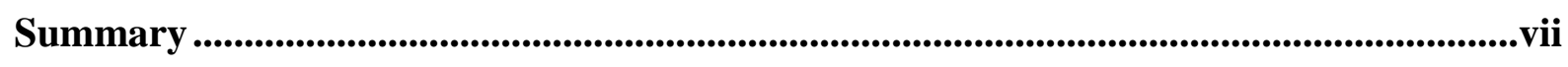

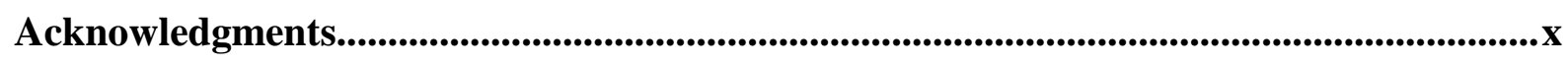

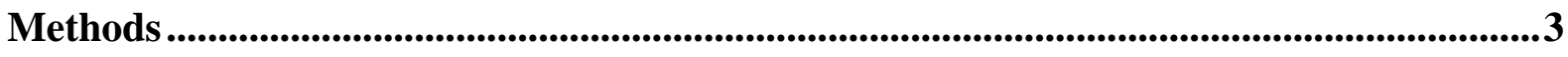

Water Velocity Measurements ........................................................................... 4

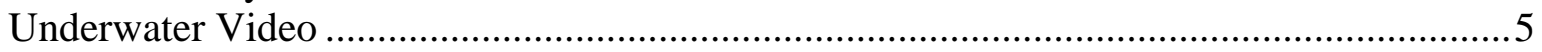

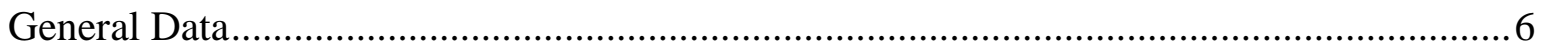

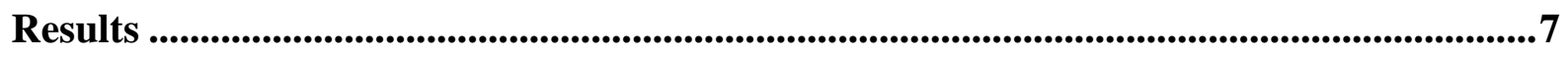

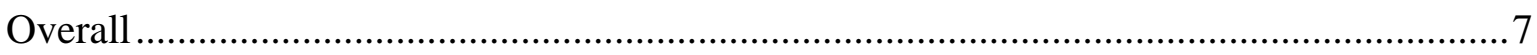

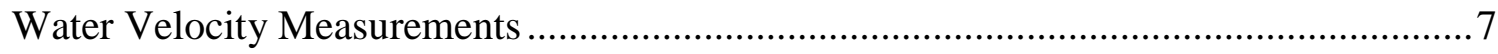

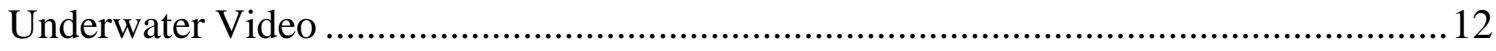

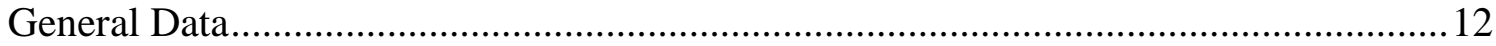

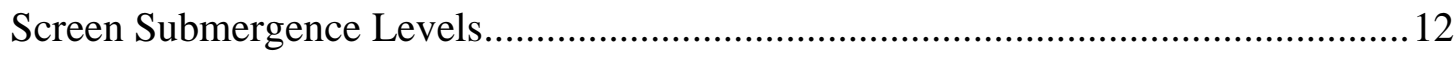

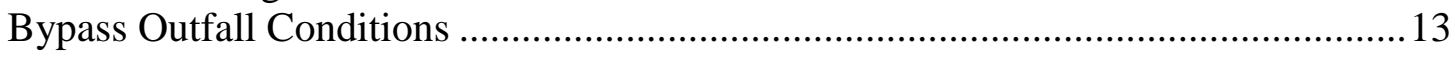

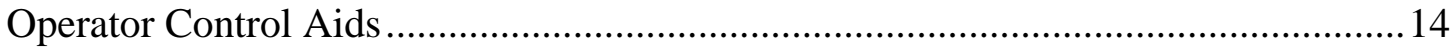

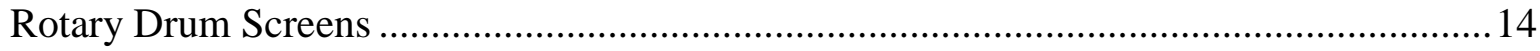

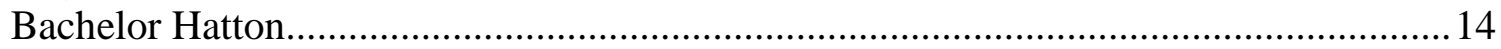

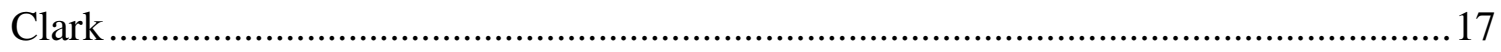

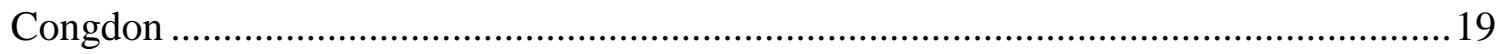

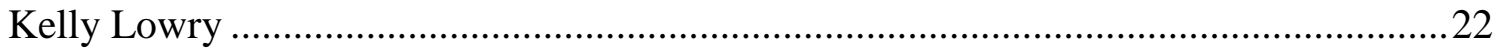

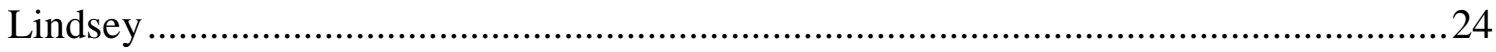

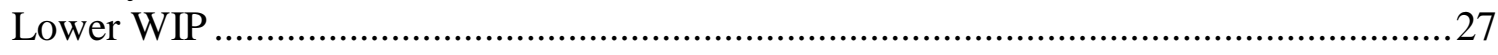

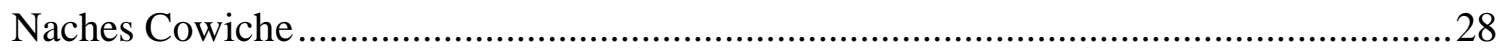

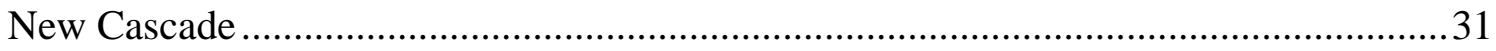

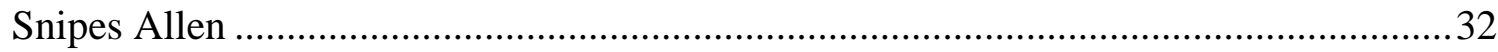

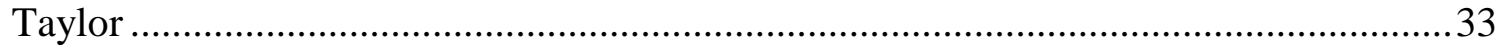

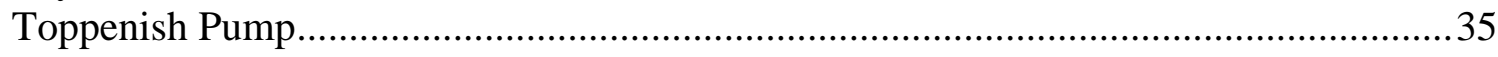

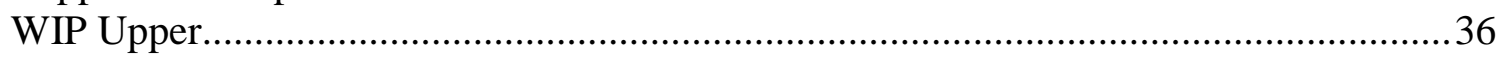

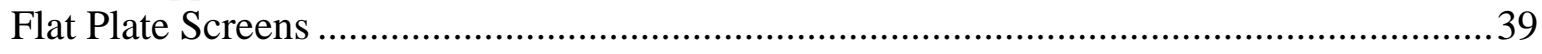

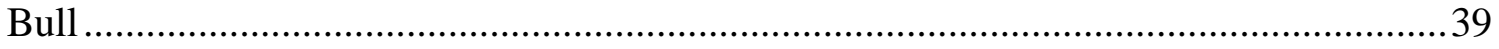

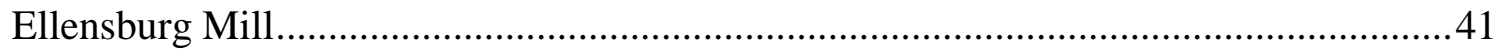

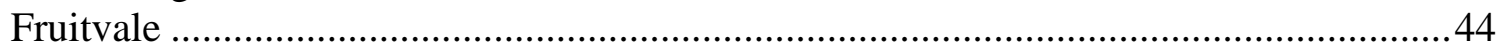

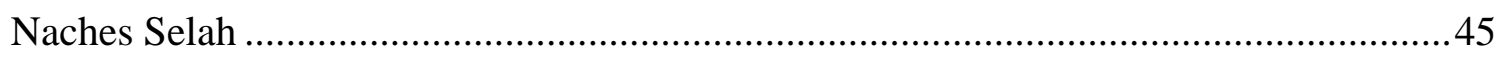

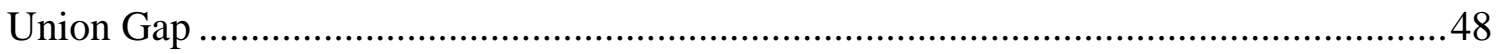

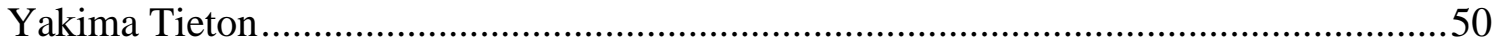

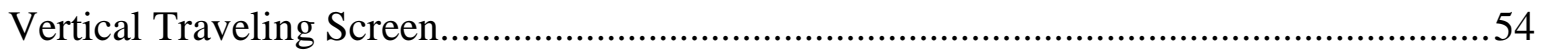

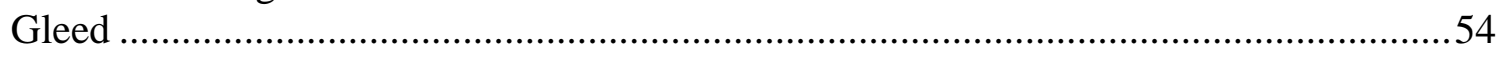

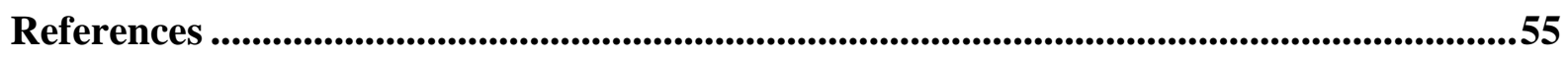




\section{Figures}

Figure 1. Yakima River Basin phase II screening facilities................................................ 3

Figure 2. Bi-directional electromagnetic probe used for measuring water velocity ....................4

Figure 3. Percentage of measurements at Yakima Basin Phase II screen sites that met or did not meet NMFS approach velocity criteria of $0.4 \mathrm{fps}$ in 1998.

Figure 4. Mean approach, sweep, and bypass velocities (fps) at Phase II fish screen facilities in the Yakima Basin in 1998.

Figure 5. Water velocities at Bachelor Hatton, 5/7/98 ....................................................... 15

Figure 6. Water velocities at Bachelor Hatton, 6/30/98 ................................................. 15

Figure 7. Unbalanced headgate openings at Bachelor Hatton, May 7, 1998........................ 16

Figure 8. Circular flow pattern at Bachelor Hatton, May 7, 1998. ......................................... 16

Figure 9. Water velocities at Clark, 5/11/98................................................................. 18

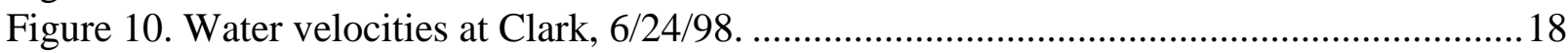

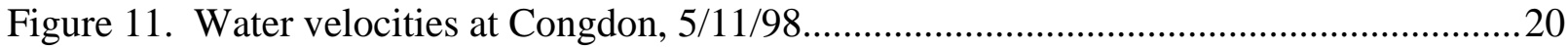

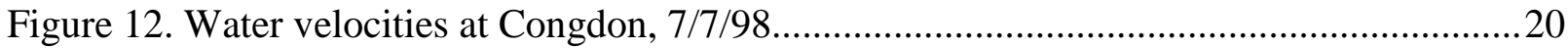

Figure 13. Water velocities at Congdon, 9/15/98.............................................................2 21

Figure 14. Water velocities at Kelly Lowry, 5/11/98.........................................................22

Figure 15. Water velocities at Kelly Lowry, 7/7/98 .......................................................23

Figure 16. Water velocities at Kelly Lowry, 9/21/98.....................................................23

Figure 17. Gap (in yellow elipse) observed under Screen 1 (upstream) at the Kelly Lowry

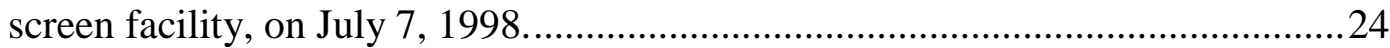

Figure 18. Water velocities at Lindsey, 5/12/98 .............................................................25

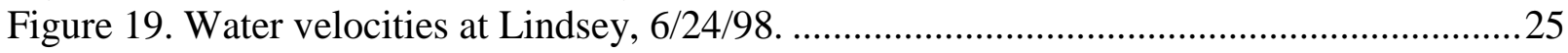

Figure 20. Water velocities at Lindsey, 9/16/98.............................................................26

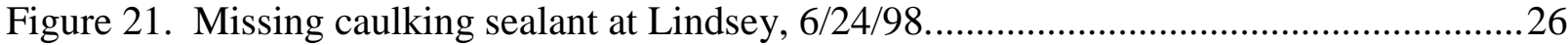

Figure 22. Flooding at Lower WIP, 5/7/98 ..................................................................2 27

Figure 23. Woody debris in the forebay at Lower WIP, 7/6/98 ..........................................28

Figure 24. Water velocities at Naches Cowiche, 5/11/98 ...............................................29

Figure 25. Water velocities at Naches Cowiche, 7/7/98 ....................................................29

Figure 26. Water velocities at Naches Cowiche, 9/15/98 ...................................................30

Figure 27. Adult rainbow trout filmed by underwater video in front of the New Cascade

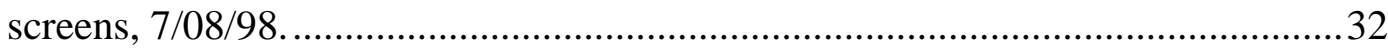

Figure 28. Water velocity at Snipes Allen, 5/7/98 ............................................................ 33

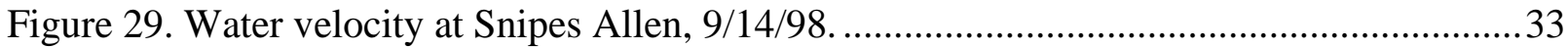

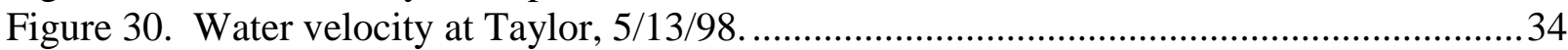

Figure 31. Island of sediment formed behind the Taylor Screens, 9/21/98 ...........................35

Figure 32. Water Velocities at Toppenish Pump, 6/30/98 ..................................................36

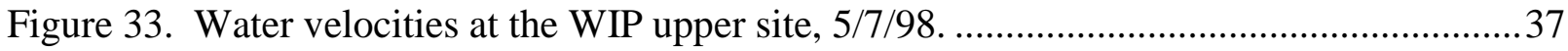

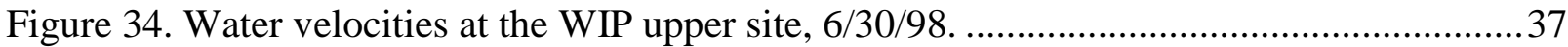

Figure 35. Water velocities at the WIP upper site, $9 / 14 / 98$.................................................. 38

Figure 36. Dry Ahtanum Creek bed (left) and bypass outfall area (right) when water was fully diverted at the WIP upper site, 9/14/98 ....................................................39

Figure 37. Water velocities at Bull, 7/7/98.

Figure 38. Water velocities at Bull, 9/17/98. 
Figure 39. Loose caulking on flat plate screen at Bull ditch diversion on 7/7/98..................41

Figure 40. Water velocities at Ellensburg Mill, 5/13/98 ...................................................42

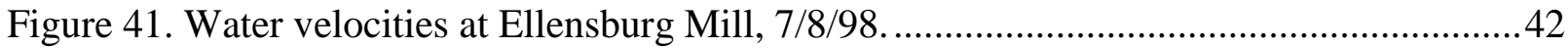

Figure 42. Water velocities at Ellensburg Mill, 9/17/98 ....................................................43

Figure 43. Loose/missing caulking on screen seal at the Ellensburg Mill diversion, 9/17/98...43

Figure 44. Debris removed from the trash rack at Ellensburg Mill, 5/13/98 ........................44

Figure 45 . New metal plate attached above the screen and $100 \%$ submergence mark on the green metal corner piece, $5 / 11 / 98$...................................................................45

Figure 46. Device used to move silt away from the screen at Naches Selah, 6/24/98.............46

Figure 47. Water velocities at Naches Selah, 5/12/98 ..................................................46

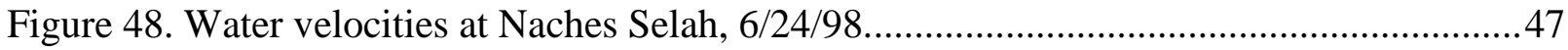

Figure 49. Water velocities at Naches Selah, 9/16/98 ...................................................... 47

Figure 50. Piles of sediment removed from the forebay at Naches Selah, 5/12/98............... 48

Figure 51. Water velocities at Union Gap, 5/11/98..........................................................49

Figure 52. Water velocities at Union Gap, 7/1/98...........................................................49

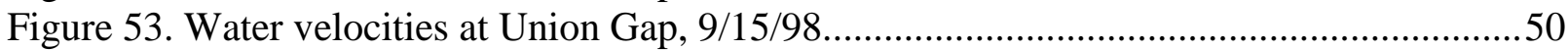

Figure 54. Water velocities at Yakima Tieton, 5/12/98 ...............................................51

Figure 55. Water velocities at Yakima Tieton, 6/23/98 ...................................................... 51

Figure 56. Water Velocities at Yakima Tieton, 9/16/98....................................................5 52

Figure 57. Leafy material accumulating on the Yakima Tieton screen, 5/12/98..................53

Figure 58. Kokanee retrieved from the bypass at Yakima Tieton, 5/12/98 .........................53 


\section{Tables}

Table 1. Summary of problem areas identified at Yakima River Basin Phase II screen sites

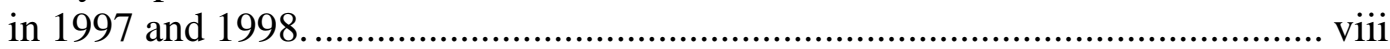

Table 2. Percent of approach velocity measurements that exceeded the NMFS criteria of 0.4 fps by screen site. Comparable percentages of velocities that exceeded 0.4 fps at these sites in 1997 are shown for comparison in parentheses. ......................8

Table 3. Mean sweep and approach velocities ( \pm standard deviation) at Phase II fish screen facilities in the Yakima Basin in 1998. ................................................................. 10 


\section{Summary}

Pacific Northwest National Laboratory (PNNL) evaluated 19 Phase II screen sites in the Yakima River Basin as part of a multi-year study for the Bonneville Power Administration (BPA) on the effectiveness of fish screening devices. The sites were examined to determine if they were being effectively operated and maintained to provide fish a safe, efficient return to the Yakima River. Data were collected to determine if velocities in front of the screens and in the bypass met current National Marine Fisheries Service (NMFS) criteria to promote safe and timely fish bypass and whether bypass outfall conditions allowed fish to safely return to the river.

In general, water velocity conditions at the screen sites met fish passage criteria set forth by the NMFS. Although velocities often fluctuated from one sampling location to the next, average sweep velocities typically exceeded approach velocities and increased toward the bypass. Mean approach velocities were below the NMFS criteria of $\leq 0.4$ feet per second at most sites (Table 1). Based on our observations in 1998, we believe that most facilities were efficiently protecting juvenile fish from entrainment, impingement, or migration delay.

Most screens were properly sealed to prevent fish entrainment and injury, although potential problems were identified at several screen sites. Seven sites (fewer than the 10 sites identified in 1997) had loose or damaged seals that might have allowed fish to be entrained (Table 1). Other sites still had spaces larger than 3/32 inch where small fish could possibly pass into the irrigation canal.

Submergence levels at the drum screen sites $(\mathrm{N}=12)$ exceeded established criteria (between 65 and $85 \%$ submerged) in $23 \%$ of the site evaluations. About two-thirds of the drum screen facilities were always within the established criteria for drum submergence (Table 1).

Water depths at the outfall pipe were acceptable at all but one site (Table 1). Generally, water depths were low near the end of the irrigation season due to low river flows. Screens were generally well maintained. Automated cleaning brushes generally functioned properly, chains and other moving parts were well greased, and inoperative and algae-covered drum screens were repaired and cleaned, typically within 1 month of notification (unless the severity of the problem 
Table 1. Summary of problem areas identified at Yakima River Basin Phase II screen sites in 1997 and 1998.

\begin{tabular}{|c|c|c|c|c|c|c|c|c|c|c|c|c|c|}
\hline \multirow[b]{2}{*}{ Year } & \multirow[b]{2}{*}{$\begin{array}{l}\text { Screen } \\
\text { Site }\end{array}$} & \multicolumn{2}{|c|}{ 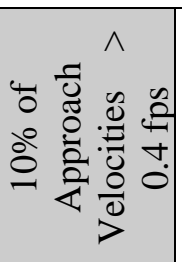 } & \multicolumn{2}{|c|}{ 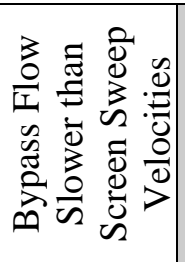 } & \multicolumn{2}{|c|}{ 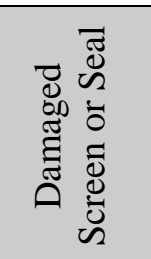 } & \multicolumn{2}{|c|}{ 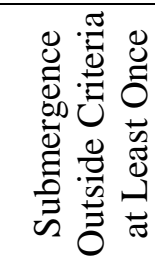 } & \multicolumn{2}{|c|}{ 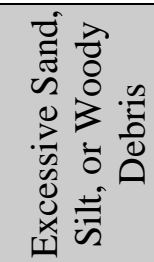 } & \multicolumn{2}{|c|}{ 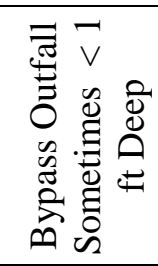 } \\
\hline & & ล̊ & $\stackrel{\infty}{\sigma}$ & à & $\stackrel{\infty}{2}$ & ลू & $\stackrel{\infty}{\sigma}$ & $\hat{\sigma}$ & $\stackrel{\infty}{2}$ & $\hat{\alpha}$ & $\stackrel{\infty}{2}$ & $\hat{a}$ & $\stackrel{\infty}{2}$ \\
\hline \multirow[t]{12}{*}{$\begin{array}{c}\text { Drum } \\
\text { Screens }\end{array}$} & $\begin{array}{l}\text { Bachelor } \\
\text { Hatton }\end{array}$ & $\bullet$ & $\diamond$ & $\bullet$ & $\diamond$ & - & $\diamond$ & & $\diamond$ & • & $\diamond$ & & \\
\hline & Clark & & & & & & & - & $\diamond$ & & $\diamond$ & - & \\
\hline & Congdon & • & & & $\diamond$ & $\bullet$ & & - & & - & & & \\
\hline & $\begin{array}{l}\text { Kelly } \\
\text { Lowry }\end{array}$ & & & & & & $\diamond$ & • & & • & & & \\
\hline & Lindsey & & $\diamond$ & & & & $\diamond$ & $\bullet$ & $\diamond$ & $\bullet$ & & $\bullet$ & \\
\hline & $\begin{array}{l}\text { Lower } \\
\text { WIP }\end{array}$ & & & & & & & - & & • & $\diamond$ & & \\
\hline & $\begin{array}{l}\text { Naches } \\
\text { Cowiche }\end{array}$ & & & & & & & • & & & $\diamond$ & & \\
\hline & $\begin{array}{l}\text { New } \\
\text { Cascade } \\
\end{array}$ & & & & & • & & & & & & & \\
\hline & $\begin{array}{l}\text { Snipes } \\
\text { Allen }\end{array}$ & & & & & - & & $\bullet$ & & & & & \\
\hline & Taylor & & & & & - & & $\bullet$ & $\diamond$ & • & $\diamond$ & & \\
\hline & $\begin{array}{l}\text { Toppenish } \\
\text { Pump }\end{array}$ & • & $\diamond$ & & & $\bullet$ & $\diamond$ & & & • & $\diamond$ & & \\
\hline & $\begin{array}{l}\text { WIP } \\
\text { Upper }\end{array}$ & • & & $\bullet$ & $\diamond$ & • & & & $\diamond$ & - & $\diamond$ & • & \\
\hline \multirow{6}{*}{$\begin{array}{l}\text { Vertical } \\
\text { Plate } \\
\text { Screens }\end{array}$} & Bull & $\bullet$ & & & $\diamond$ & & & $\bullet$ & 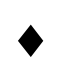 & & & & \\
\hline & $\begin{array}{l}\text { Ellensburg } \\
\text { Mill }\end{array}$ & & & & & $\bullet$ & & & & & $\diamond$ & & \\
\hline & Fruitvale & $\bullet$ & & & & & & $\bullet$ & $\diamond$ & & $\diamond$ & • & \\
\hline & $\begin{array}{l}\text { Naches } \\
\text { Selah }\end{array}$ & & & & & - & $\diamond$ & & & & $\diamond$ & & 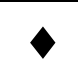 \\
\hline & Union Gap & & & $\bullet$ & & & & & & & & & \\
\hline & $\begin{array}{l}\text { Yakima } \\
\text { Tieton }\end{array}$ & - & & & & & 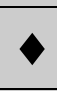 & & & & & & \\
\hline $\begin{array}{c}\text { Vertical } \\
\text { Traveling } \\
\text { Screen }\end{array}$ & Gleed & & & & & 0 & $\diamond$ & & & • & $\diamond$ & & \\
\hline
\end{tabular}


required removal of the screens, in which case they were repaired following the irrigation season), by the Washington Department of Fish and Wildlife's Screen Shop staff. However, removal of sediment build-up and accumulated leafy and woody debris are areas where improvement should be considered. Some cleaning brushes should have been set to operate more frequently. Maintenance checks should include observation of bypass outfalls on a regular basis to ensure that bypassed fish have an unobstructed re-entry into the stream channel, as conditions at the end of the bypass pipe are likely to change seasonally, especially in streams with high gradients or unstable gravel.

Continued periodic, regular screen evaluations will increase the effectiveness of screen operation and maintenance practices by confirming the effectiveness (or ineffectiveness) of screen operating procedures at individual sites. Where procedures are being followed and problems still occur, evaluation results will suggest means to better protect fish at screening facilities. There has been a progressive improvement in the design, construction, maintenance and effectiveness of these Phase II fish screen facilities during the past several years, in part as a result of regular screen evaluations and the rapid feedback of information necessary to improve operations of these important fish protection devices. 


\section{Acknowledgments}

The successful completion of this project depended on the involvement and cooperation of many people. Jodi Stroklund and Ken Barnhart, Bonneville Power Administration (BPA), directed the project. John Easterbrooks, Washington Department of Fish and Wildlife (WDFW), provided valuable background information on the sites and also comments on the operation and maintenance of individual sites. Scott Abernethy, Corey Duberstein, Bill Mavros, and Bob Mueller of PNNL, and students Jeff Marco, and Anita Musik assisted during field evaluations and/or data interpretation. 


\section{Introduction}

Over the years, irrigation has played an important role in the development of the middle Columbia River Basin. Water has been diverted from western rivers since the mid-1850's to irrigate crops. During the 1920's, some of these diversions were equipped with fish protection devices, but it wasn't until the Mitchell Act of 1938 provided funding to protect fish that screening irrigation diversions and evaluating their effectiveness truly got underway (Bryant and Parkhurst 1950) .

In more recent history, the Bonneville Power Administration (BPA) and the Northwest Power Planning Council (Council) expanded screening efforts to protect and enhance fish populations. The Council's Columbia River Fish and Wildlife Program (Program) lists fish protection through effective screening of irrigation diversions as an essential element in their plan to restore declining steelhead (Oncorhynchus mykiss) and salmon runs (NPPC 1984, 1987, 1994).

Research on the effectiveness of fish screening devices initiated changes in design and operating procedures of screening facilities over the years. For example, maximum allowable screen size openings decreased as protecting fish at their earliest developmental stages became a national concern. Such new requirements for fish protection are developed by the National Marine Fisheries Service (NMFS) and adopted by individual state agencies. Changes in the regulations require that older, less efficient screening facilities be updated or replaced. Through a regional Conservation and Electric Power Plan implemented under the Pacific Northwest Electric Power Planning and Conservation Act, the BPA and the Bureau of Reclamation (BoR) funded construction of and improvements to fish passage and protection facilities at irrigation diversions in the Yakima River Basin. Construction and enhancements of the Phase II screens are part of this plan. In addition, BPA has established a monitoring and evaluation program to ensure that new and updated screening facilities meet current fish protection standards.

PNNL staff have conducted a number of fish screen evaluations in the Yakima Basin since 1985. Initially, staff monitored Phase I screening facilities to determine whether fish that entered irrigation canals were diverted back to the river safely (Neitzel et al. 1985; 1986; 1988; 1990a; and 1990b). Additional studies examined water velocities in front of the screens to determine whether NMFS criteria were being met (Abernethy et al. 1990). Two studies conducted at PNNL's Aquatic Laboratory in Richland, Washington, used modular drum screens 
constructed by the Washington Department of Fish and Wildlife (WDFW) to determine fish survival through submerged orifices and the relative effectiveness of two screen configurations at bypassing fish (Abernethy et al. 1996; Neitzel et al. 1997). The methods developed while conducting these studies were incorporated into Phase II screen site surveys conducted in 1997 (Blanton et al. 1998).

In 1997, 19 Phase II sites were evaluated. Those evaluations addressed three main questions:

1. Are screens designed, operated, and maintained to meet NMFS criteria standards over a wide range of conditions?

2. Do velocities/flows meet NMFS criteria?

3. Are screens effective at protecting fish from injury and from unnecessary migration delay?

Surveys were conducted at the same 19 Phase II sites in 1998 to evaluate operations and maintenance of the screens over time and changing water conditions. This report presents the results of the 1998 surveys. 


\section{Methods}

Nineteen operating screen sites in the Yakima, Naches, and Tieton river basins were evaluated between 5/7/98 and 9/21/98 (Figure 1).

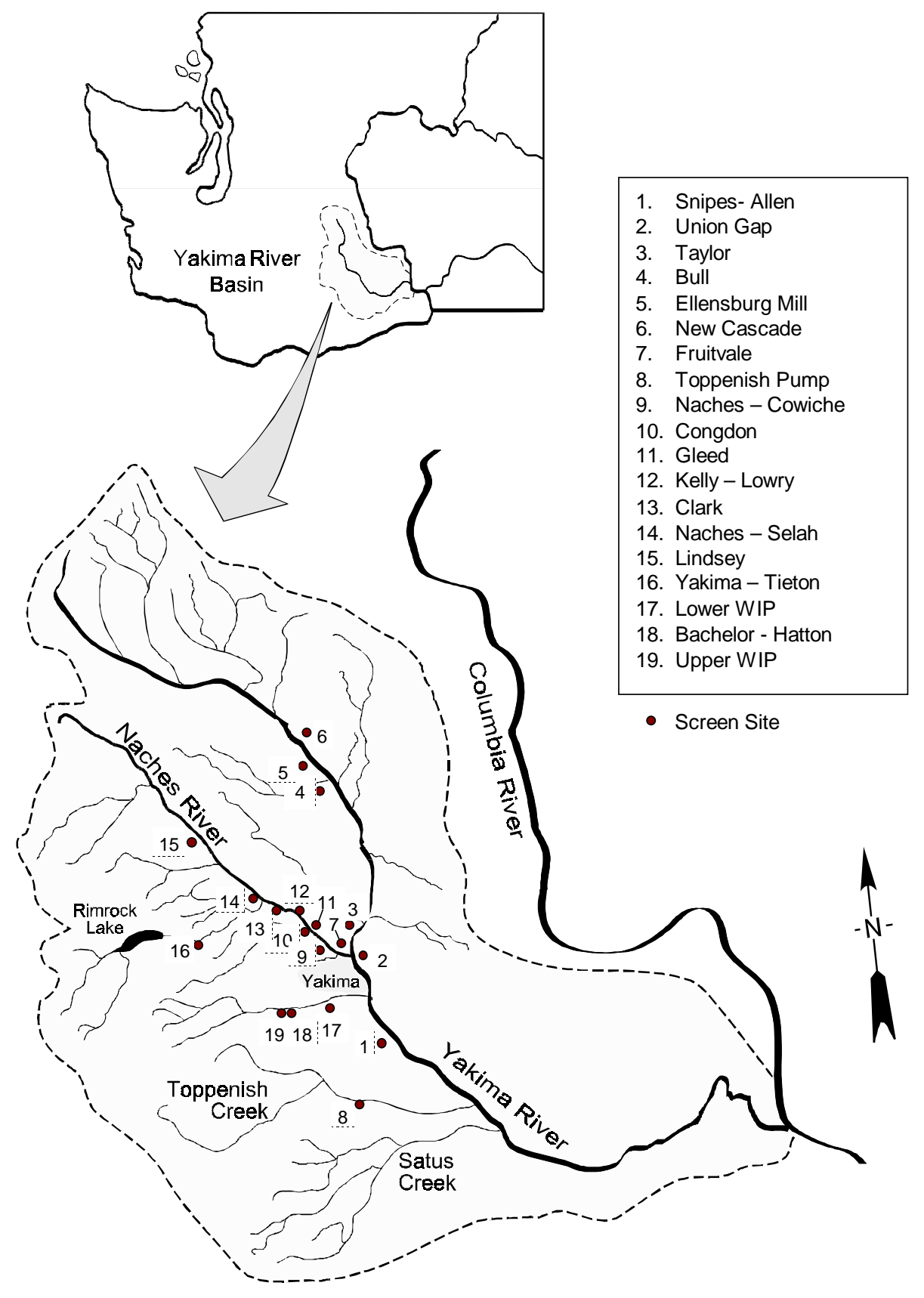

Figure 1. Yakima River Basin phase II screening facilities. 
Most of the 19 sites were visited three times during 1998. The three rounds of evaluations were conducted during May, late June/early July, and September, 1998. Three types of data were collected. These included water velocity measurements, underwater video, and general data (i.e., screen submergence, bypass conditions, fish presence, operator aids), as described below.

\section{Water Velocity Measurements}

\section{Equipment}

Water velocities in front of the screens and in the bypass were measured with a MarshMcBirney Model $511^{\circledR}$ electromagnetic water current meter. The meter used a bi-directional probe (Figure 2) that allowed measurement of flows in two directions (approach and sweep) simultaneously. Output was read visually from a panel gage. The probe was securely mounted to a horizontal metal arm that extended approximately 12 in. from a vertical pole. The length of the horizontal arm and its position on the vertical pole were adjustable. The probe support assembly was positioned at least 12 in. downstream or outside the probe's sensors to minimize interference from the vertical pole when taking velocity readings.

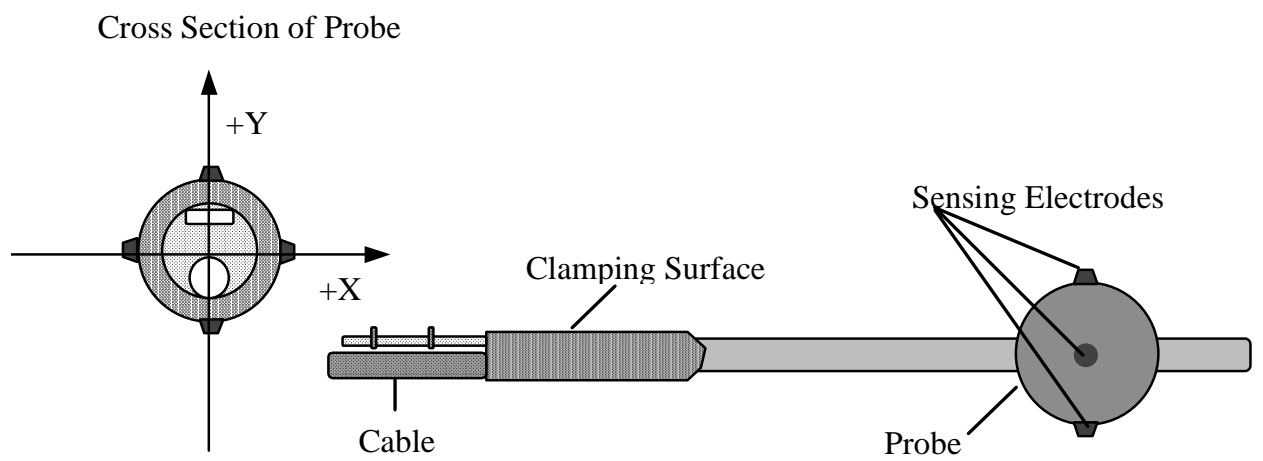

Figure 2. Bi-directional electromagnetic probe used for measuring water velocity

\section{Probe Positioning}

Velocity measurements were taken in front of all screens. The vertical pole was placed close to the front of the screen, but was never in contact with the screen face. The bottom of the pole rested on the concrete forebay floor (usually on the raised sill), but the pole was not allowed to come in contact with metal (e.g., walking platform, gantry, or girder) to reduce the likelihood of electrical interference. The probe was pointed upstream and was positioned within 3 in. of the 
screen face. Because the screens are constructed at an angle to the canal flow, all measurements were taken with the probe orientation parallel (sweep) and perpendicular (approach) to the screen face, not to canal flow. Measurements were taken across the screen face at 0.2 and 0.8 of the water depth when the forebay depth was $\geq 4 \mathrm{ft}$. Measurements were taken only at 0.6 of the water depth where forebay depth was $<4 \mathrm{ft}$. Velocity measurements were taken at either three or five evenly spaced positions across each screen or panel.

Velocities were also measured in the bypass. Two measurements were recorded. The first was taken immediately inside the vertical slot bypass entrance at mid-water depth. The second was recorded halfway between the bypass entrance and the overflow weir, again at midwater depth.

\section{Data Collection and Analysis}

Flow measurements were taken in front of every screen during all three site visits. Power-todrum screens and cleaning brushes were disconnected to decrease the likelihood of electrical interference. Average ( \pm 1 standard deviation) sweep and approach velocities at each site were calculated for each visit.

\section{Underwater Video}

Equipment

An underwater video system was used to investigate screen seal condition and to monitor debris build-up and fish presence. The system consisted of a high-sensitivity remote camera (Sony, model HVM-352 ${ }^{\circledR}$ ) with a wideangle lens $\left(70^{\circ}\right.$ Sony, model VCL-06HS $\left.{ }^{\circledR}\right)$. The camera was housed in a water-resistant case (Sony, model WPC-140 ${ }^{\circledR}$ ) and connected by $66 \mathrm{ft}$ of quadraxial cable to an 8-mm

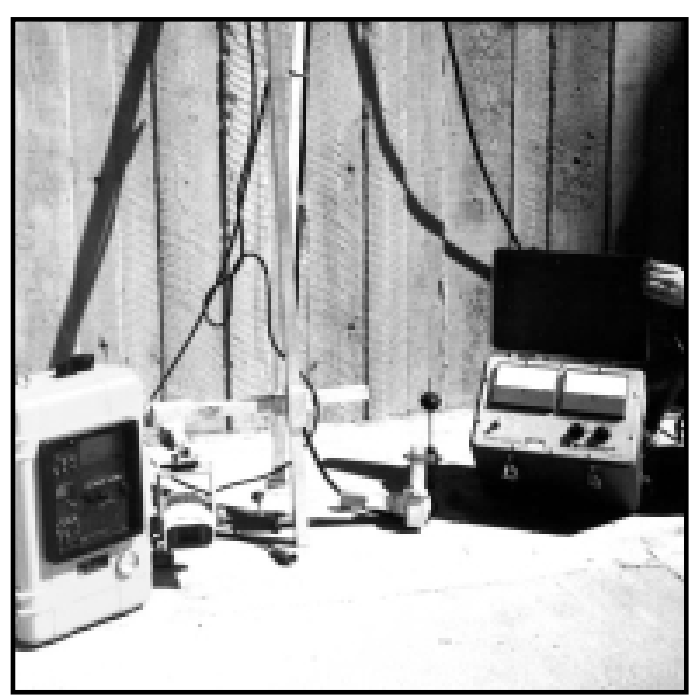
camcorder (Sony, model CCD-FX710 Handycam Hi- ${ }^{\circledR}$ ) in a weatherproof housing. The case was fitted with external weatherproof controls, a 4-in. black and white monitor, and internal battery power supply for the system. The underwater camera operated at extremely low light levels ( $<1$ lux), so that artificial light sources were not necessary to obtain video images during daylight hours. 


\section{Camera Positioning}

The camera was securely mounted under a horizontal metal arm that extended approximately 15 in. from a vertical pole. The length of the horizontal arm and its position on the vertical pole was adjustable. The camera was usually angled slightly downward to observe the area between the screen and the bottom seal where there was a potential for gaps to occur. The camera was moved from upstream to downstream, following the side and bottom seal/screen interfaces. Flatplate screens had vertical seals between panels that were also observed and recorded on videotape. Where there were signs of excessive debris or of fish presence, images were also recorded showing the forebay area and/or bypass.

\section{Data Collection and Analysis}

Video footage was recorded only during the second and third site visits in 1998 because high turbidity (>6 NTU) precluded video analysis during the first round. All screens and seals were videotaped during each of the two evaluations. Written observations were also made when something of interest was seen (i.e. faulty seals, gaps, fish). The videotapes were later reviewed in detail and images of interest were digitized using Snappy Video Snapshot ${ }^{\circledR}$ Version 3.30 software.

\section{General Data}

Additional data collected during each evaluation included the following:

- general site descriptions and photographs

- screen and seal conditions

- screen submergence levels

- cleaning system operation and the incidence of headloss across the screen face

- bypass flow conditions

- bypass outfall flow conditions

- fish presence

- observations of debris in the forebay or bypass

- presence or absence of operator control aids such as water gages and drum submergence marks on screen frames. 


\section{Results}

\section{Overall}

Water velocity measurements, underwater video, and general data collection results for all screen sites are described in this section. Most sites were operating in a manner that would be expected to provide for the safe passage of juvenile salmonids.

\section{$\underline{\text { Water Velocity Measurements }}$}

The NMFS has defined several conditions concerning velocity that screen operators should try to achieve at all sites (NMFS 1995). These include:

- maintaining a uniform flow distribution over the screen surface to minimize approach velocity

- $\quad$ keeping approach velocities less than or equal to 0.4 feet per second (fps)

- achieving sweep velocities that are greater than approach velocities, and

- effecting a bypass flow greater than or equal to the maximum flow velocity vector resultant upstream of the screens.

In addition, there should be a gradual and efficient acceleration of flow into the bypass entrance to minimize delay by outmigrants.

Water velocities at the 19 screen sites evaluated were highly variable, both spatially and temporally. Site-specific information is given following these overall results. Flows were typically not uniform over screen surfaces. Often, there were distinct differences between top and bottom approach velocity values. Where a pattern could be determined, it often showed that approach velocities were higher at the center of drum screens and lower at the ends of the screens. There were no obvious patterns to the fluctuations of approach velocity observed at flat plate screens.

Overall, $92.7 \%$ of all approach velocity measurements met criteria (up from $86 \%$ in 1997). However, approach velocities were always within criteria at only 7 of 18 screen sites screen sites evaluated (no velocity data was collected at Gleed) (Table 2, Figure 3). Areas of screen (i.e., top, bottom, upstream, downstream) that exceeded these criteria were dependent on 
factors individual to the sites. At only one site, Toppenish Pump, average approach velocities exceeded the NMFS criteria of $0.4 \mathrm{fps}$.

Table 2. Percent of approach velocity measurements that exceeded the NMFS criteria of $0.4 \mathrm{fps}$ by screen site. Comparable percentages of velocities that exceeded $0.4 \mathrm{fps}$ at these sites in 1997 are shown for comparison in parentheses.

\begin{tabular}{|c|c|c|}
\hline Screen Site & $\begin{array}{c}\text { Percent of } \\
\text { Approach Velocity } \\
\text { Measurements }>0.4 \mathrm{fps}\end{array}$ & $\begin{array}{c}\text { Number of } \\
\text { Measurements }\end{array}$ \\
\hline Clark & $0(0)$ & $\overline{6} 6$ \\
\hline Ellensburg Mill & $0(0)$ & 24 \\
\hline Union Gap & $5.0(2.3)$ & 60 \\
\hline Kelly Lowry & $0(3.3)$ & 26 \\
\hline Lindsey & $0(3.3)$ & 13 \\
\hline Fruitvale & $\mathrm{a}(12.5)$ & 0 \\
\hline Snipes Allen & $0(3.3)$ & 29 \\
\hline New Cascade & $\mathrm{ND}^{\mathrm{a}}(4.2)$ & 0 \\
\hline Taylor & $0(4.2)$ & 12 \\
\hline Naches Selah & $2.8(5.5)$ & 108 \\
\hline Naches Cowiche & $0(6.6)$ & 52 \\
\hline Lower WIP & $\mathrm{ND}^{\mathrm{b}}(8.3)$ & 0 \\
\hline Yakima Tieton & $5.2(10.5)$ & 192 \\
\hline Bachelor Hatton & $34.1(12.5)$ & 44 \\
\hline Upper WIP & $9.4(17.5)$ & 64 \\
\hline Congdon & $4.4(31.1)$ & 69 \\
\hline Bull & $2.9(36.1)$ & 34 \\
\hline Toppenish Pump & $60(43.0)$ & 30 \\
\hline \multicolumn{3}{|c|}{$\begin{array}{l}{ }^{a} \text { No data, electrical interference prevented velocity measurements. } \\
\text { b No data, flooded in May and nearly dry by July in } 1998 \text {. }\end{array}$} \\
\hline
\end{tabular}


Sites such as Bachelor Hatton and Toppenish Pump, where greater than $10 \%$ of the approach velocities measured exceed criteria indicate potential problems that may be the result of flow imbalance, poorly sized screens, or over-use by the irrigator.

Averaging velocities for each screen site presented a clearer picture of the flows at these sites (Figure 3; Table 3). Considering only averages, sweep velocity was typically greater than approach velocity. All ratios were $\geq 1.5$, except at Bachelor Hatton and Gleed. Sweep velocities at these sites were negative due to large eddies created by high flows.

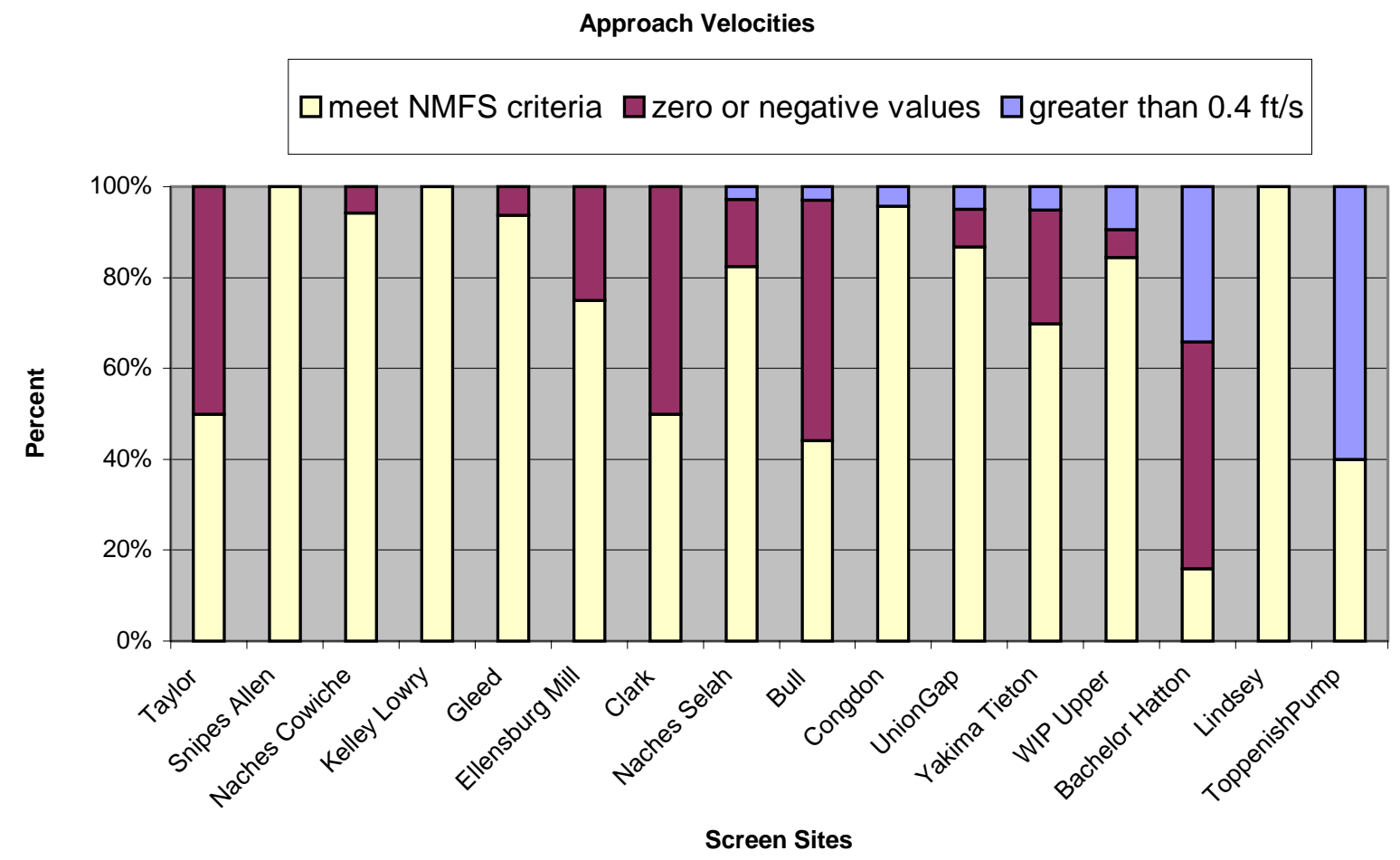

Figure 3. Percentage of measurements at Yakima Basin Phase II screen sites that met or did not meet NMFS approach velocity criteria of $0.4 \mathrm{fps}$ in 1998. 
Table 3. Mean sweep and approach velocities ( \pm standard deviation) at Phase II fish screen facilities in the Yakima Basin in 1998.

\begin{tabular}{|c|c|c|}
\hline Site & $\begin{array}{c}\text { Mean Sweep } \\
\text { Velocity } \pm \text { S.D. }\end{array}$ & $\begin{array}{c}\text { Mean Approach } \\
\text { Velocity } \pm \text { S.D. }\end{array}$ \\
\hline Bachelor Hatton & $-0.18 \pm 1.00$ & $0.19 \pm 0.47$ \\
\hline Bull & $0.37 \pm 0.87$ & $0.01 \pm 0.13$ \\
\hline Clark & $0.22 \pm 0.09$ & $-0.01 \pm 0.22$ \\
\hline Congdon & $0.72 \pm 0.28$ & $0.26 \pm 0.10$ \\
\hline Ellensburg Mill & $0.52 \pm 0.36$ & $0.13 \pm 0.15$ \\
\hline Fruitvale & $\mathrm{ND}^{\mathrm{a}}$ & $\mathrm{ND}^{\mathrm{a}}$ \\
\hline Gleed & $-0.06 \pm 0.80$ & $0.13 \pm 0.20$ \\
\hline Kelly Lowry & $0.56 \pm 0.10$ & $0.20 \pm 0.05$ \\
\hline Lindsey & $0.42 \pm 0.14$ & $0.17 \pm 0.10$ \\
\hline Lower WIP & $\mathrm{ND}^{\mathrm{b}}$ & $\mathrm{ND}^{b}$ \\
\hline Naches Cowiche & $0.62 \pm 0.16$ & $0.18 \pm 0.09$ \\
\hline Naches Selah & $1.37 \pm 0.34$ & $0.20 \pm 0.13$ \\
\hline New Cascade & $\mathrm{ND}^{\mathrm{a}}$ & $\mathrm{ND}^{\mathrm{a}}$ \\
\hline Snipes Allen & $0.35 \pm 0.35$ & $0.17 \pm 0.07$ \\
\hline Taylor & $0.21 \pm 0.20$ & $0.13 \pm 0.15$ \\
\hline Toppenish Pump & $1.21 \pm 0.33$ & $0.48 \pm 0.15$ \\
\hline Union Gap & $1.36 \pm 0.28$ & $0.21 \pm 0.12$ \\
\hline Upper WIP & $0.72 \pm 0.33$ & $0.21 \pm 0.14$ \\
\hline Yakima Tieton & $1.88 \pm 0.46$ & $0.17 \pm 0.19$ \\
\hline \multicolumn{3}{|c|}{$\begin{array}{l}\text { a } \text { No data, electrical interference prevented velocity measurements. } \\
{ }^{\mathrm{b}} \text { No data, flooded in May and nearly dry by July in } 1998 \text {. }\end{array}$} \\
\hline
\end{tabular}


Mean top sweep velocities were generally greater than mean bottom sweep velocities. Mean top and bottom approach velocities were more evenly mixed.

The four largest approach-to-sweep ratios occurred at flat plate screen sites. In general, flow patterns in front of flat plate screens were less variable than those in front of drum screens. In addition, sweep and approach velocities were more discrete at flat plate screens.

The ratio of sweep velocities to approach velocities at the flat plate screens were generally greater than at drum screens. This characteristic also retained approach velocities $<0.4$ fps. This condition is likely to minimize the time it takes for fish to reach the bypass.

Only two of the sites had average bypass velocities less than their average sweep velocities (Union Gap and Naches Selah). Bypass flows were usually faster than the average flow past the screens (Figure 4).

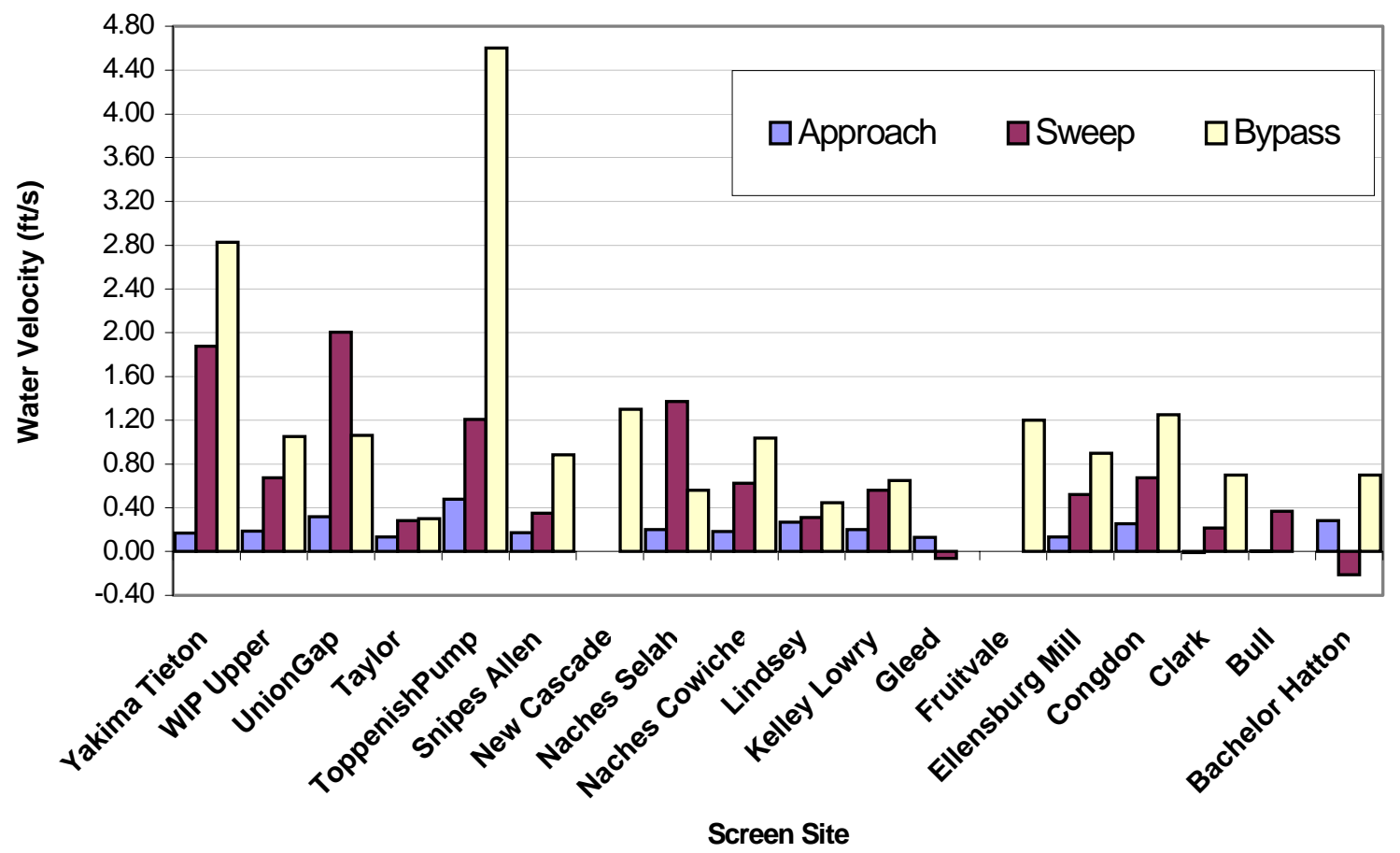

Figure 4. Mean approach, sweep, and bypass velocities (fps) at Phase II fish screen facilities in the Yakima Basin in 1998. 


\section{$\underline{\text { Underwater Video }}$}

Underwater video was used to monitor and document sediment and debris accumulation in front of a screen and to provide a permanent record of conditions. This is important because debris can severely decrease seal life, cause drag on screen motors, and provide cover for predator fish species. Most often, it is impossible to see this debris from above the water's surface. While a pole can be placed in the water to gage the depth of accumulated sediments, one cannot determine exactly the kind of debris present and how it is affecting water flow through or past the screen.

Most of the visible screen seals were in good condition (approximately 71\%). Bottom frame seals were sometimes buried in sediment and could not be evaluated. All drum screen seals classified in "good condition" were tight against the screen and not cracked or punctured in any way. Many rubber seals were covered in algae, but this was not considered a defect. Flat plate screen sealant was generally in good condition with the exception of some panels showing loose or missing caulking (e.g., Ellensburg Mill, Naches Selah, and Yakima Tieton).

\section{$\underline{\text { General Data }}$}

\section{Screen Submergence Levels}

Canal operating conditions are designed to provide water levels that cover between $65 \%$ and $85 \%$ of a drum screen's diameter. At higher water levels, fish may roll over the top of the screen and enter the canal. Lower water levels can prevent the screen from efficiently removing debris from the forebay area.

Percent screen submergence was calculated at every drum screen site $(\mathrm{N}=12)$ for each evaluation. The percent of time that screens met the $65 \%$ to $85 \%$ submergence guidelines was $69.2 \%$. Levels exceeded $85 \%$ submergence for $23.1 \%$ of our evaluations. High water levels occurred at 4 of 11 drum screen sites (Bachelor Hatton, Lindsey, Taylor, Upper WIP). Most of these sites experienced high levels for only one evaluation period; however, the Lindsey site exceeded the criteria all three times. Only two screen sites were measured below $65 \%$ submergence. These were the Clark and Taylor sites near the end of the irrigation season. 
Flat plate screen sites do not have the same roll over and debris removal issues to contend with as rotary drum screens. However, should a screen become completely submerged, fish can freely enter the irrigation canals by swimming over top of the screen. Total screen submergence was observed at two of six flat plate screen sites, Bull and Fruitvale. The side channel of the Yakima River that flows past the Bull site had no headgate control. During spring flooding the screen was at $100 \%$ submergence. However, strategic placement of cement "ecology" blocks around the screen structure prevented overtopping at this site. Fruitvale's screen was overtopped on 7/29/97 (as recorded in the operator's log).

\section{Bypass Outfall Conditions}

The NMFS established a number of guidelines and criteria concerning bypass conduit design and outfall conditions (NMFS 1995). These criteria state that, "for diversions $25 \mathrm{cfs}$ and greater, the required pipe diameter shall be greater than or equal to 24 in. $(61 \mathrm{~cm})$ and that the minimum depth of open-channel flow in the bypass conduit shall be greater than or equal to 9 inches $(23 \mathrm{~cm})$, unless otherwise approved by the NMFS." Pipe diameter criteria exist primarily to minimize debris clogging and sediment deposition and to facilitate cleaning. For screens with a diversion flow less than 25 cubic feet per second (cfs), the requirements are a 10-in. diameter pipe and a minimum allowable water depth in the pipe of 1.8 in. $(4.6 \mathrm{~cm})$.

All screens with bypasses that were evaluated, with the exception of Clark, Lindsey, and Lower WIP, are designed and built for diversion flows $\geq 25 \mathrm{cfs}$. However, many of the sites had bypass pipes with diameters much smaller than the NMFS criteria. Most of the sites appeared to meet the minimum requirements for in-pipe water depth, although it was impossible to be certain when the outfall was submerged. 


\section{Operator Control Aids}

Although not required, visual operator control aids are extremely useful for maintenance and operations personnel periodically inspecting sites. They compliment the operating criteria and help to "flag" operational or procedural problems. Operator aids include marks indicating submergence level on drum screen frames, water depth or elevation gages in the forebay, aftbay, and irrigation canal, and marks indicating how far headgate, bypass weir, or canal intakes are open. Providing highly visible indicators of screen system operation as it relates to NMFS criteria or of proper water diversion to the canal can save time and reduce incidences of operator error that may result in fish impingement, entrainment, or stranding at a site.

Most sites were equipped with gages measuring elevation or water depth, although gages were not always present both in front of and behind the screens. Drum screen submergence marks were present at most sites, but were difficult to read late in the season due to algae growth. We recommend regular cleaning of these marks to facilitate operator adjustments and evaluation.

\section{Rotary Drum Screens}

\section{Bachelor Hatton}

The Bachelor Hatton site was evaluated 5/7/98, 6/30/98, and 9/14/98. In May, there were extremely poor approach hydraulics. This was complicated by closure of the bypass in June. By early July, all water in Ahtanum Creek was diverted upstream of this facility at the WIP Upper site so that Bachelor Hatton was not operational when we performed our September evaluation.

High water and poor hydraulic conditions created a large eddy in the forebay that produced negative sweep and approach velocities in front of the two upstream screens (Figure 5 and Figure 6). The eddy was due, in part, to the imbalance of the headgate structure openings, as shown in Figure 7. The gate on the left allowed a greater amount of water into the forebay than the gate on the right. As this water entered the forebay, it hugged the wall farthest from the screens until it reached the bypass area. The water then turned in toward the screens and flowed upstream, creating the negative velocity patterns (Figure 8). 
During May, approach velocities increased from upstream to downstream and exceeded $0.4 \mathrm{fps}$ in front of the two screens nearest the bypass, and a 4.5-in. headloss was observed between the forebay and aftbay. In June, all approach velocities were negative, suggesting that little or no water passed into the irrigation canal. Overall, 50\% of the recorded approach velocities at this site were zero or negative and $34 \%$ were greater than $0.4 \mathrm{fps}$. Thus, just $16 \%$ of the approach velocities fell between 0 and 0.4 fps.

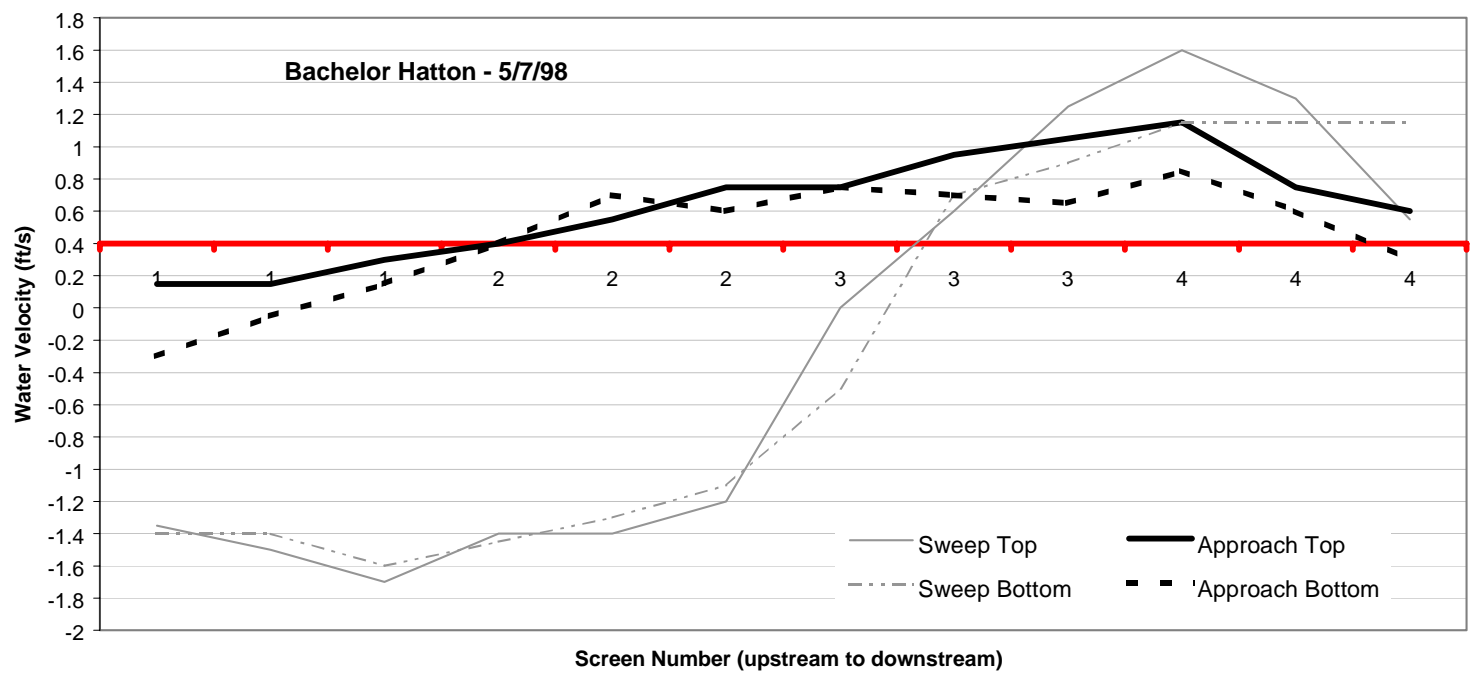

Figure 5. Water velocities at Bachelor Hatton, 5/7/98.

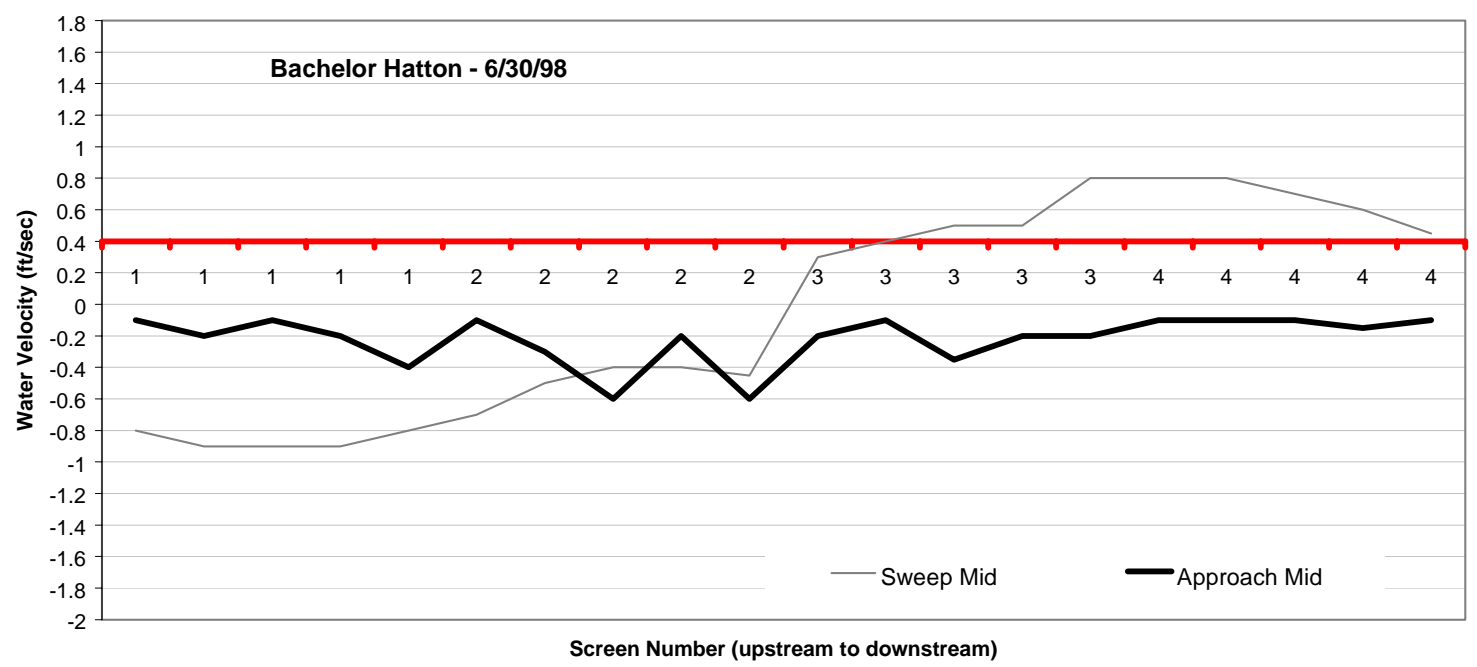

Figure 6. Water velocities at Bachelor Hatton, 6/30/98. 


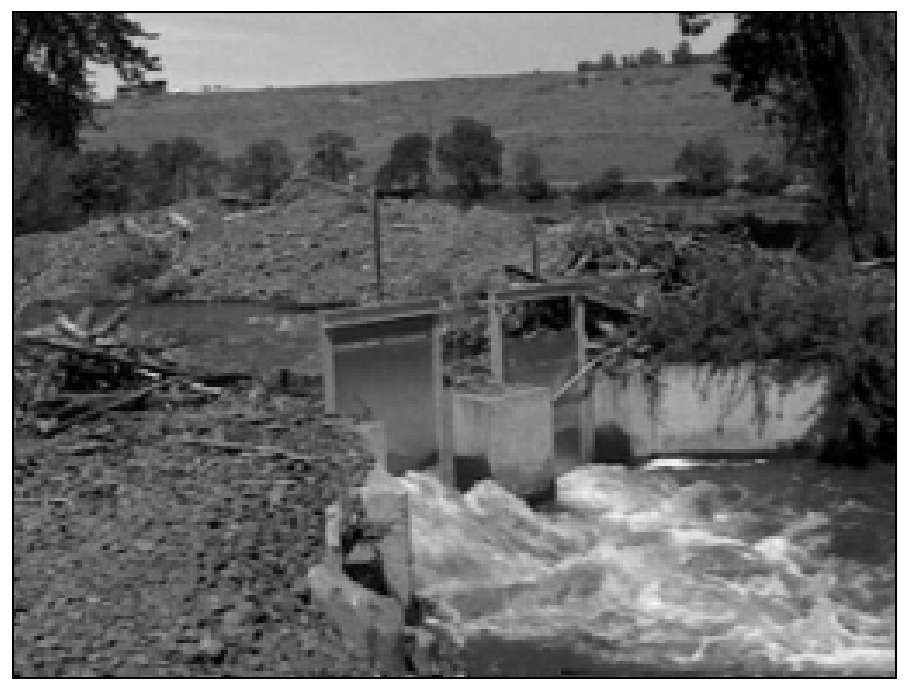

Figure 7. Unbalanced headgate openings at Bachelor Hatton, May 7, 1998.

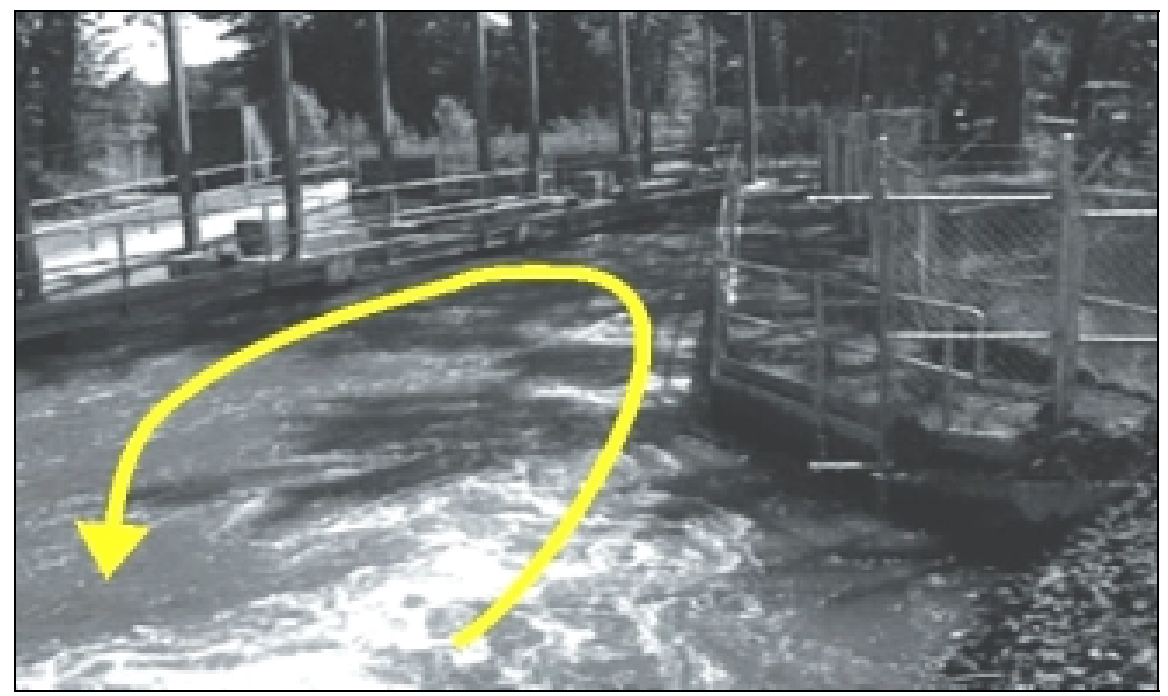

Figure 8. Circular flow pattern at Bachelor Hatton, May 7, 1998.

The screens and side and bottom seals were in good condition though covered with diatoms. A log record from August 19, 1998, indicated that the WDFW found a gap in Screen 3 and a dent in Screen 4. Both conditions were repaired the next day.

Water flowed over the bypass weir only during our May evaluation when water was backed up behind the weir and submergence was $88 \%$. Bypass outfall conditions were good for fish passage in May. The bypass was closed in June, and screen submergence was approximately 75\%. Water did not reach the site in September. 
Gravel, large cobble, and sand were observed with underwater video in front of the screens. The water backed up behind the weir in May indicated that the bypass may have been blocked with the sand that accumulated at this site. In June, we observed 7 to 8 in. of sediment on top of the sills. Sediments had been cleared from the forebay just prior to our September evaluation.

Regarding operator control aids, there were no submergence marks painted on the screen frames or gages provided for measuring weir depth. One staff gage was present in the aftbay to track water levels.

\section{$\underline{\text { Clark }}$}

Clark was evaluated 5/11/98,6/24/98, and 9/21/98. Prior to May 12, all water was bypassed. The site was operating in June, though little water flowed into the canal or bypass. Boards in front of the paddle wheel, meant to regulate flow, were not always properly positioned. In June, the top board in front of the paddle wheel had floated to the surface allowing more water to flow over the lower board than the top board. In September, more water was present in the canal than in June, but water levels in the forebay were so low that nothing passed over the bypass weir, even when it was lowered as far as possible.

Improvements to the site since 1997 included lines marking percent submergence that were painted on the screen frame at the 70,80 , and $90 \%$ levels. Unfortunately, the lower markings were obscured with algae growth over the course of the season so that only the $90 \%$ mark was legible in September.

Half of all approach velocity measurements recorded in 1998 were between 0 and $0.4 \mathrm{fps}$. The remaining 50\% of the recorded approach velocities were negative values. Sweep velocities were extremely slow, but were consistently greater than approach velocities and increased toward the bypass (Figure 9 and Figure 10). Approach velocities were all negative in June (Figure 10). 


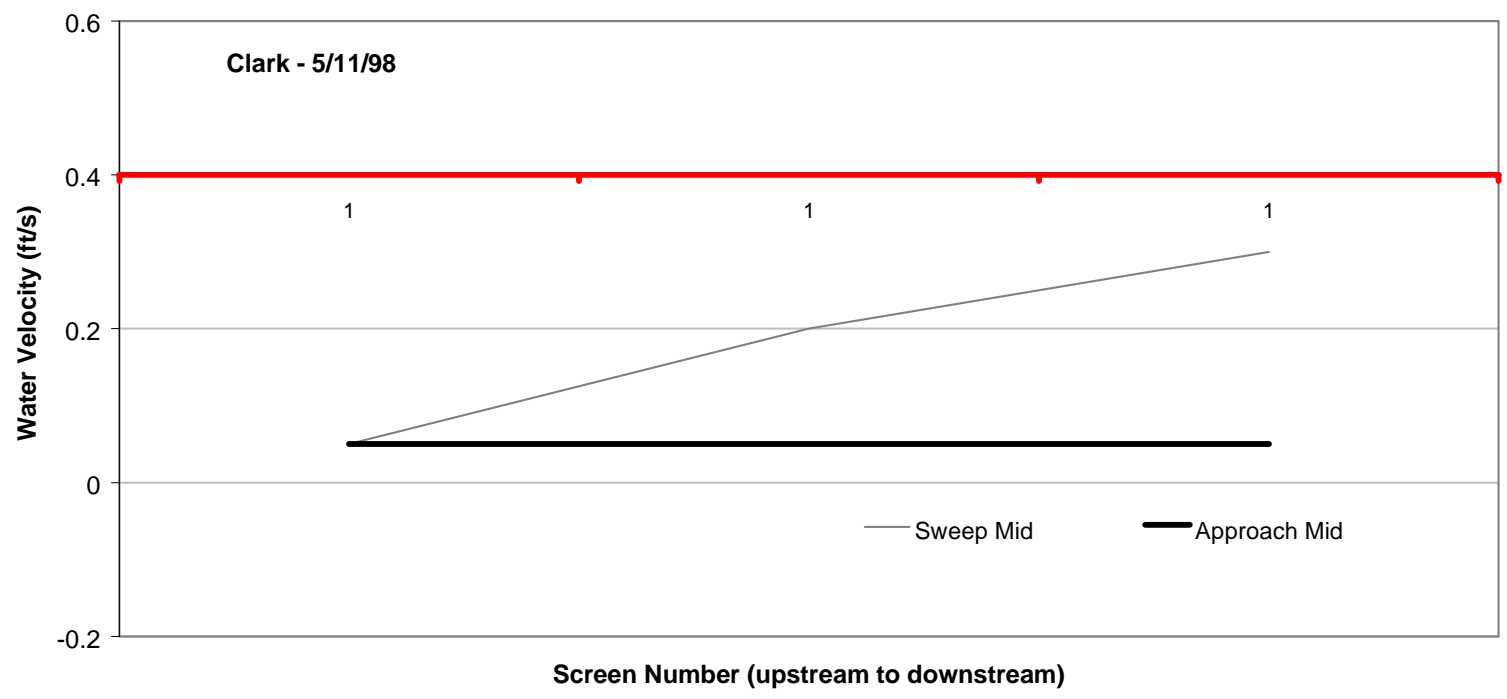

Figure 9. Water velocities at Clark, 5/11/98.

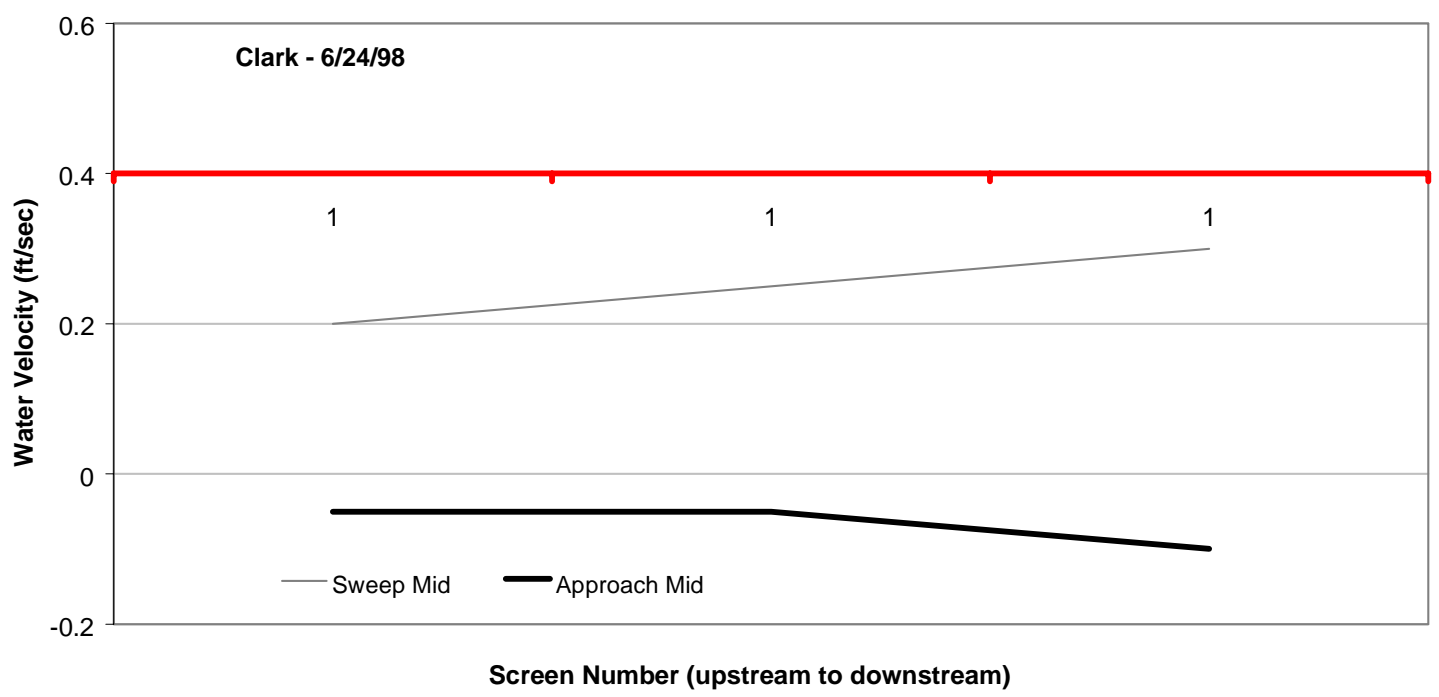

Figure 10. Water velocities at Clark, 6/24/98.

Screen submergence was measured at 75,81 , and $48 \%$ over the course of the season. However, mud marks observed on the frame in September indicated that the screen was more than $90 \%$ submerged earlier in the season. The screen and the seals were consistently in good condition. The single drum screen rotated very slowly. In May, it didn't turn at all because all water was bypassed. If the screen remains inoperable for long periods over the spring and 
summer, algae could accumulate on the portion of the screen that is constantly under water, possibly making smooth operation at start-up difficult and water flow through the screen uneven.

Conditions at the outfall pipe were always good at the Clark site when water was being bypassed. The site does not appear to collect a lot of debris. A few sticks and some algae buildup were noted at the downstream, lower-velocity end of the screen, but not enough to cause problems for fish.

\section{Congdon}

The Congdon screen site was evaluated 5/11/98, 7/798, and 9/15/98. Improvements to the site prior to 1998 included submergence marks on one frame. However, these were only lines and had no numbers associated with them. The marks were already faint at the beginning of the season and very hard to see by September. Re-marking the lines and adding numbers would be helpful. In addition, a board with measurement markings was present in July and

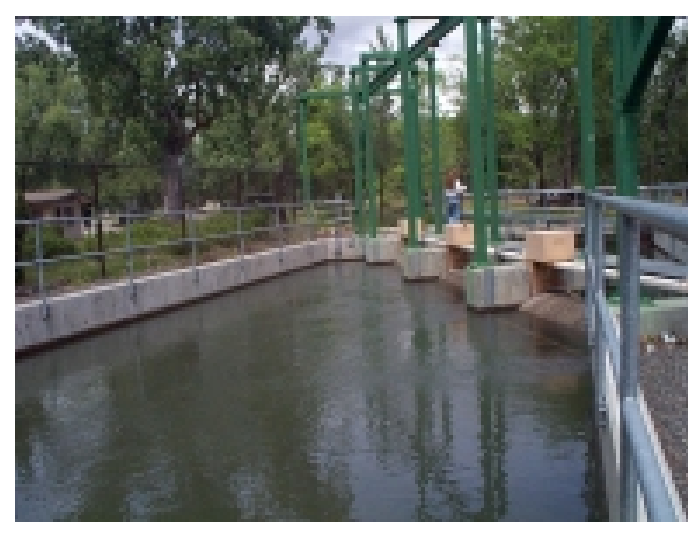
September to measure the weir crest.

Ninety-six percent of the recorded approach velocities met NMFS criteria at the Congdon site. The remaining $4 \%$ of the recorded velocities were greater than $0.4 \mathrm{fps}$. In general, sweep velocities were greater than approach velocities and increased near the bypass (Figure 11, Figure 12, and Figure 13). The only places sweep velocities were less than approach velocities or where approach velocities exceeded criteria were in front of Screen 1 (furthest upstream) in July and September. 


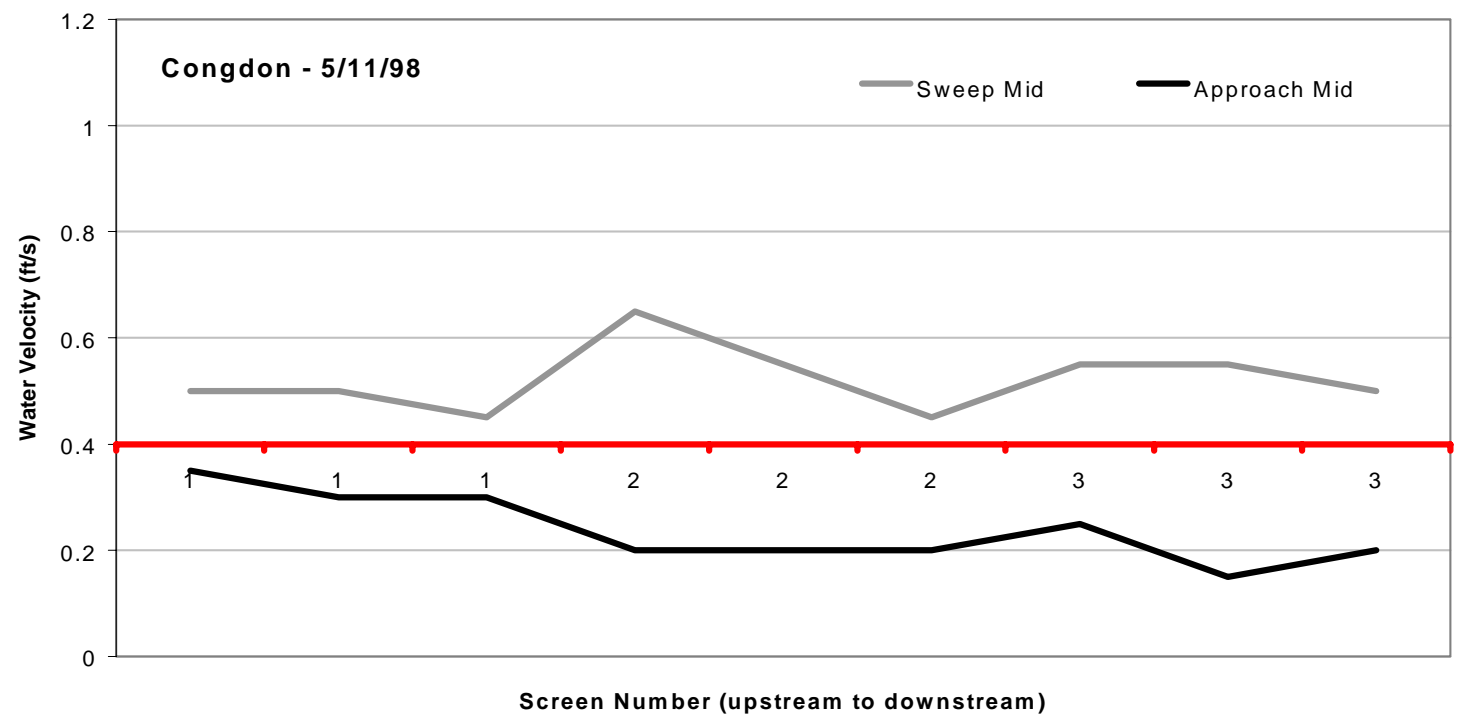

Figure 11. Water velocities at Congdon, 5/11/98.

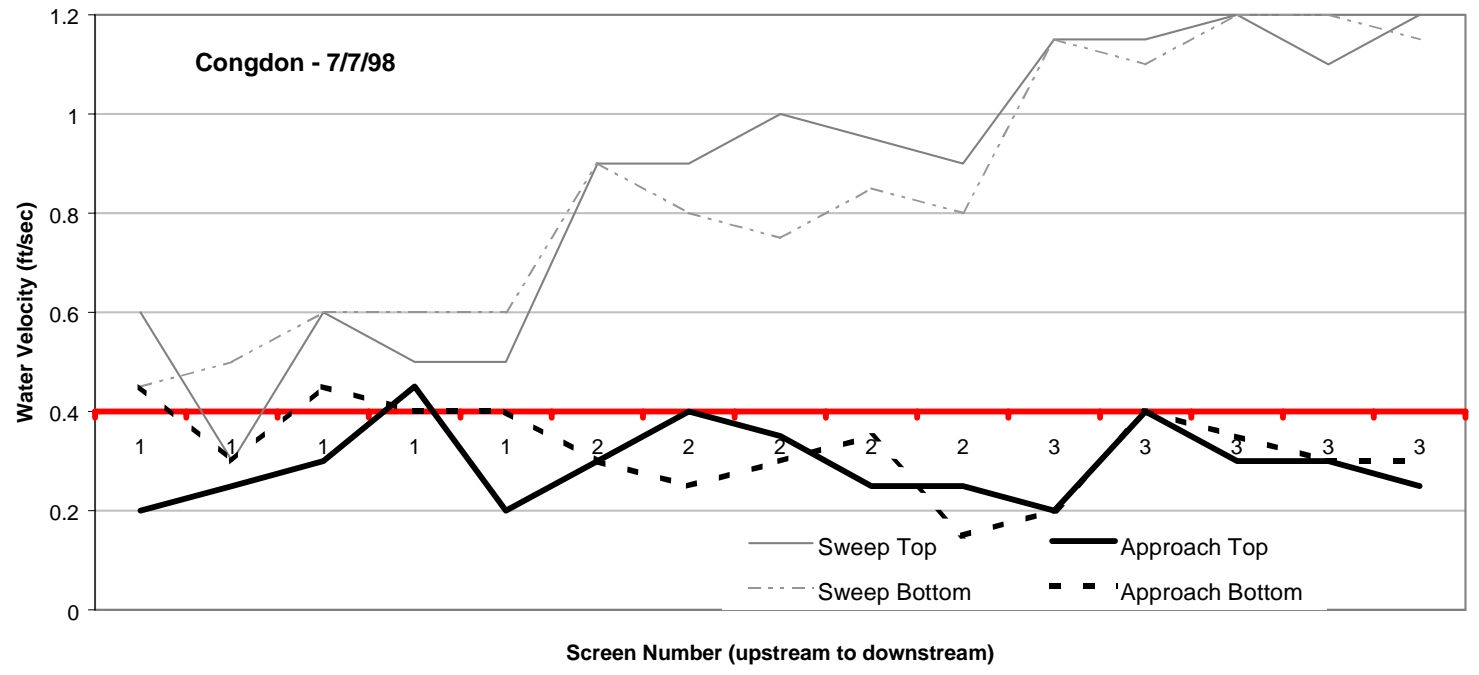

Figure 12. Water velocities at Congdon, 7/7/98. 


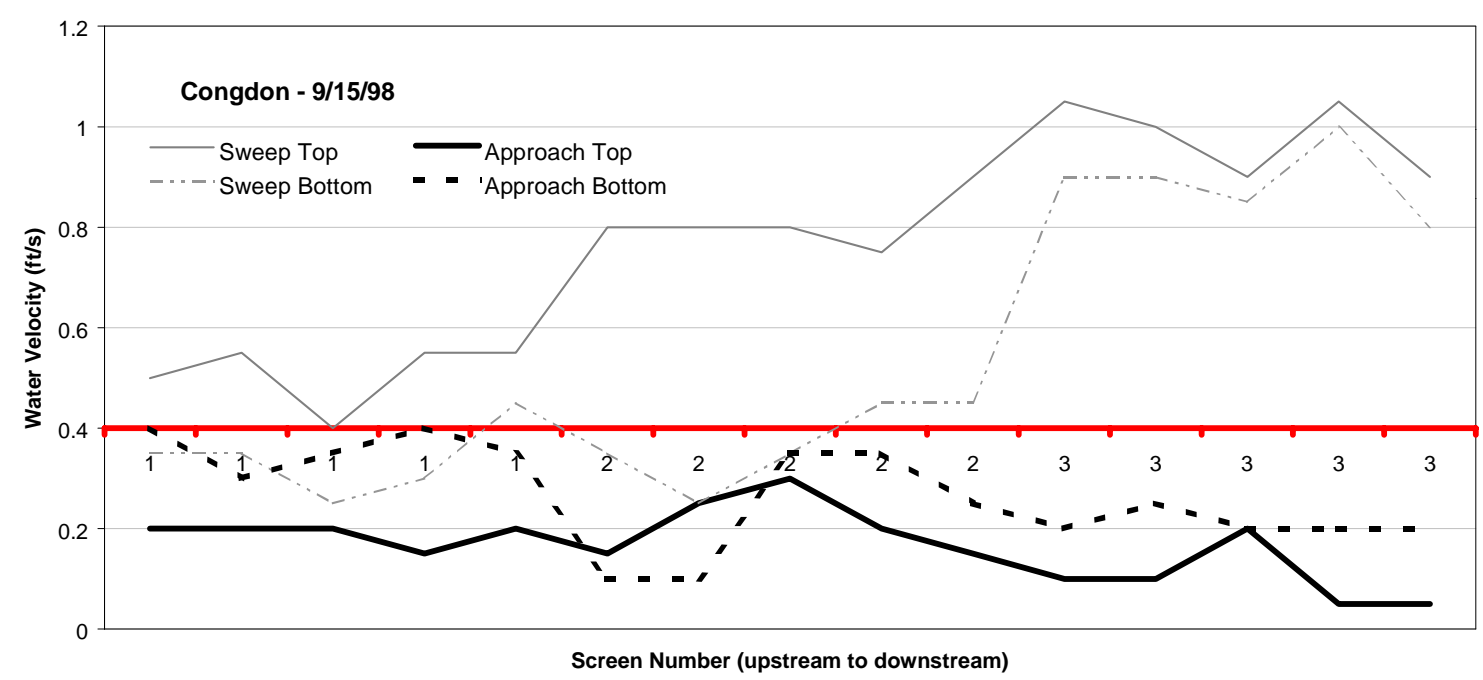

Figure 13. Water velocities at Congdon, 9/15/98.

Screen submergence was approximately $82.5 \%$ throughout the season, and water always flowed over the bypass weir. Water ran freely through the outfall pipe, which was always submerged at its terminus, but never completely full of water (evidenced by the bubbles that were observed).

The screens were brown with algae/diatom build-up, but not clogged or impaired in any way. The seals were in good condition and screens always turned smoothly.

The accumulation of debris at Congdon was not obvious from above water; however, there were minor accumulations of branches and silt deposits observed on underwater video. Most woody debris was caught on the trashrack and cleaned off regularly in-season. Silt was deepest in September and accumulated most heavily in front of Screen 1 (farthest upstream). There were 6 in. of silt at Screen 1, but that tapered to 4 in. at Screen 2 and none at Screen 3 near the bypass. Silt accumulation was generally less than $1 \mathrm{in}$. deep earlier in the season. 


\section{$\underline{\text { Kelly Lowry }}$}

The Kelly Lowry screen site was evaluated 5/11/98, 7/7/98, and 9/21/98.

Improvements to the site in 1998 included the addition of a submergence mark at the $80 \%$ level on the screen frame and the installation of a gage to measure weir crest. The submergence mark was fading by September and should be repainted.

Fully $100 \%$ of the approach velocities recorded at this site met NMFS criteria (Figure 14, Figure 15, and Figure 16). Sweep velocities always exceeded approach velocities, but sometimes decreased near the bypass instead of increasing. Bypass flows were generally within criteria (i.e., they exceeded sweep velocities), but in May, bypass flow was slightly lower than the average sweep velocity ( $0.35 \mathrm{fps}$ compared to $0.45 \mathrm{fps}$ ). Screen submergence levels met NMFS criteria at 65,80 , and $77 \%$.

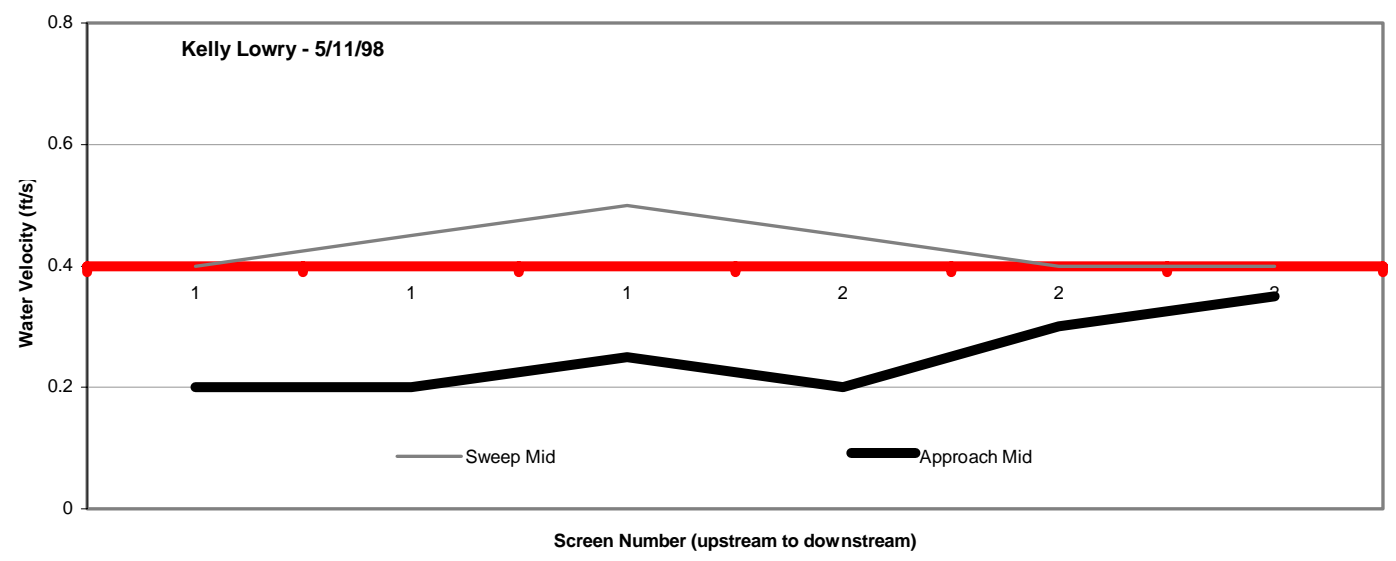

Figure 14. Water velocities at Kelly Lowry, 5/11/98. 


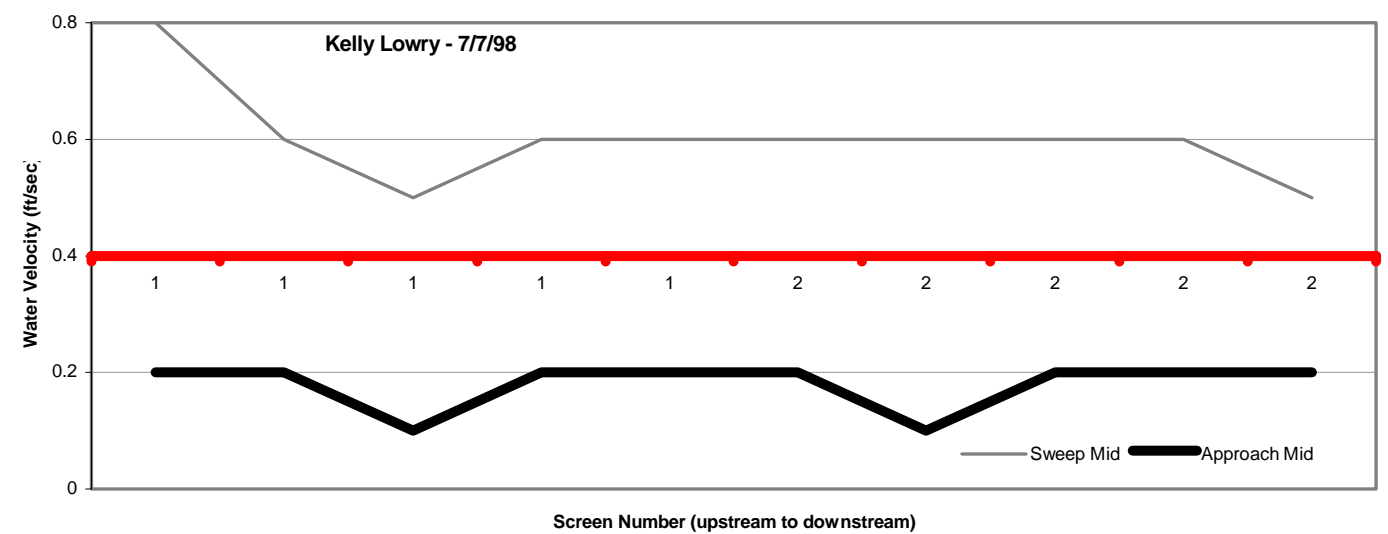

Figure 15. Water velocities at Kelly Lowry, 7/7/98.

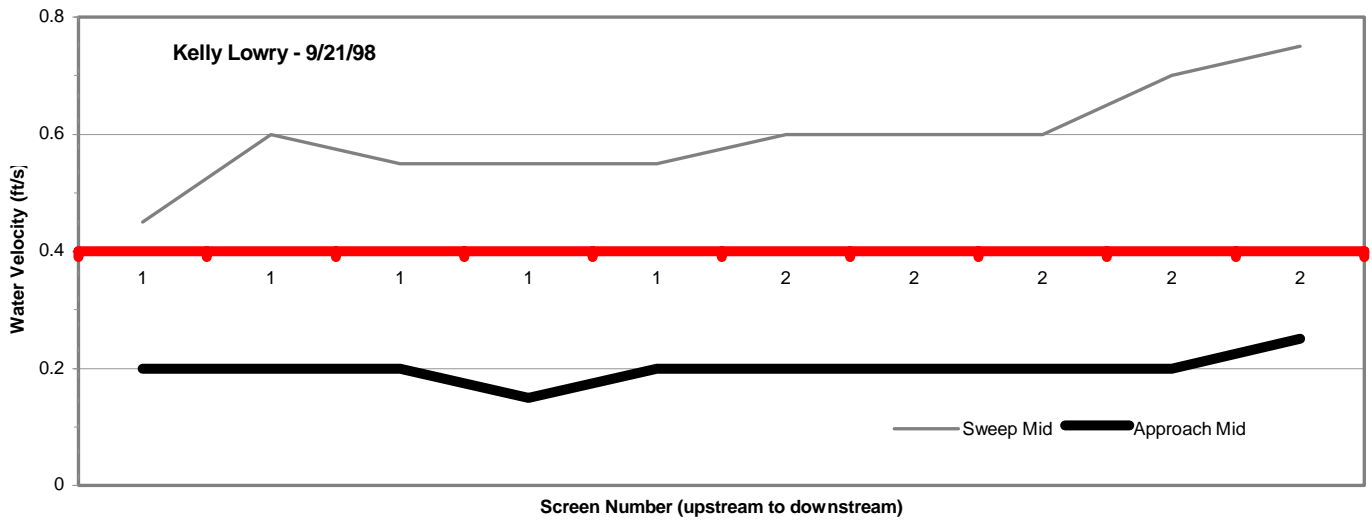

Figure 16. Water velocities at Kelly Lowry, 9/21/98.

There were a few concerns regarding screen condition. In July, a small gap was noticed between the bottom seal and Screen 1 (upstream of the middle of the screen, Figure 17). Also, small oil slicks were observed in the water behind Screen 2. Otherwise, the screens were in good shape. They were brown with algae and diatoms, but the openings were not blocked, and the drums turned evenly. With the exception of the gap at Screen 1, the seals were in good condition. 


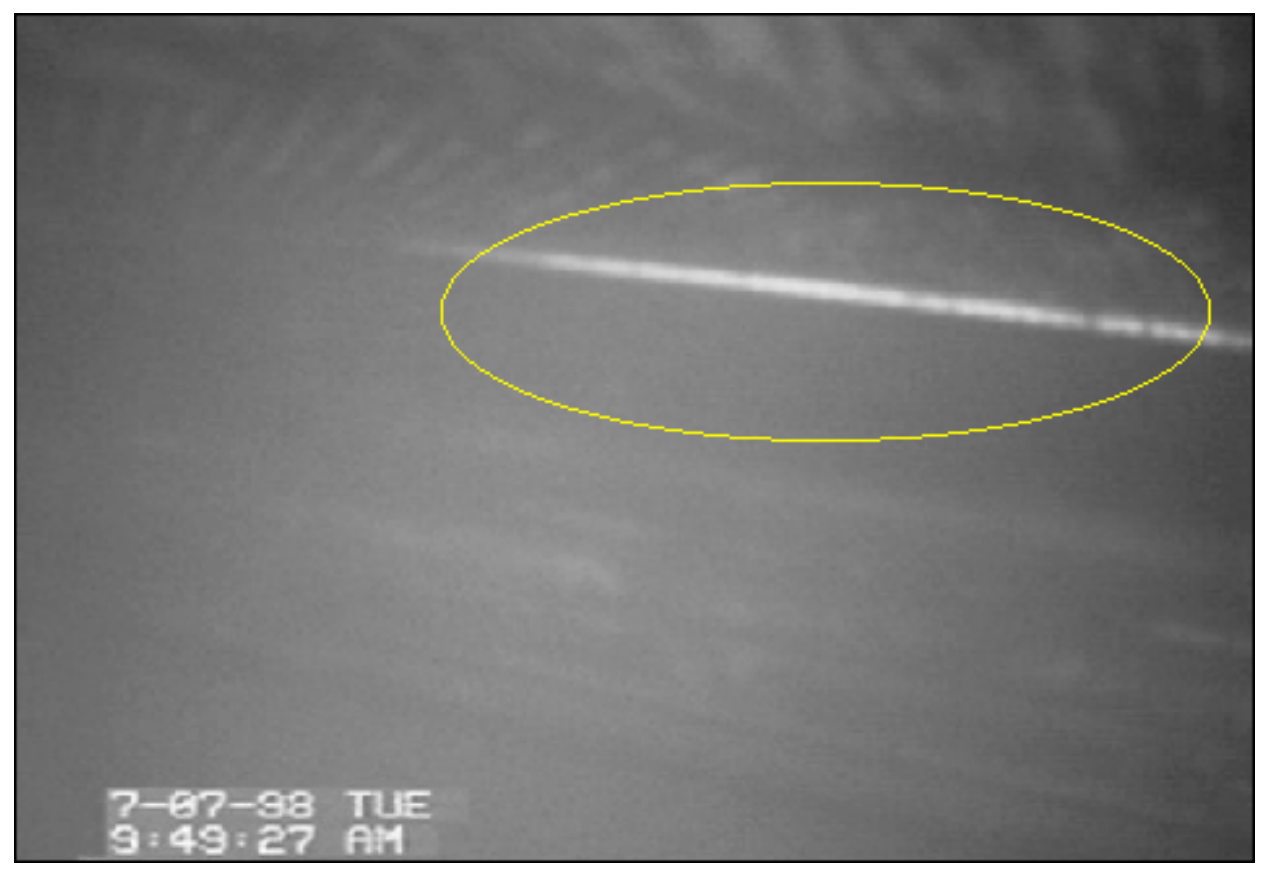

Figure 17. Gap (in yellow elipse) observed under Screen 1 (upstream) at the Kelly Lowry screen facility, on July 7, 1998.

Water always ran freely over the bypass weir, and conditions for fish at the outfall site were always good.

The trashrack kept many sticks out of the forebay and was cleaned regularly in-season. There was some accumulation of silt on top of the sill in front of both screens throughout the season, but always less than 2 in.

Several small fish (non-salmonids) were observed in the aftbay during our evaluation in September.

\section{Lindsey}

The Lindsey screen site was evaluated 5/12/98, 6/24/98, and 9/16/98.

Improvements at this site in 1998 included planting near the bypass outfall site for bank stabilization a new headgate structure. A yardstick was present in September and may have been used as a gage to measure weir crest and other operational parameters. Submergence marks on 
the screen frame were applied in 1997, and though still present, were difficult to read by September 1998.

All recorded approach velocities at this site met NMFS criteria. Sweep velocities were consistently greater than approach velocities, but did not always increase near the bypass (Figure 18, Figure 19, and Figure 20). Screen submergence levels were always slightly high at 88, 90, and $86.1 \%$.

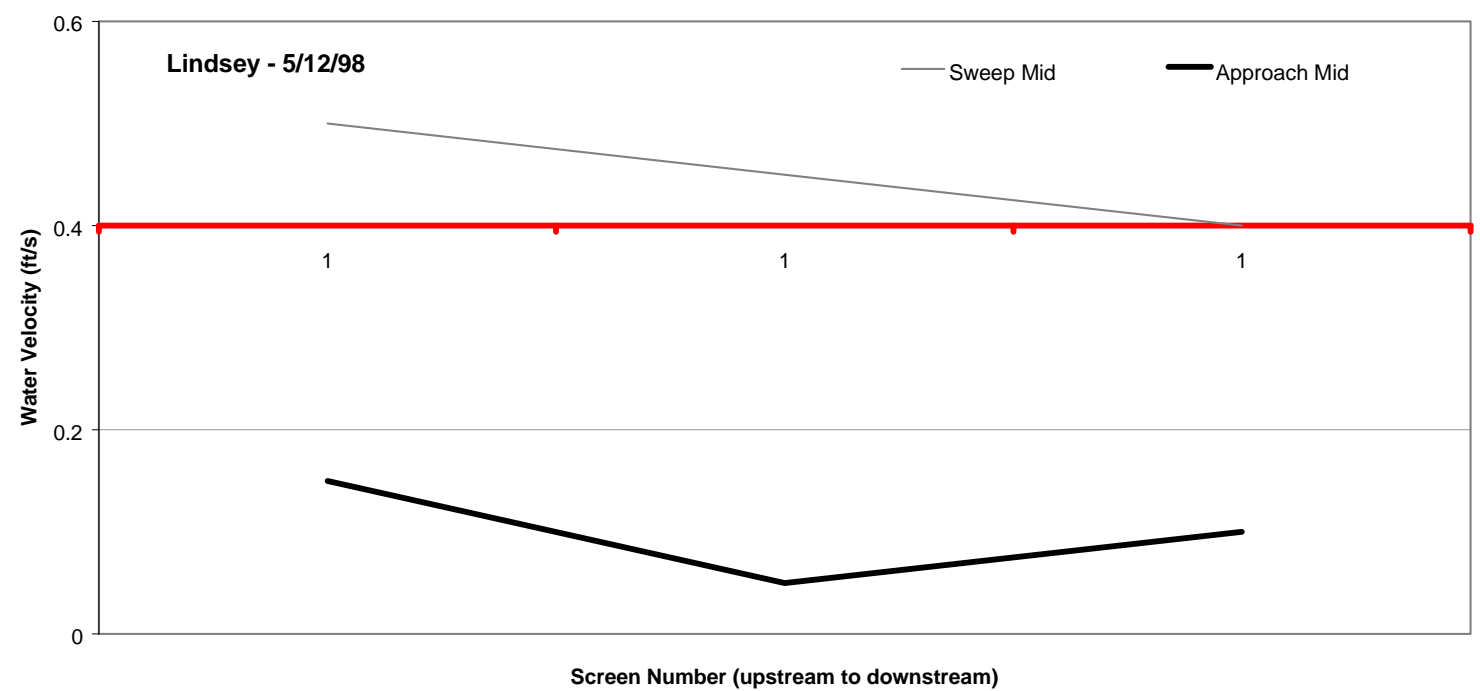

Figure 18. Water velocities at Lindsey, 5/12/98.

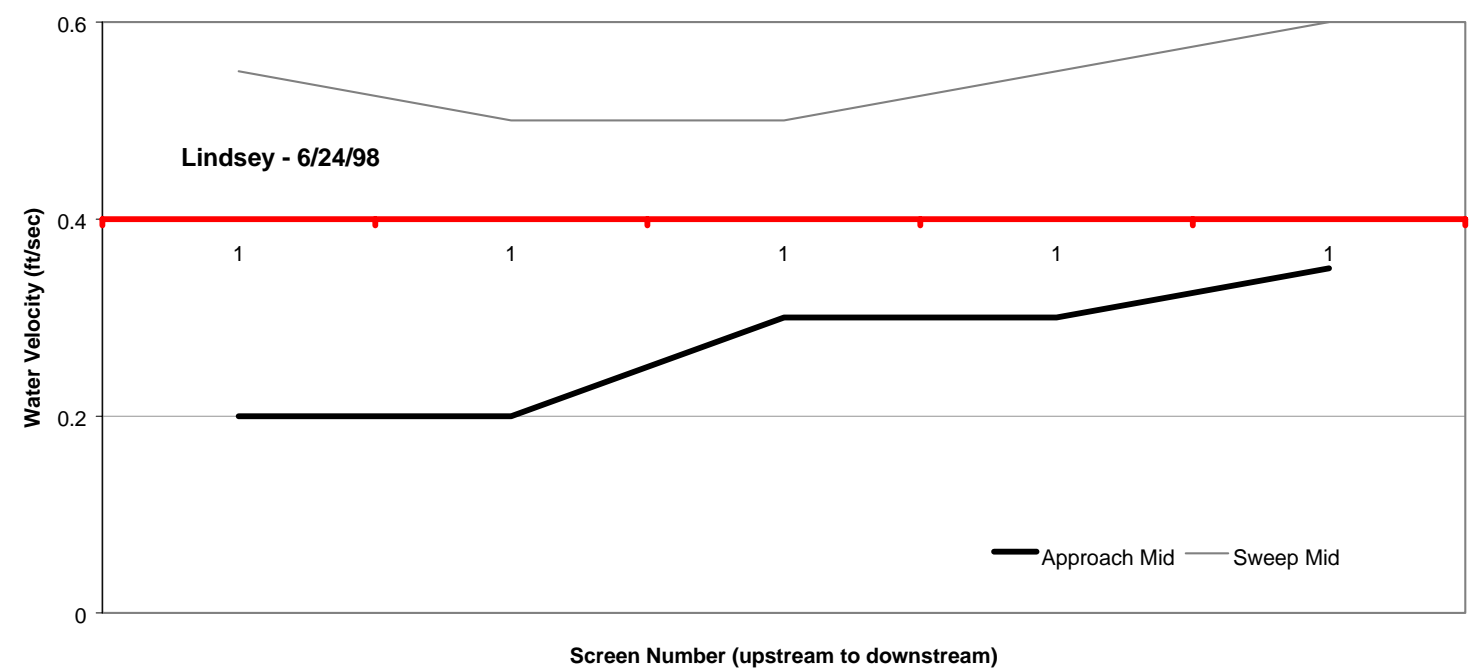

Figure 19. Water velocities at Lindsey, 6/24/98. 


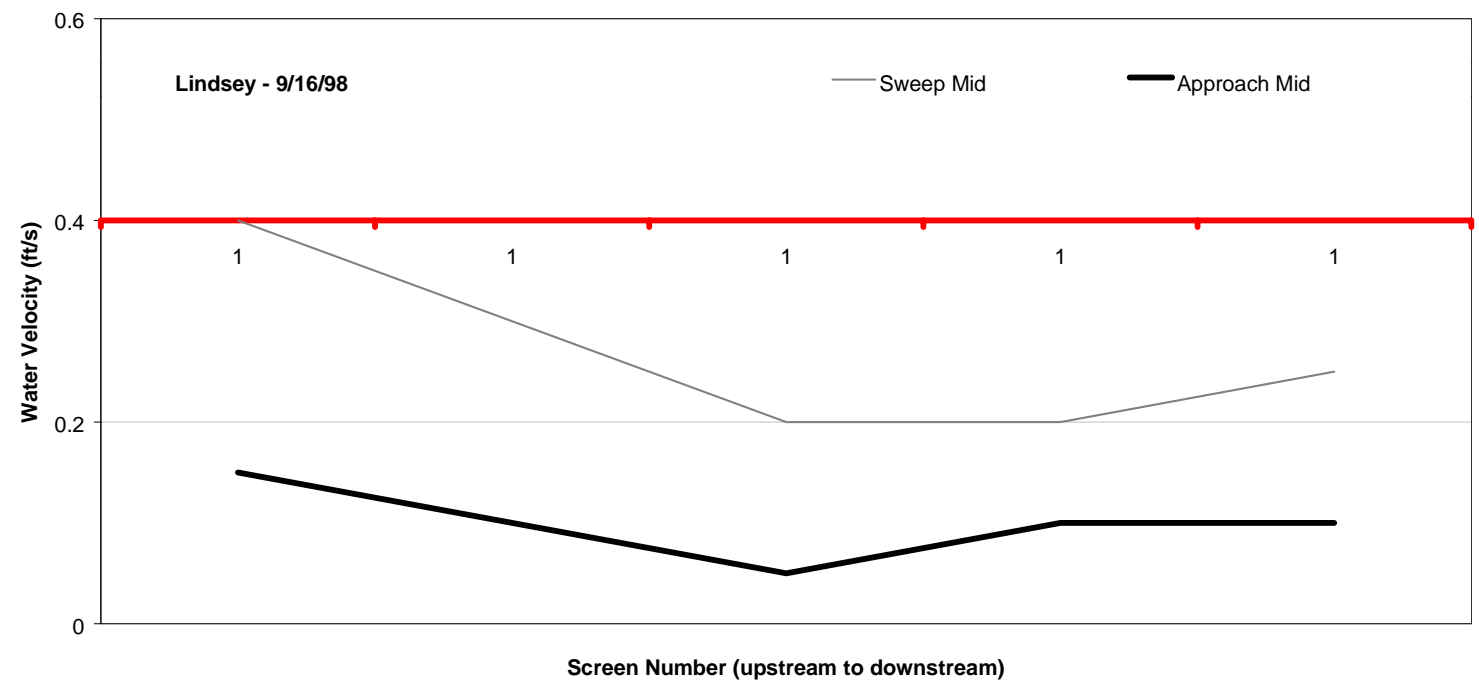

Figure 20. Water velocities at Lindsey, 9/16/98.

Some streaking from uneven contact between the screen and bottom seal was observed in September. Video also recorded small amounts of light passing between the bottom seal and screen near the upstream end, indicating the presence of a small gap. There were several places where caulking was missing along the bottom where small fish could try to hide (Figure 21). Many dace were observed inside the drum screen in September. The side seals were in good condition and the screen always rotated evenly.

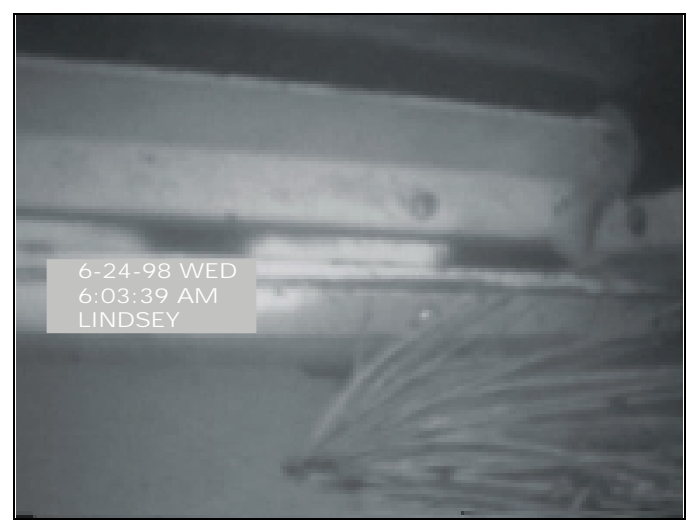

Figure 21. Missing caulking sealant at Lindsey, 6/24/98.

Because this site is remote, maintenance checks generally occur on a weekly, rather than daily, basis. During our evaluations, there were problems with bypass weir height and 
submergence that could have been remedied if maintenance was conducted more frequently. During May, only 2 in. of water flowed over the bypass weir. In September, this was reduced to only $0.25 \mathrm{in}$. In addition, pine needles had built up along the lip of the weir and threatened to block it altogether. In both instances, the weir could be lowered at least $10 \mathrm{in}$. to provide ample flow for fish to use the bypass. Bypass conditions were better in June, although the ramp had been left in "flush" mode to induce silt removal and, perhaps, to keep the screen from overtopping under high water conditions. Conditions at the outfall were adequate, but rocks were accumulating near the pipe terminus in September. Several small chinook salmon (3 to 5 in. long) were observed near the outfall pipe in September, and one fish was observed swimming from the river into the pipe.

Levels of silt and sand were not excessive. The forebay was clear in May, and a maximum of $2 \mathrm{in}$. accumulated on top of the sill during the remainder of the season. This silt was deepest near the middle of the screen. Woody debris was not a problem, though a small pile of sticks had been removed from the forebay and piled near the bypass entrance in June.

\section{Lower WIP}

Lower WIP was visited 5/7/98 and 7/6/98. No velocity measurements or video were recorded in May because of flood conditions. Ahtanum Creek cut through the bank upstream of the screen site and water flowed directly from the creek into the irrigation ditch behind the screen (Figure 22). In July, flooding had subsided, but because most of the creek was diverted upstream at the WIP Upper site, little water entered Lower WIP.

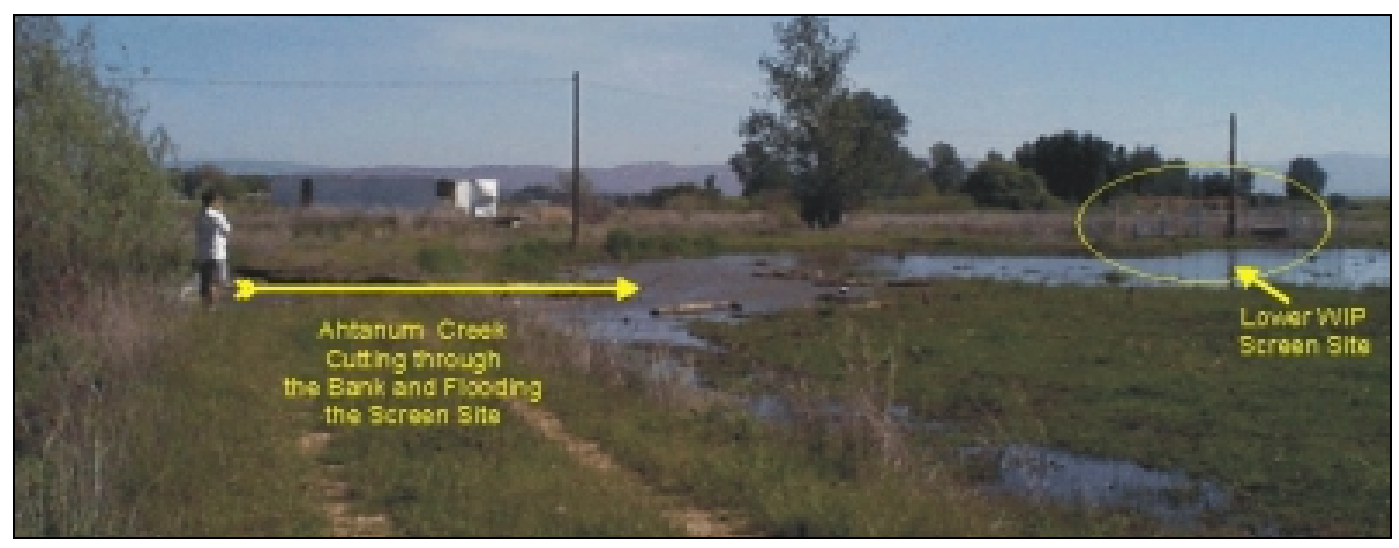

Figure 22. Flooding at Lower WIP, 5/7/98. 
The bypass was closed, and the site looked abandoned. Again, flow data were not collected because the site was not in operation.

During July, the screens were operating and turned evenly despite the tremendous amount of sediment (>10 in. above the sill). There were only 2-5 in. of water above the sediment. The side seals visible above the silt appeared to be in good condition. Besides the sediment problem, the forebay was also filled with woody debris (Figure 23). Clearly, this site needed to be dredged. A number of small, non-salmonid fish were observed in front of the downstream screen.

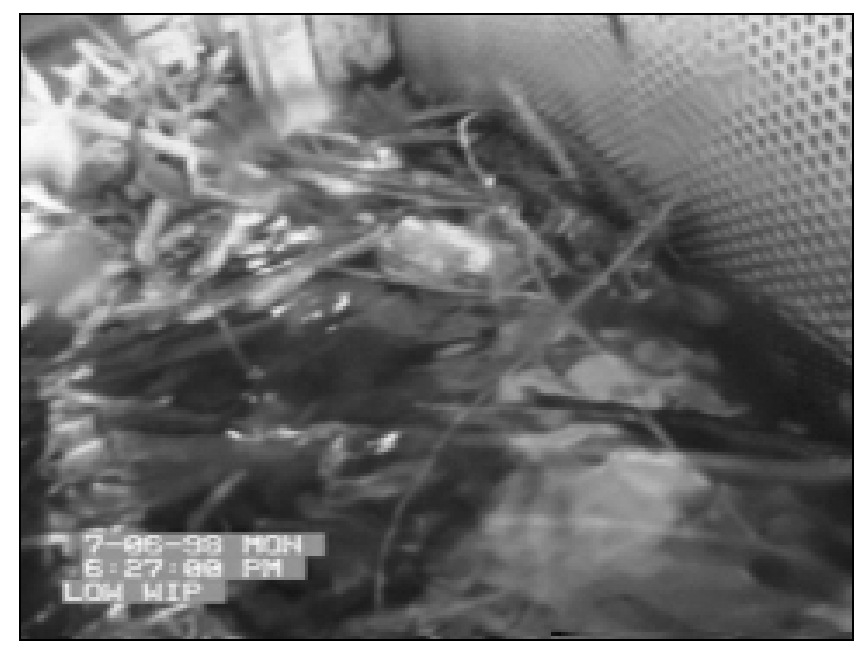

Figure 23. Woody debris in the forebay at Lower WIP, 7/6/98.

\section{Naches Cowiche}

The Naches Cowiche site was evaluated 5/11/98, 7/798, and 9/15/98.

Improvements to the site in 1998 included submergence marks painted on the frame at $10 \%$ submergence increments. Also, a means to measure weir crest was noticed in September, but the measurement lines were faded and difficult to read.

None of the recorded approach velocity values exceeded $0.4 \mathrm{fps}$; however $6 \%$ were zero or negative velocities. Sweep velocities were always greater than their corresponding approach velocities and, except in September, sweep velocities increased near the bypass (Figure 24, Figure 25, and Figure 26). Screen submergence levels were always within the bounds set by NMFS criteria, specifically 78,84 , and $80.8 \%$. 


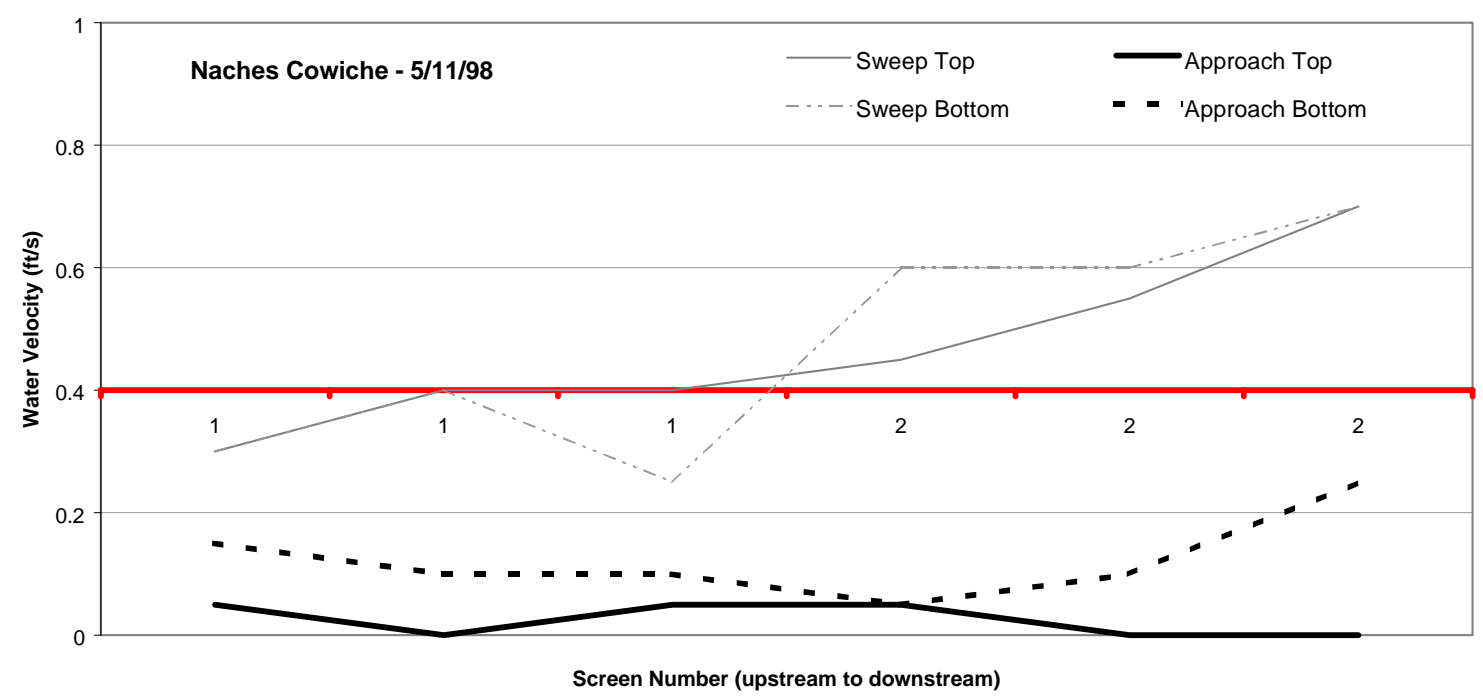

Figure 24. Water velocities at Naches Cowiche, 5/11/98.

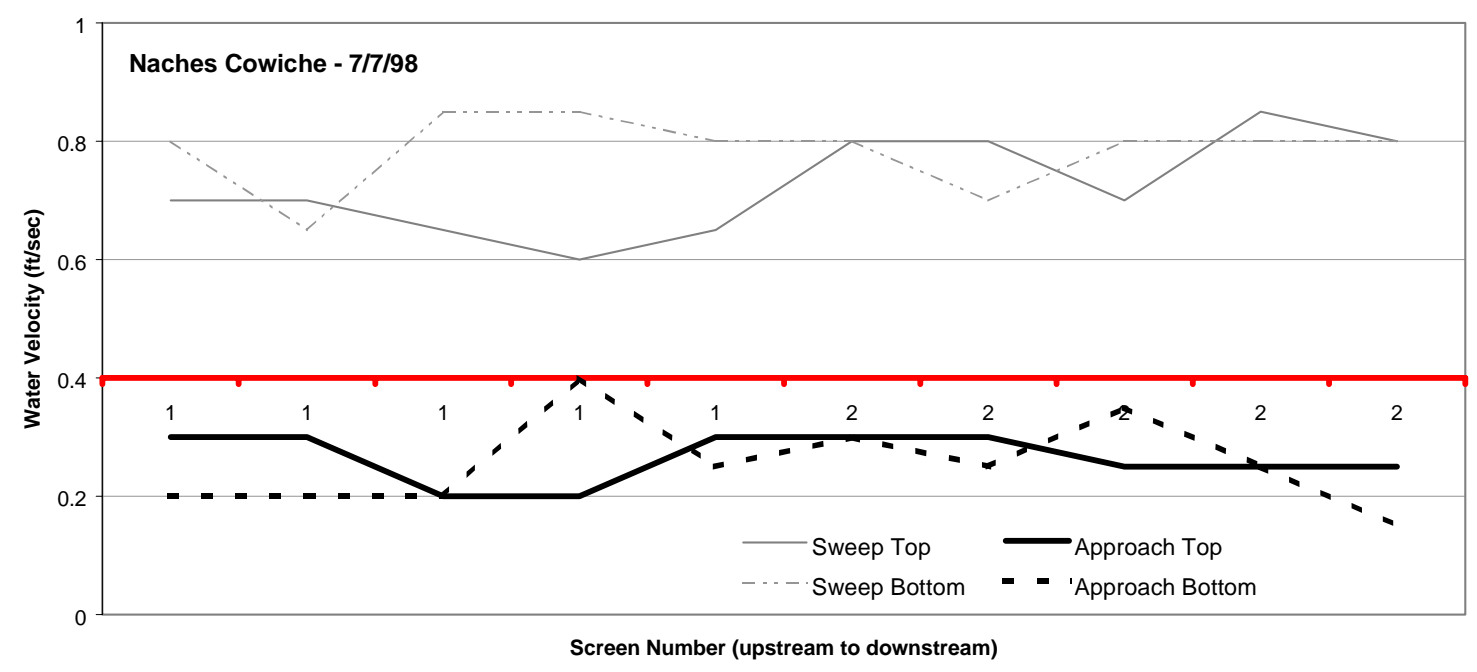

Figure 25. Water velocities at Naches Cowiche, 7/7/98. 


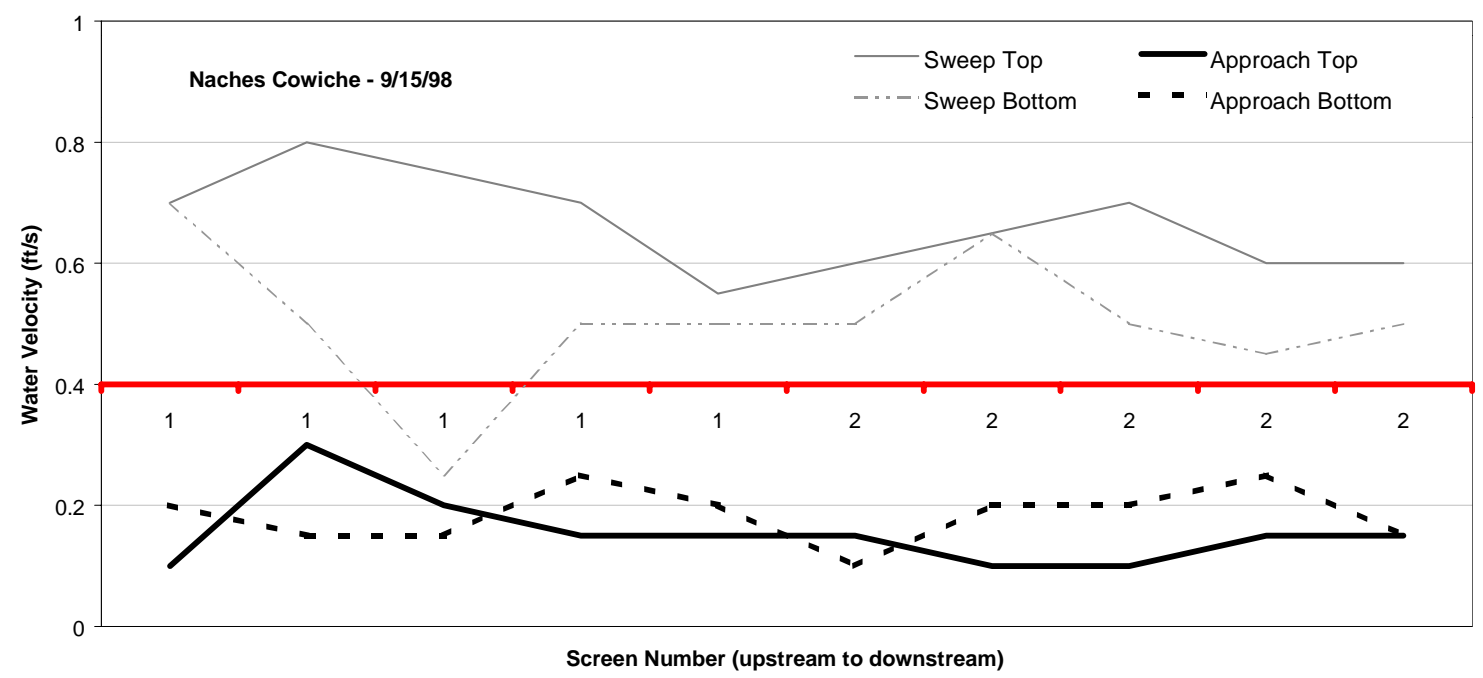

Figure 26. Water velocities at Naches Cowiche, 9/15/98.

Screens and seals were in good condition. Some algae/diatom buildup was observed, but it was not enough to affect screen performance.

Water always flowed over the weir, but improvements could have been made to bypass weir operations. Only 3 in. of water flowed over the weir in May and 6 in. during our July evaluation. Screen submergence levels would have allowed the bypass weir to be lowered without adversely affecting screen performance for fish protection. Conditions for fish at the outfall site were always good.

Siltation was a problem at this site. For example, in May there were 2 in. of silt in front of Screen 1 (the upstream screen) and 4 in. of silt in front of Screen 2. In July, silt depth had increased to 8 in. in front of Screen 1 and 4 in. in front of Screen 2. Little silt was observed in front of the screens in September, but the bypass contained a pile of silt at least 12 in. deep. A WDFW employee arrived while we performed the evaluation and opened the bypass ramp to the "flush" position and attempted to remove the silt from the bypass. Woody debris accumulation was not excessive. 


\section{New Cascade}

The site was evaluated 5/13/98, 7/8/98, and 9/17/98. Because of electrical interference with our flow meter, we were unable to collect reliable flow data.

Improvements to the site in 1998 included the addition of submergence marks on the screen frames at $10 \%$ increments. Because these screens are so large, $5 \%$ increments would be useful if more are added in the future. Screen submergence levels recorded during our evaluations did not vary greatly and averaged $82 \%$.

The screens were brown with algae and diatoms. Screen 8 (nearest the bypass) showed an indication of uneven wear against the bottom seal. Some of the brown algae growth had rubbed off at its downstream end. Generally, the screens operated well until September, when Screen 1 (furthest upstream) did not operate at all and Screen 8 jerked instead of turning smoothly. Also, by September, the seals on Screen 8 appeared to be worn and in need of replacement.

Water always flowed freely over the bypass weir and provided plenty of opportunity for fish passage. Outfall conditions for fish were always acceptable.

Although there was no excessive, sand, silt, or woody debris, there was a tremendous amount of vegetation growing in front of the screens at New Cascade. Vegetation increased through the season and sometimes interfered with our ability to view the bottom seals. Silt in front of the screens was deeper upstream than downstream, though never so deep that operation of the screens was impaired. Maximum sediment depth was only 2 in. during July and 6 in. during September.

Many fish were observed at this site, including some juvenile (chinook salmon) and adult (rainbow trout; Figure 27) salmonids. Some smaller fish (non-salmonids) were observed in the aftbay. 


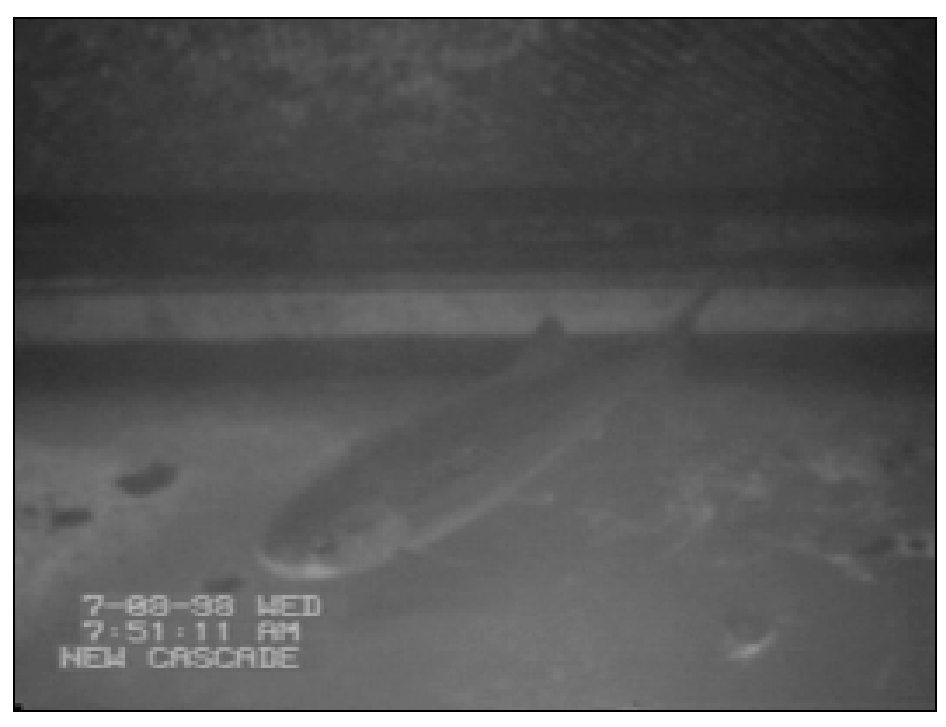

Figure 27. Adult rainbow trout filmed by underwater video in front of the New Cascade screens, 7/08/98.

\section{$\underline{\text { Snipes Allen }}$}

The Snipes Allen site was evaluated 5/7/98 and 9/14/98. In May, water was very high and water was backed up behind the bypass weir, possibly even flowing in reverse. Conditions were improved in September.

All approach velocities (Figure 28 and Figure 29) recorded at the Snipes Allen site met NMFS criteria as did screen submergence levels, recorded at 83.3 and $79.2 \%$.

Although the screens were brown with algae by September, they rotated evenly, and the seals were in good condition. Submergent plants grew abundantly in the forebay, but sediment was not present in excessive amounts.

Water behind the bypass weir did not flow smoothly. In May, water levels were so high there was reverse flow through the bypass. In September, water surged over the weir, hit the far wall and bounced back in a wave-like pattern. The outfall was submerged in May, and the pipe was full, but bubbles coming from the pipe in September indicated the pipe was not running full. Other outfall conditions were acceptable for fish bypass. 


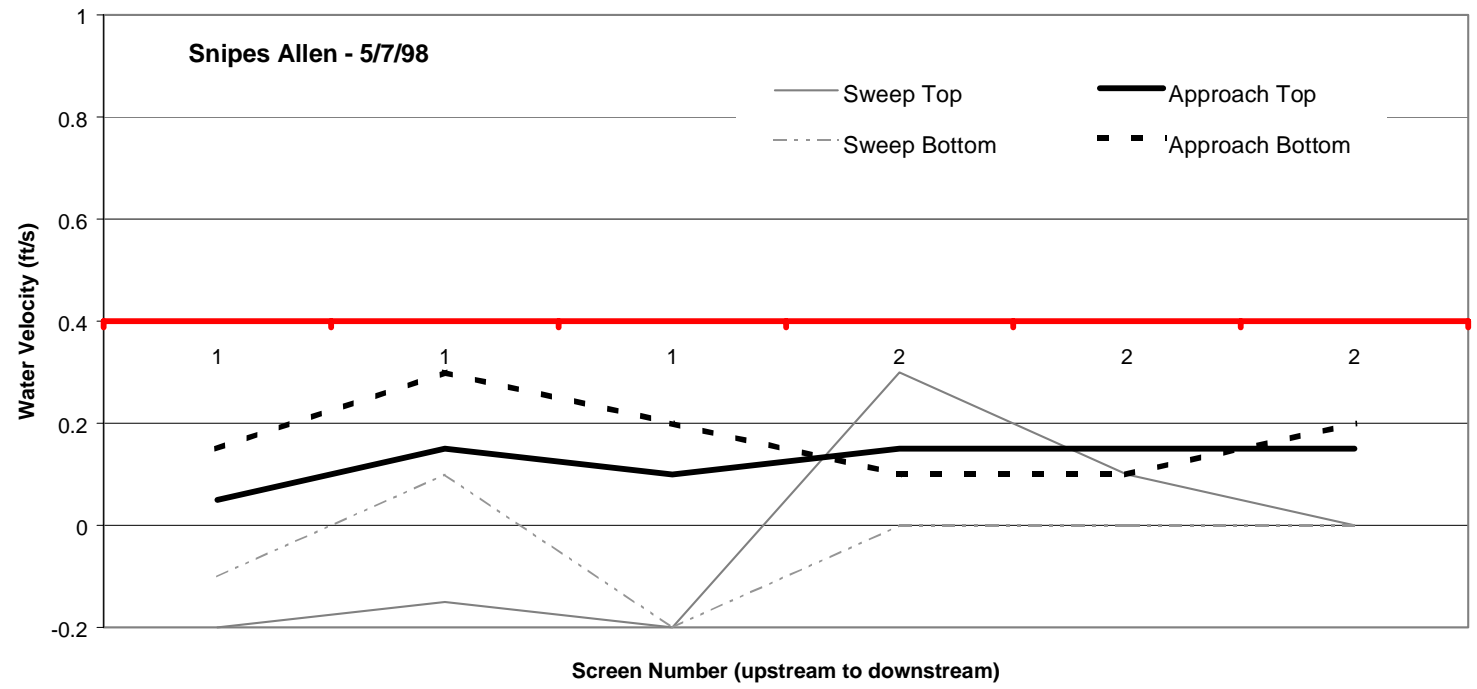

Figure 28. Water velocity at Snipes Allen, 5/7/98.

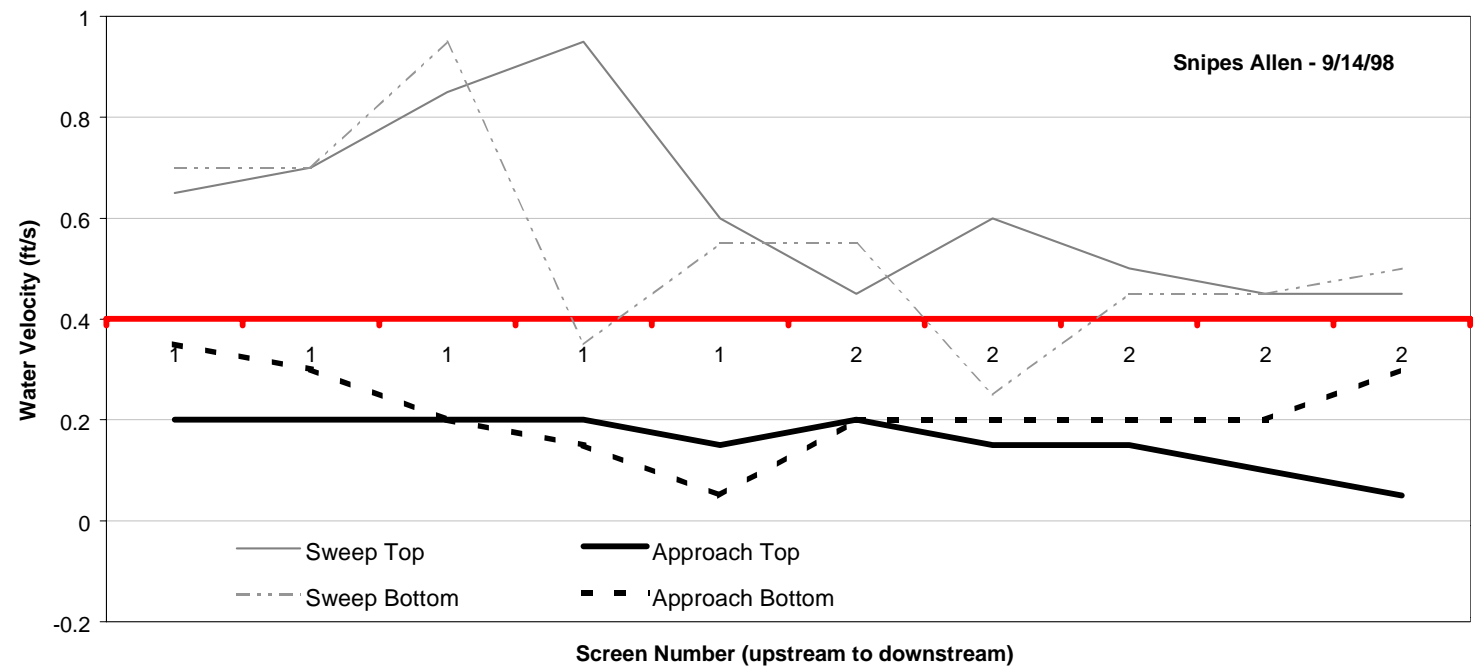

Figure 29. Water velocity at Snipes Allen, 9/14/98.

\section{$\underline{\text { Taylor }}$}

The Taylor site was evaluated 5/13/98, 7/7/98, and 9/21/98. Graphs of water velocities are not provided for July and September because there was no flow ( $0 \mathrm{fps})$ in any direction.

All approach velocities recorded in May met NMFS criteria. Sweep velocities were greater than the corresponding approach velocities and sweep velocities, increased toward the 
bypass (Figure 30). Screen submergence was very high (95\%) in May but was only $45 \%$ in September.

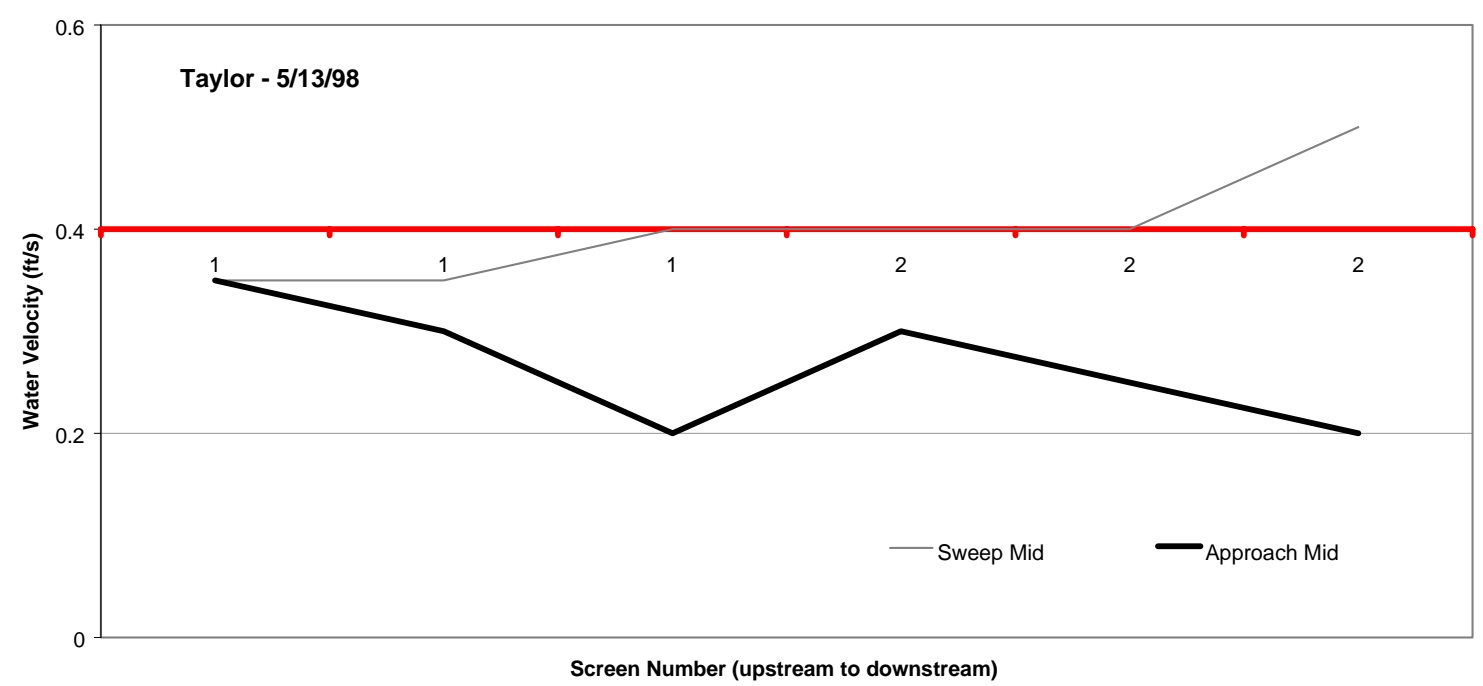

Figure 30. Water velocity at Taylor, 5/13/98.

Screens operated smoothly during the first evaluation, but in July Screen 1 was not operating and in September Screen 2 exhibited a rough jerking motion. The screen seals, however, were in good condition.

In May, the bypass weir ramp had been raised, effectively closing the bypass. This was done to prevent high river flows from entering the screen forebay through the bypass pipe. Since the waters had receded when we performed our evaluation, we lowered the weir so the screens would not be overtopped. Maintenance crews had not inspected the site for a full week, not often enough to keep up with the changing water conditions at Taylor, especially when the bypass had been blocked.

In September, the headgates were partially closed, and the bypass weir had been completely removed. No water was flowing through the site, and submergence levels were extremely low. However, logbook records stated that the site had been overtopped earlier.

Sedimentation increased over the course of the season. In May, there were 4 in. of silt in front of Screen 1 and none in front of Screen 2. Little woody debris was seen, though it appeared that tumbleweeds had previously been removed from the forebay. By our September evaluation, 
sediments practically blocked the entrance to the canal, though most of the sediments and plant growth were behind the screens and were deep enough to form an "island" (Figure 31). Only one inch had accumulated on top of the sill in front the screens.

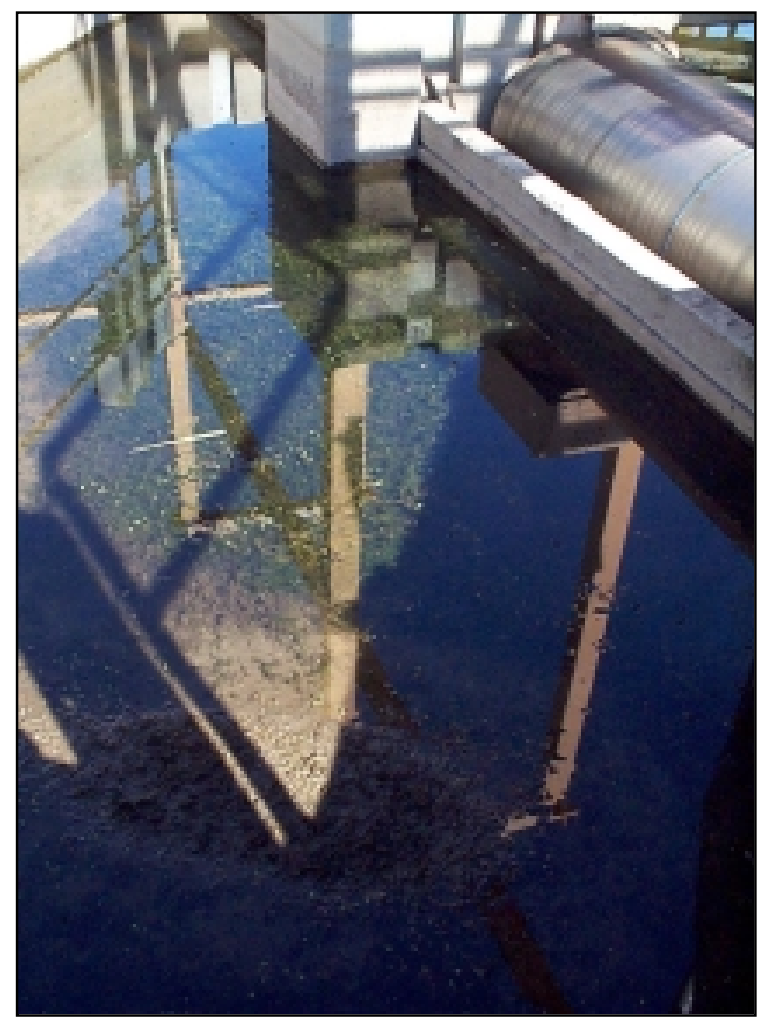

Figure 31. Island of sediment formed behind the Taylor Screens, 9/21/98.

\section{Toppenish Pump}

This site was evaluated 6/30/98. Flooding early in the season prevented earlier evaluation.

This site had an average approach velocity of $0.48 \mathrm{fps}$, exceeding NMFS criteria for $60 \%$ of the recorded velocities (Figure 32). Screen submergence was approximately $78 \%$. 


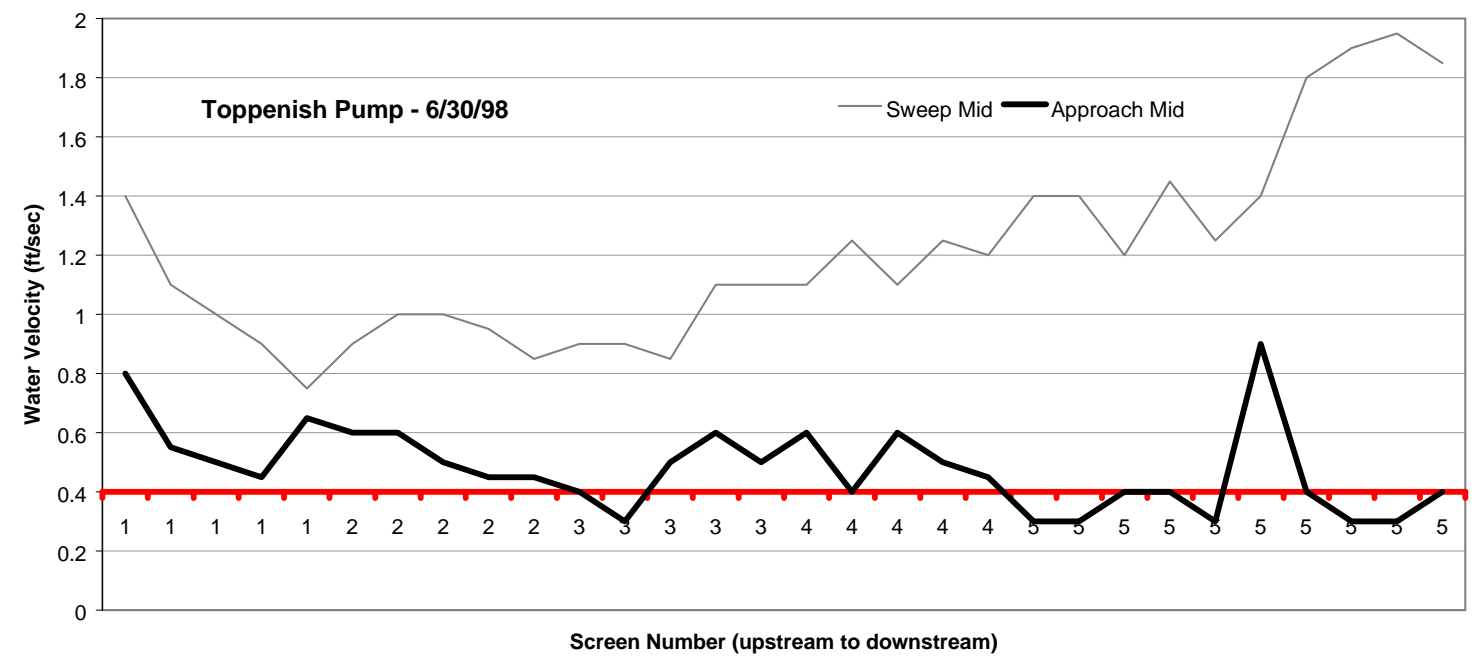

Figure 32. Water Velocities at Toppenish Pump, 6/30/98.

The screens were brown with diatoms and algae. All screens turned smoothly except Screen 1 (farthest upstream), which was turned off.

Water flowed freely over the bypass weir, and all outfall conditions were acceptable for fish bypass. However, the area above the outfall pipe accumulates floating debris and a mat of sticks about 4 in. thick was observed.

There was generally 4-6 in. of silt in the forebay, with more noted upstream than downstream. Six to $10 \mathrm{in}$. of silt and some woody debris had accumulated in front of the screen that was not rotating. Water in the canal was too turbid to observe the bottom seal with the underwater video camera.

\section{WIP Upper}

The WIP upper site was visited 5/7/98, 6/30/98, and 9/14/98. Improvements to the site included submergence marks on the screens and a tool for measuring the weir crest.

Eighty-five percent of the recorded approach velocities met NMFS criteria. Six percent were zero velocities, and the remaining 9\% were greater than $0.4 \mathrm{fps}$ (Figure 33, Figure 34, and Figure 35). Approach velocities exceeded bottom sweep velocities measured in May in front of 
Screens 3 and 4 (those closest to the bypass). In all other cases, sweep velocities were greater than approach velocities, though they did not generally increase near the bypass in May and September. Screen submergence levels were 84, 81.3, and 88.5\%.

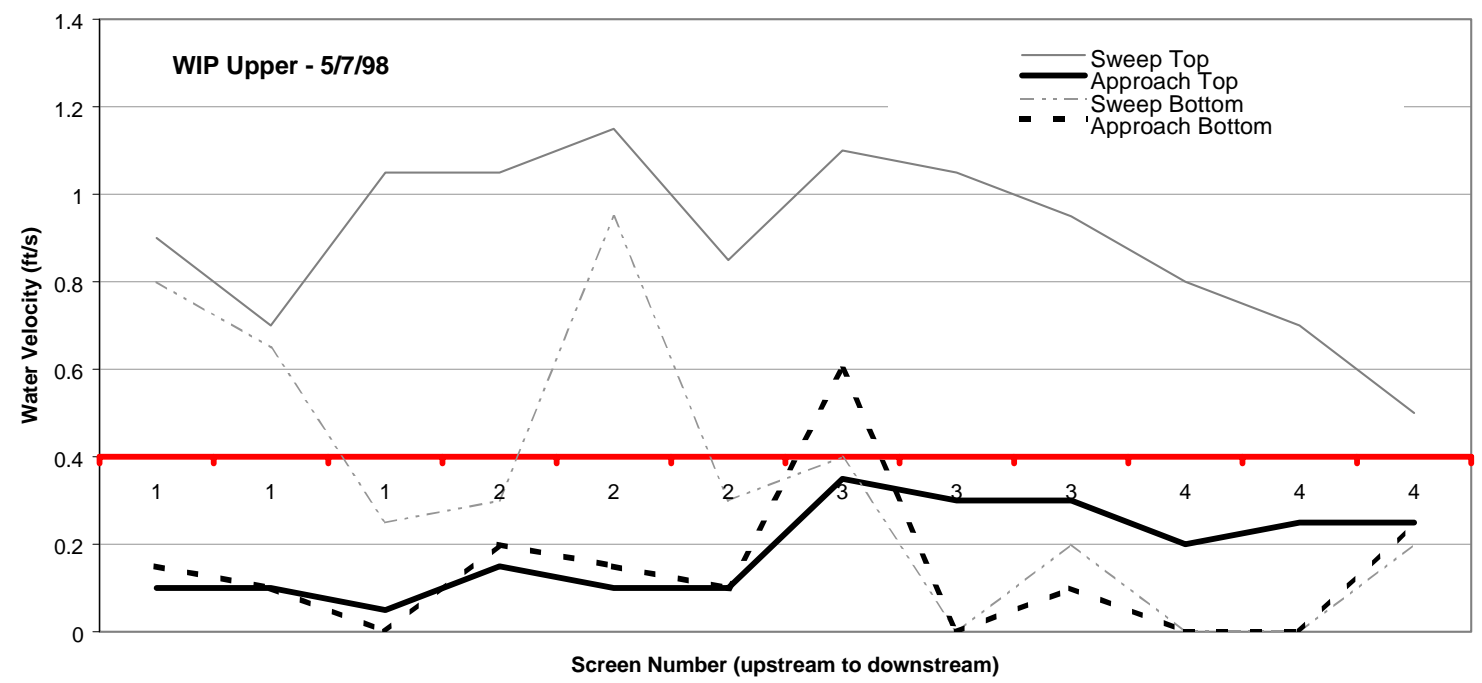

Figure 33. Water velocities at the WIP upper site, 5/7/98.

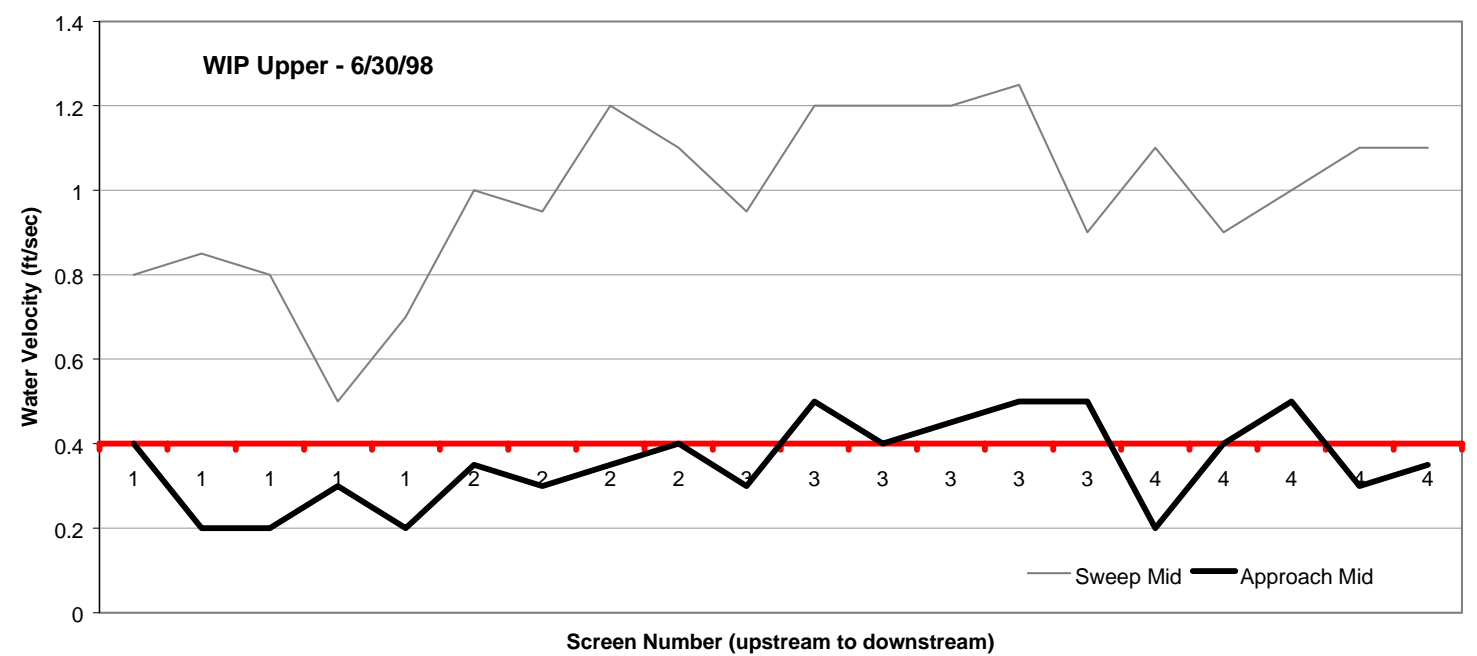

Figure 34. Water velocities at the WIP upper site, 6/30/98. 


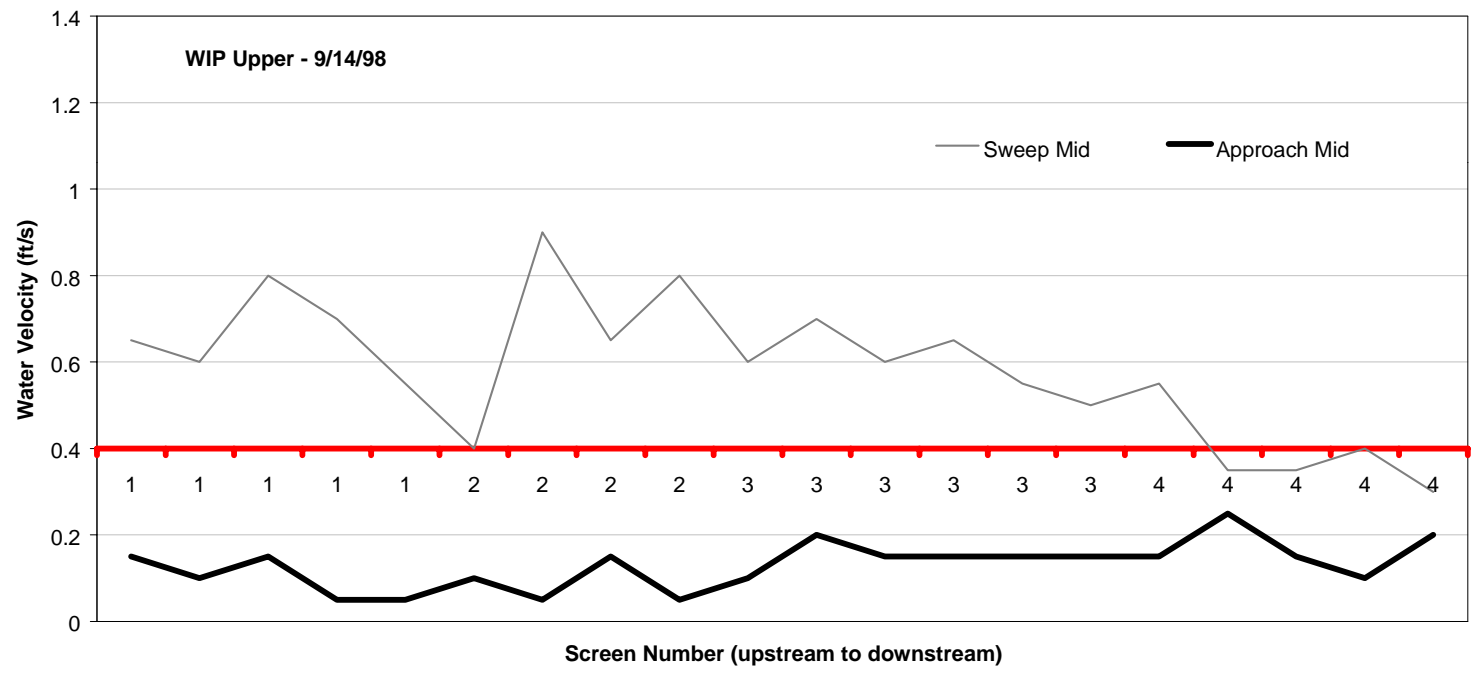

Figure 35. Water velocities at the WIP upper site, 9/14/98.

Uneven wear was noted by observing patterns of algae growth on the screens. Screens 1 and 4 had some clean (rubbed) sections while Screens 2 and 3 were covered with an even growth of brown diatoms/algae. During May, Screen 3 (second from the bypass) was not operational, and Screens 1 and 2 (furthest upstream) made loud noises. The screens operated well in June, but Screen 2 operated noisily again in September.

Adequate water was bypassed in May and June, but the bypass was blocked in September since all water in Ahtanum Creek was diverted to the irrigation canal (Figure 36). Water was slightly backed up in the forebay during the May evaluation because of the high water, but flow conditions were generally good. Outfall conditions at the terminus of the bypass pipe were good for fish passage in May and June. 

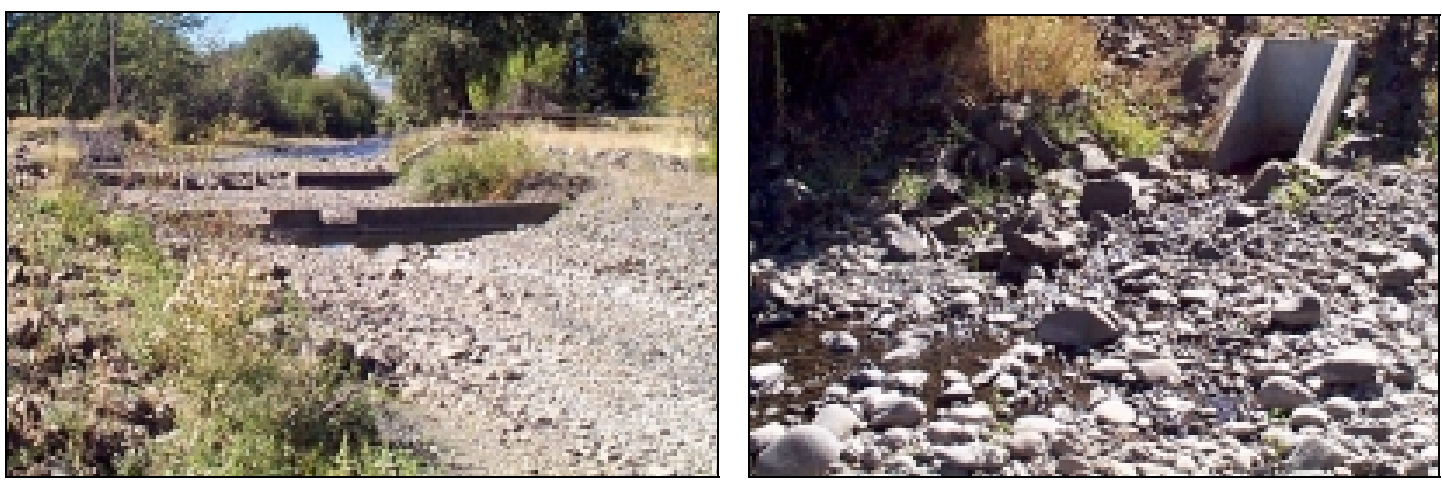

Figure 36. Dry Ahtanum Creek bed (left) and bypass outfall area (right) when water was fully diverted at the WIP upper site, 9/14/98.

Sediment and woody debris were excessive at the WIP upper site. In May a 12-in. porosity board was found and removed from the bypass entrance and woody debris created "hot spots" (areas of high velocity) in front of Screens 3 and 4 as we measured water velocity. In June, when the water was clear enough to use the underwater video camera, there was approximately $10 \mathrm{in.} \mathrm{of} \mathrm{silt} \mathrm{in} \mathrm{front} \mathrm{of} \mathrm{all} \mathrm{four} \mathrm{screens,} \mathrm{generally} \mathrm{obstructing} \mathrm{our} \mathrm{view} \mathrm{of} \mathrm{the}$ bottom seals. There was 11 in. of silt in the bypass. In September, even more sediment and woody debris had accumulated. The debris was a good refuge for fish; both large and small salmonids were observed in front of Screens 1, 3 and 4.

\section{Flat Plate Screens}

\section{$\underline{\text { Bull }}$}

The Bull site was evaluated 5/13/98, 7/7/98, and 9/17/98. In May the site was sandbagged to keep water from overtopping the site. We opted not to record water velocities at that time because the sandbags covered parts of the platform.

Improvements to the site in 1998 included installation of hinges on the platform above the screen that allowed easy access to the area in front of the screen panels. This greatly 
enhanced our ability to evaluate water velocities, screen and seal condition, and effectiveness of the cleaning brushes.

On 7/7/98, 3\% of the recorded approach velocities exceeded 0.4 fps. Forty-four percent were between 0 and $0.4 \mathrm{fps}, 15 \%$ were $0 \mathrm{fps}$, and $38 \%$ were negative values (Figure 37 and Figure 38). Surface sweep velocities were consistently greater than bottom sweep velocities.

Overall, sweep was slow and bottom sweep values were often less than corresponding approach velocities. Water in front of the screens was always high and submergence values for the flat plate screen were approximately 100, 100, and $91.7 \%$.

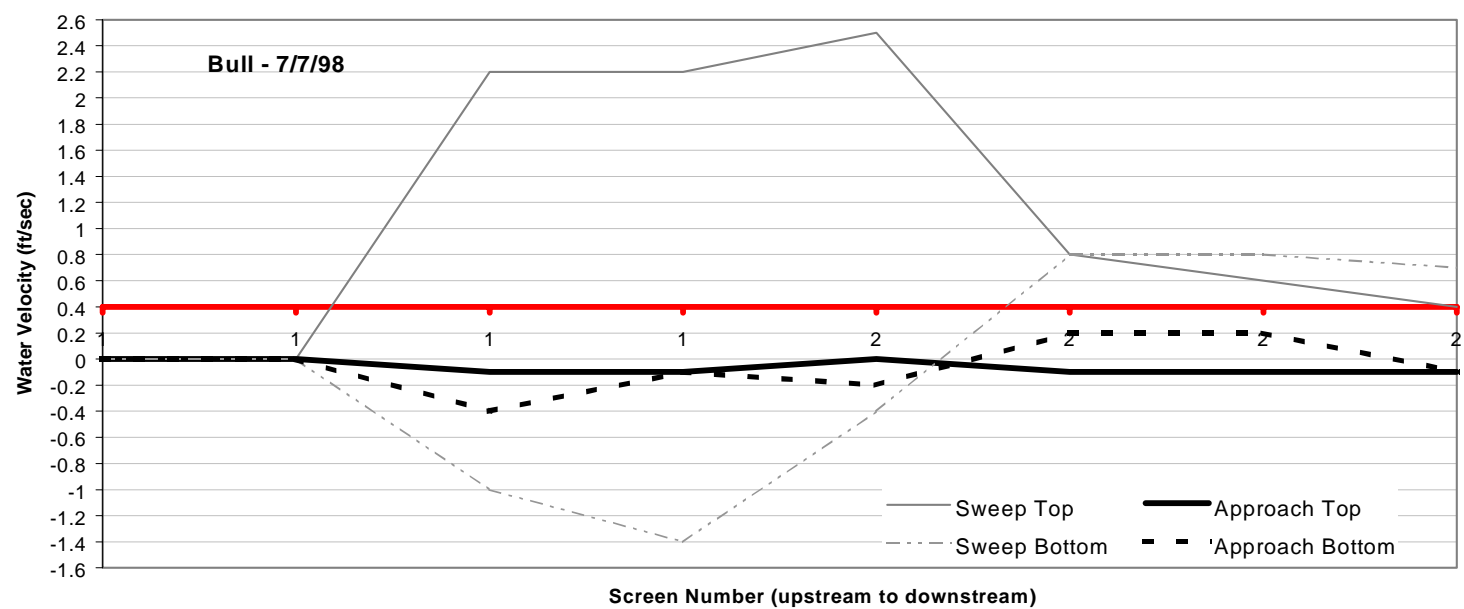

Figure 37. Water velocities at Bull, 7/7/98.

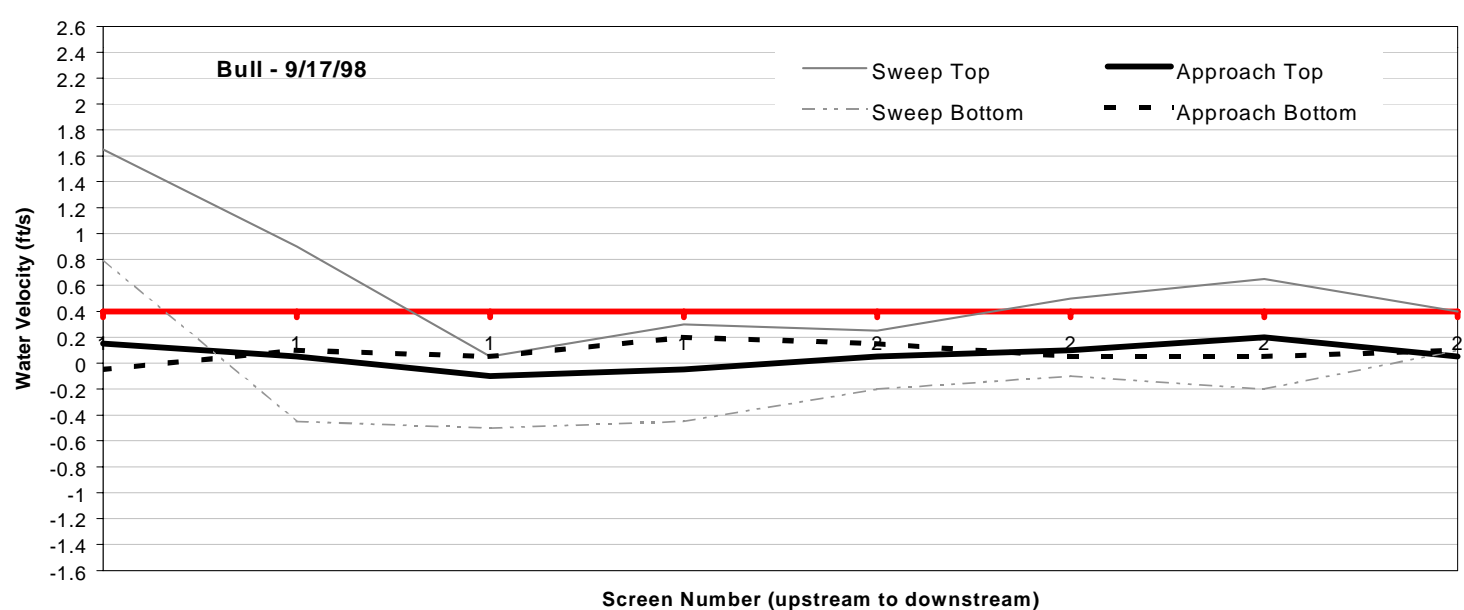

Figure 38. Water velocities at Bull, 9/17/98. 
The screens and seals were generally in good condition. A small amount of loose caulking was observed along the bottom and side of the third metal panel (near the bypass; Figure 39

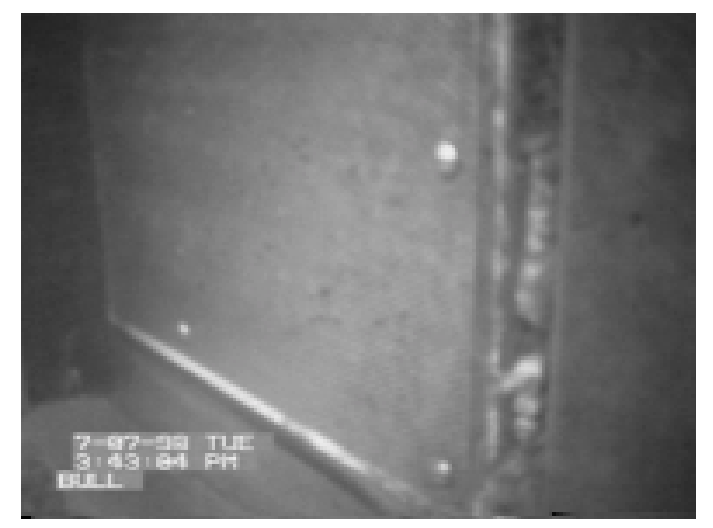

Figure 39. Loose caulking on flat plate screen at Bull ditch diversion on 7/7/98.

Small sticks and gravel were observed in front of the screens in July. Some leafy material was getting stuck on the screen. More leaves had accumulated in September and many were stuck in the cleaning brushes, making the brushes ineffective. Only about 1 in. of silt was observed along the upstream end of the screen and less downstream until the very end of the screen where approximately 5 in. of sand and leaves had accumulated.

In September, we observed many fish in front of the screen, some salmonids. No fish were observed behind the screen.

\section{Ellensburg Mill}

The Ellensburg Mill site was evaluated 5/13/98, 7/8/98, and 9/17/98.

In May, approach velocities exceeded sweep at the very upstream end of the screen (Figure 40). The louvers behind the screen were wide open at that position, so closing them slightly would probably have alleviated the effect. 
In most other cases, sweep velocities exceeded their corresponding approach velocities (Figure 41 and Figure 42). However, sweep did not generally increase near the bypass. Seventyfive percent of the recorded approach velocities were between 0 and $0.4 \mathrm{fps}$. Four percent were zero velocities and $21 \%$ were negative approach velocities. All the negative approaches were recorded in July. This flat plate screen does not appear to have any submergence problems as measured submergence values were only 68.1, 56.9, and 61.1\% during the 1998 season.

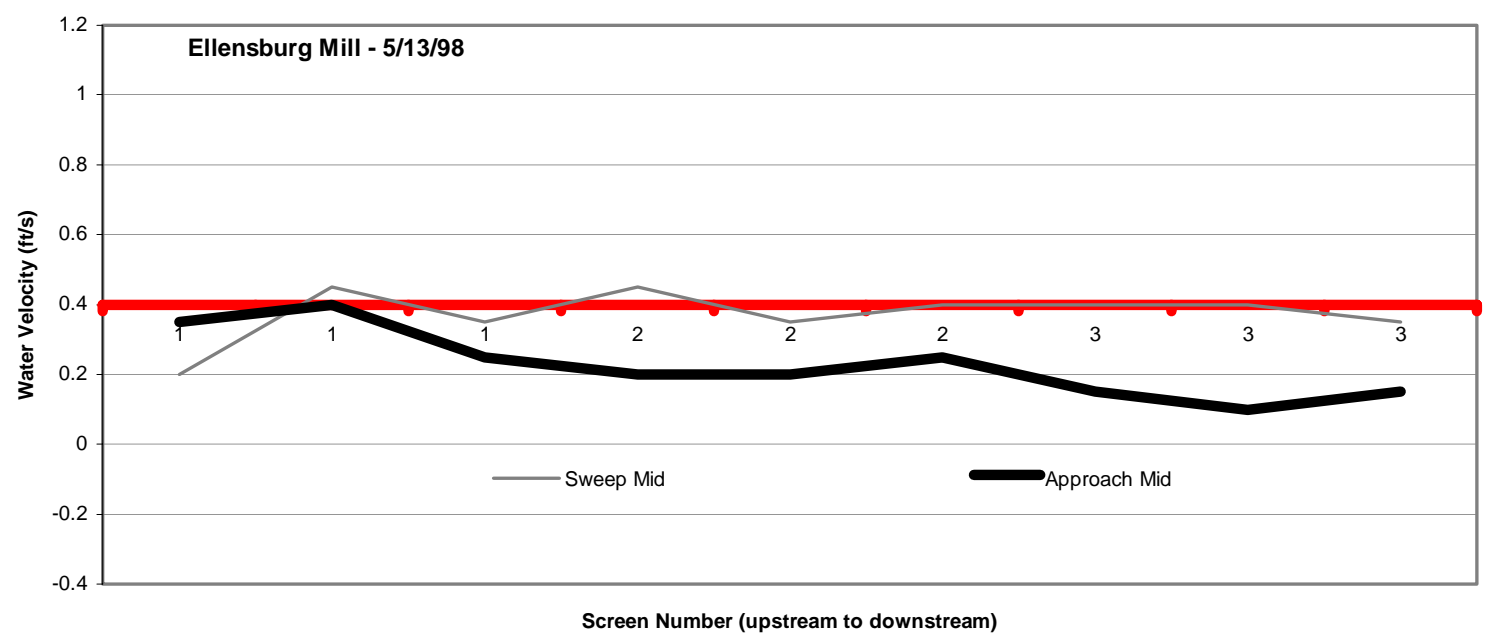

Figure 40. Water velocities at Ellensburg Mill, 5/13/98.

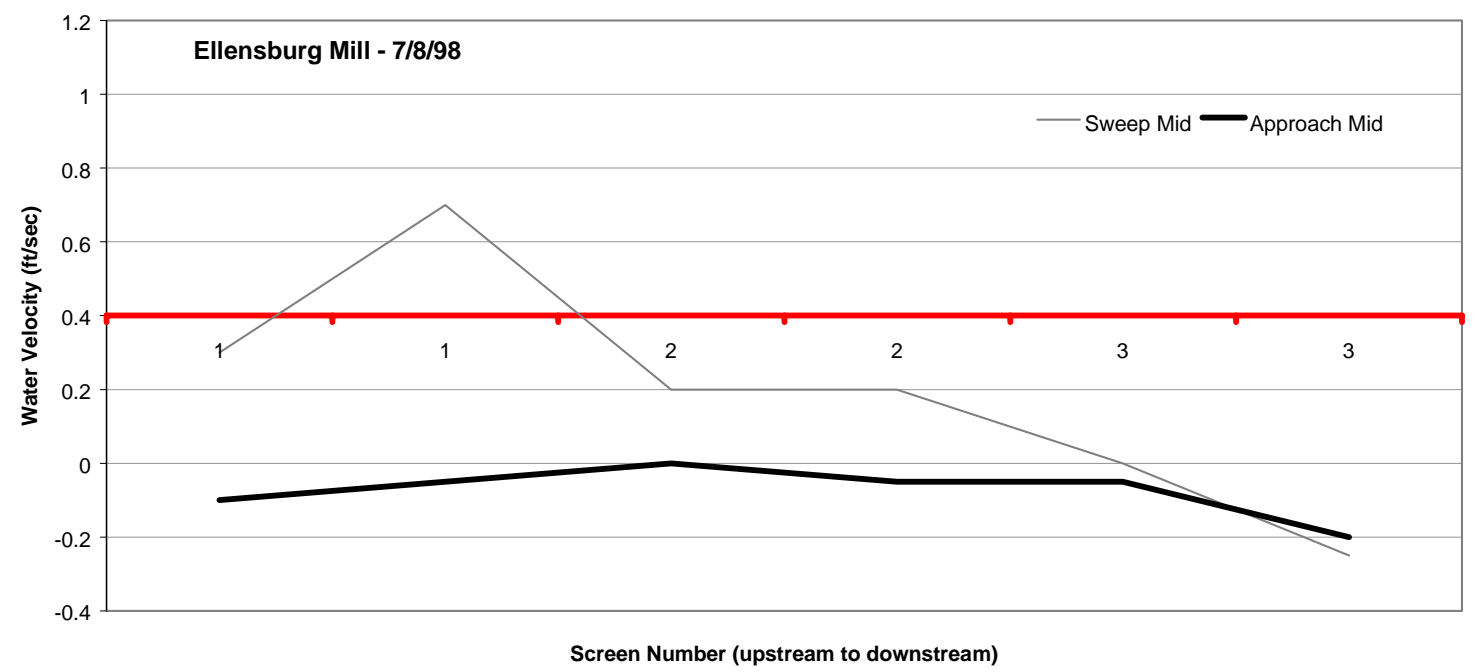

Figure 41. Water velocities at Ellensburg Mill, 7/8/98. 


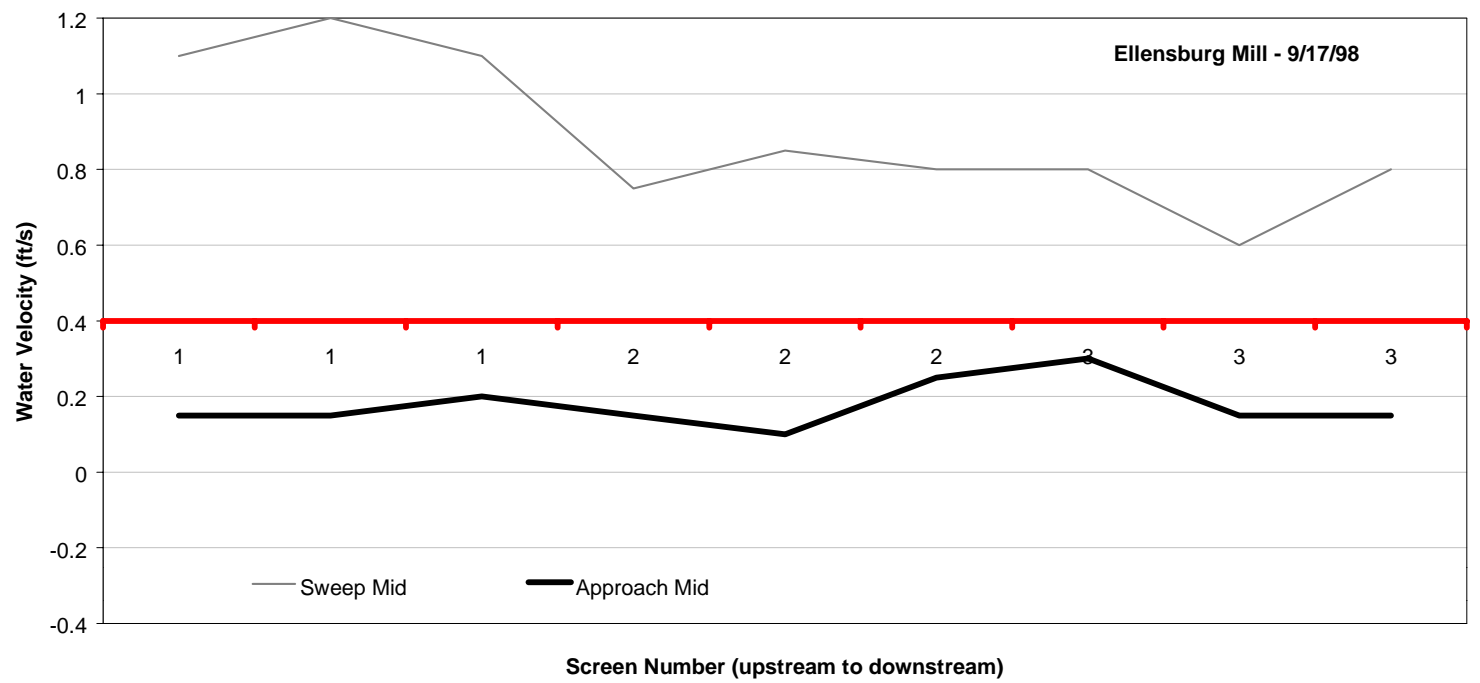

Figure 42. Water velocities at Ellensburg Mill, 9/17/98.

The screens were in good condition, but much of the seal caulking under water had come loose or was missing (Figure 43).

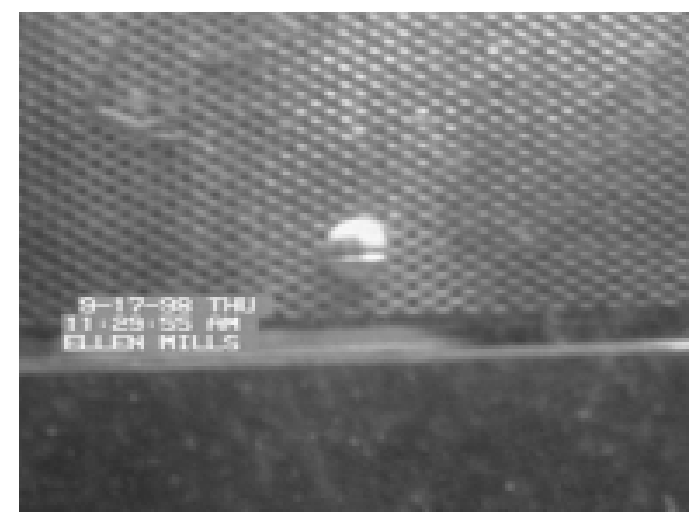

Figure 43. Loose/missing caulking on screen seal at the Ellensburg Mill diversion, 9/17/98.

Water flowed over the bypass weir in May and September, but not in July. During our July evaluation the ramp was raised (33 in. above its full open position) so water could not pass over it into the bypass, even though conditions at the outfall were good for fish passage. Conditions were also good for fish passage in May and September. 
There was woody debris on the trash rack in May, though many branches had already been pulled out and piled on shore (Figure 44). Silt had also accumulated in front of the screens. There was 4 to $6 \mathrm{in}$. upstream that decreased to 1 to $2 \mathrm{in}$. near the bypass. There were 2 to $3 \mathrm{in}$. of silt on the sill between all the louvers. The bypass had 3 in. of silt. In July and September, weeds and sediment blocked our view of the bottom seal at Panel 1 (farthest upstream). Weeds interfered with the velocity probe, so measurements had to be taken higher in the water column to avoid touching them.

In September, many fish were visible on both sides of the screen; some behind the screen were as long as 8-10 in. (possibly trout or northern pikeminnows).

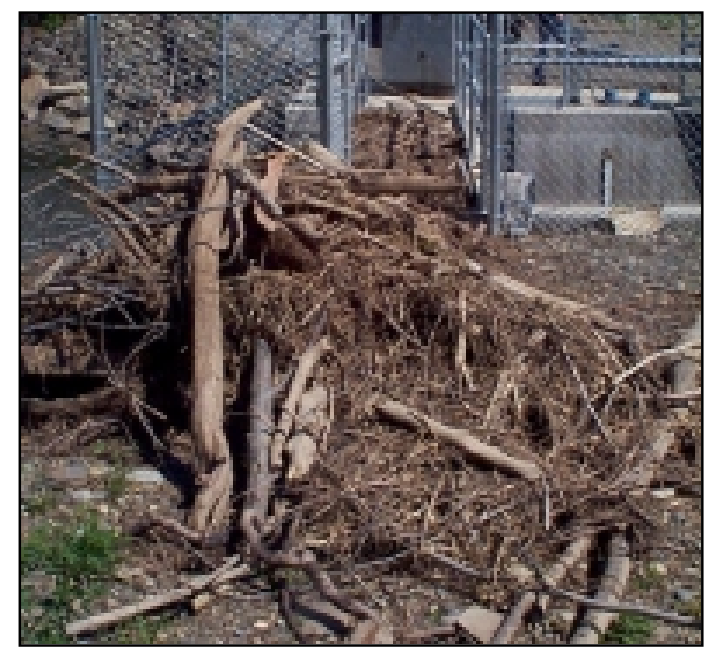

Figure 44. Debris removed from the trash rack at Ellensburg Mill, 5/13/98.

\section{Fruitvale}

The Fruitvale site was evaluated 5/11/98, 6/23/98, and 9/21/98. Electrical interference kept us from collecting any reliable water velocities. In addition, extremely turbid water during all three evaluations made accurate documentation of screen and seal condition difficult. Screen submergence levels were approximately 95, 99, and 99\%. The log book recorded that the screen was overtopped around July 29 , and the water was so high it had flowed down the access road.

Improvements to the site in 1998 included a new 6 in.-tall metal extension above the screen to keep it from overtopping and a 100\% submergence mark (Figure 45). 


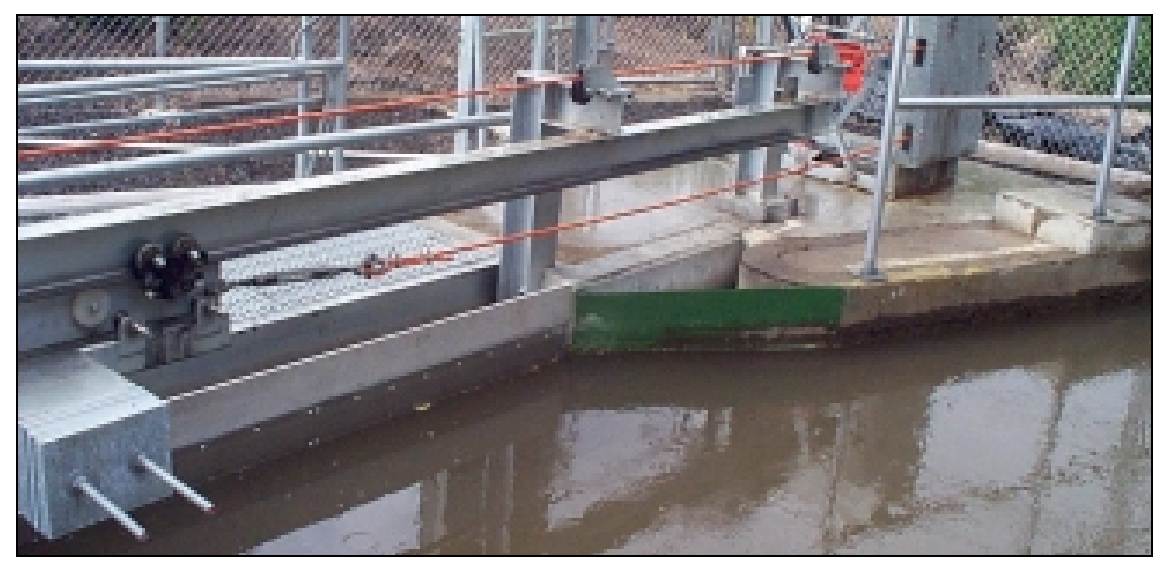

Figure 45. New metal plate attached above the screen and $100 \%$ submergence mark on the green metal corner piece, $5 / 11 / 98$.

Adequate water always flowed over the bypass weir, and outfall conditions were good for fish passage.

There was not much sediment observed in front of the screen in May, although some was present in the aftbay. In June, sediment was approximately $1 \mathrm{ft}$. deep in the center of the forebay, but sediments near the screen were just 4 to 6 in. deep and concentrated at the upstream end of the screen. In June, the bypass ramp had been removed for repairs because its flush gate would not close. Boards had been inserted in the weir slot while repairs were made.

\section{$\underline{\text { Naches Selah }}$}

This site was evaluated 5/12/98, 6/24/98, and 9/16/98.

Improvements to the site in 1998 included a new mechanism for clearing silt from in front of the screens. The device consisted of an air hose attached to a pipe that extended to the bottom of the screen and split into two nozzles (Figure 46). The pipe was attached to the cleaning brush so it could move back and forth over the length of the screen. 


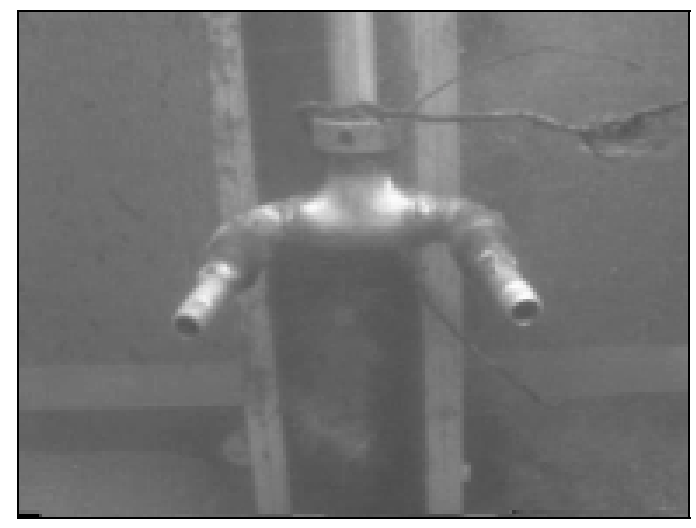

Figure 46. Device used to move silt away from the screen at Naches Selah, 6/24/98.

Flows at Naches Selah were very good. Bypass velocities were always higher than the average sweep velocities (Figure 47, Figure 48, and Figure 49). Also, sweep velocities were always much greater than their corresponding approach velocities. Eighty-two percent of the approach velocities recorded at Naches Selah were between 0 and 0.4 fps. Only 3\% exceeded 0.4 fps. Thirteen percent were zero velocities, and $2 \%$ were negative velocity values. Screen submergence values for this flat plate screen were approximately 86.8, 94.4, and $84.7 \%$.

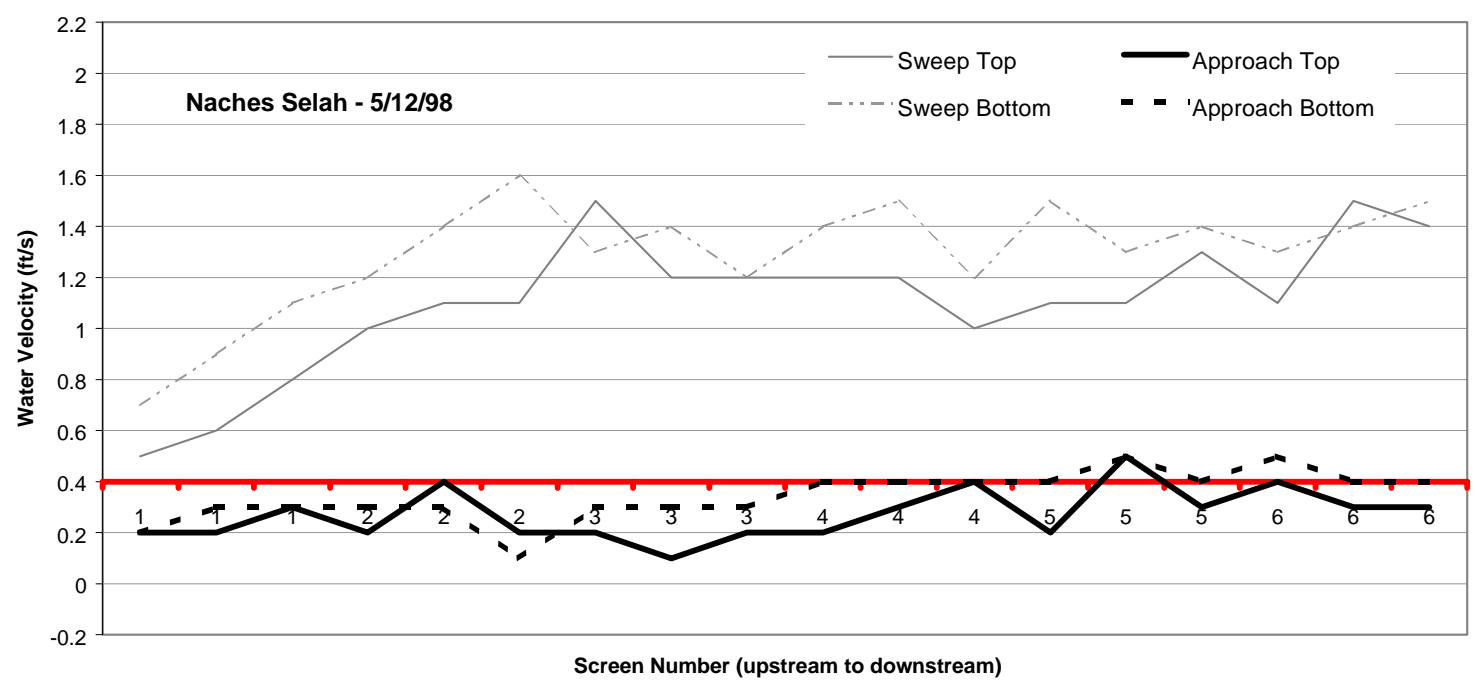

Figure 47. Water velocities at Naches Selah, 5/12/98. 


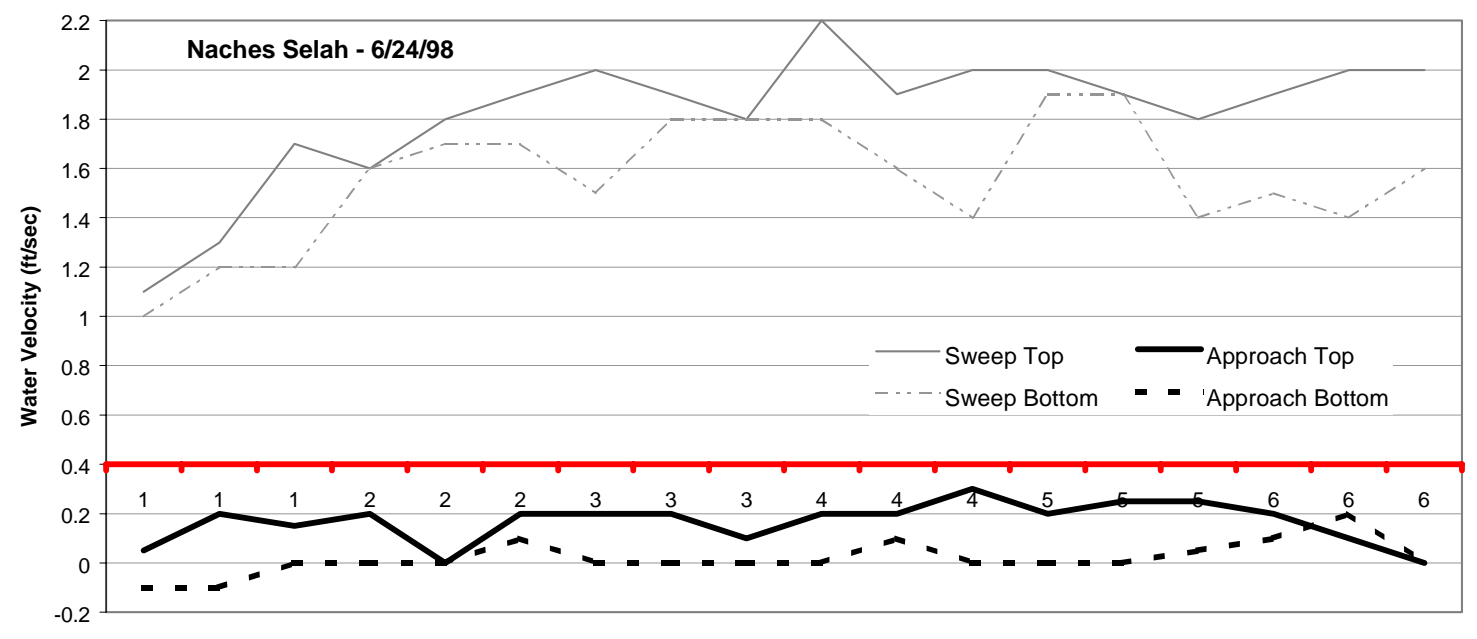

Screen Number (upstream to downstream)

Figure 48. Water velocities at Naches Selah, 6/24/98.

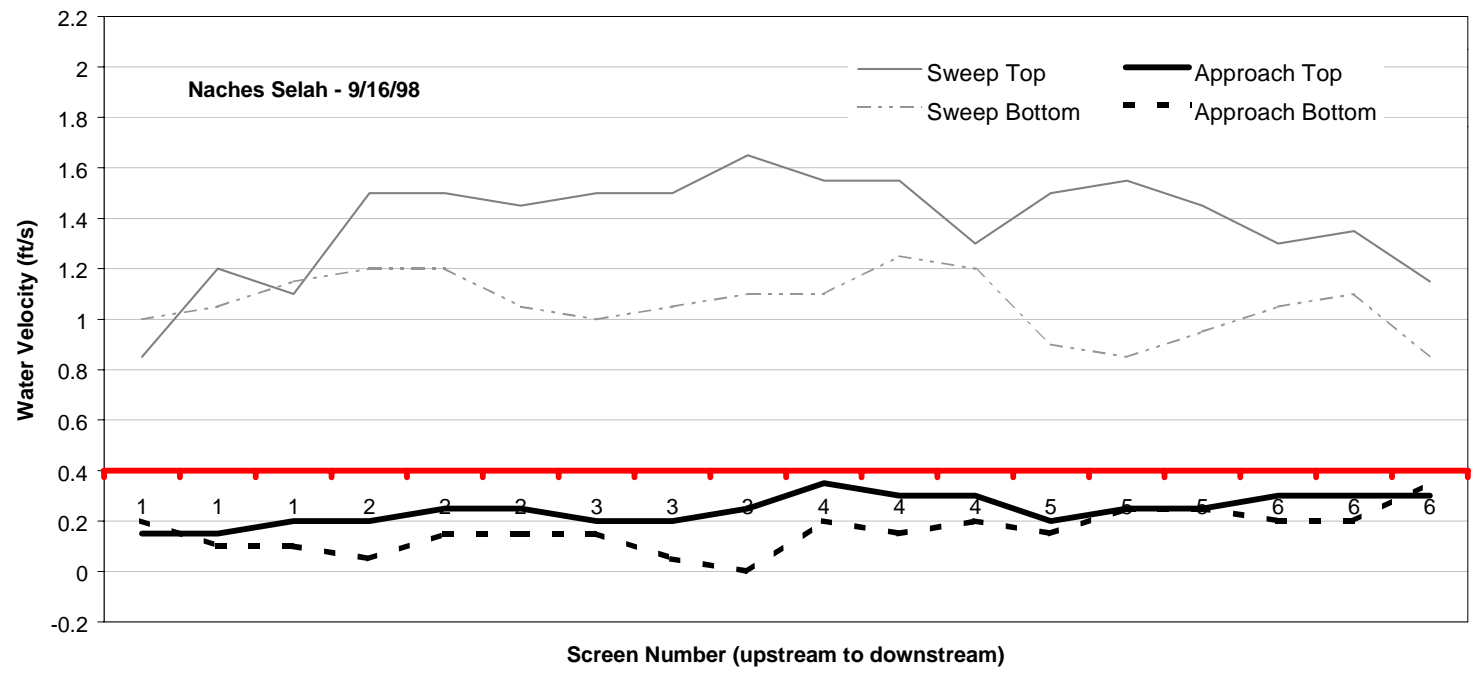

Figure 49. Water velocities at Naches Selah, 9/16/98.

The screen was in good condition. Some algae growth was observed between the wedgewire in September, but it was not enough to impact screen performance. Underwater video revealed some loose caulking between the panels.

Adequate amounts of water flowed over the weir at all times, and most outfall conditions were good for fish passage. Water depth was generally shallow at the terminus of the pipe (6 to 8 in. deep), especially within the wingwalls. However, strong flow through the pipe probably mitigated this impact, and deeper water beyond the wingwalls was adequate for fish passage. 
Sedimentation was excessive at Naches Selah. Although we always evaluated the site immediately after silt had been removed, there was evidence that a large amount of silt had been recently removed (Figure 50). In May, maintenance crews removed sediment approximately $3 \mathrm{ft}$ deep adjacent to the screens and sediment approximately $4 \mathrm{ft}$ at the forebay entrance just one day prior to our evaluation. The sediment had been so deep, cleaning brushes were unable to move through it. Lesser amounts of sediment and debris were observed in June, although a small log had entered the forebay, and some leafy debris had accumulated on the screen in between brush operation cycles. In September, we evaluated the site within a week of sediment removal from the forebay. We observed only small amounts of sandy silt and small gravel in front of the screens. An artifact of manual sediment removal appears to be an increase in sediment depth between the screen and the louvers, often as deep as $10 \mathrm{in.}$

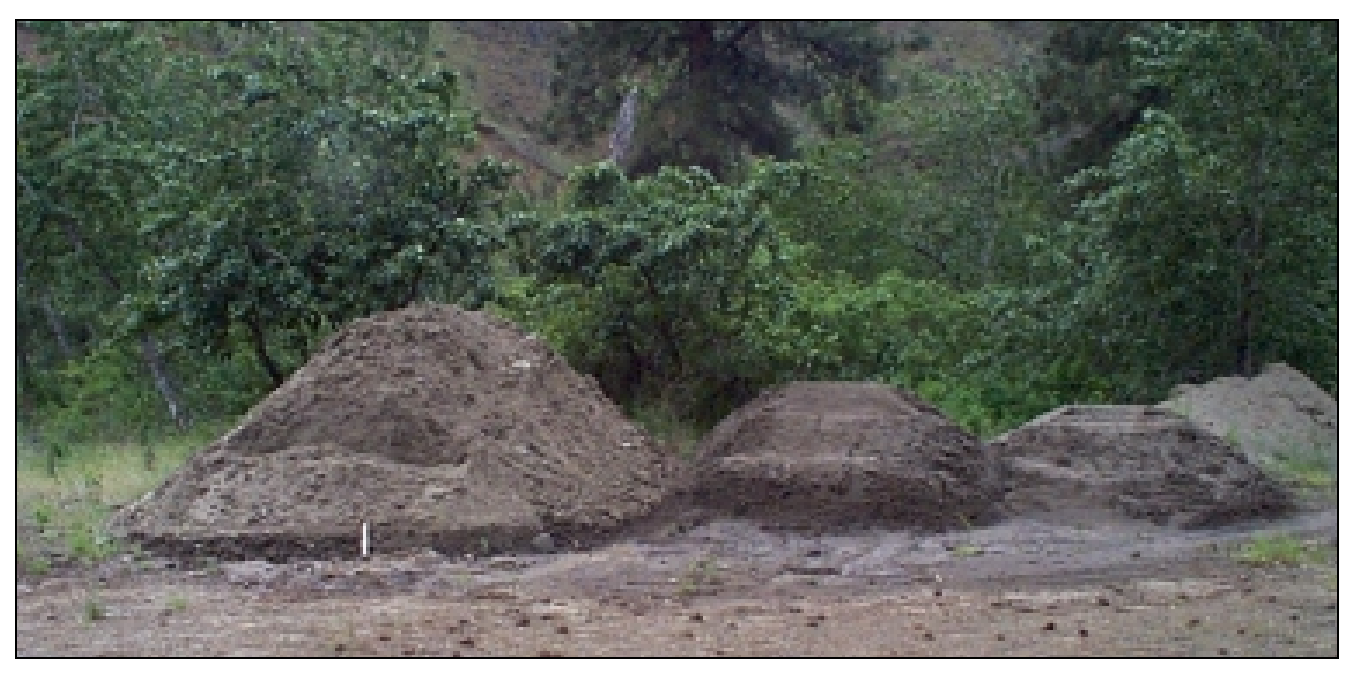

Figure 50. Piles of sediment removed from the forebay at Naches Selah, 5/12/98.

A number of juvenile chinook salmon were observed in the bypass. One small unidentified fish was observed on the downstream side of the screens in the aftbay.

\section{$\underline{\text { Union Gap }}$}

The Union Gap site was evaluated 5/11/98, 7/1/98, and 9/15/98. Comments recorded during the May evaluation noted that the site was in good condition and operating well under high-water conditions. 
Improvements to the site in 1998 included the addition of a gage to measure weir crest. This was simply a pole marked in inches up to $2 \mathrm{ft}$ and a "closed" position was marked on the frame of the weir gate.

Eighty-seven percent of the recorded approach velocities were between 0 and $0.4 \mathrm{fps}$ (Figure 51, Figure 52, and Figure 53). Eight percent of the approach velocity records were zero values, but only $5 \%$ were outside NMFS criteria and greater than $0.4 \mathrm{fps}$. Sweep velocities, while always greater than corresponding approach velocities, generally decreased toward the bypass and were much faster than the bypass velocities. Screen submergences at this flat plate site were $93.3,93.3$, and $90 \%$.

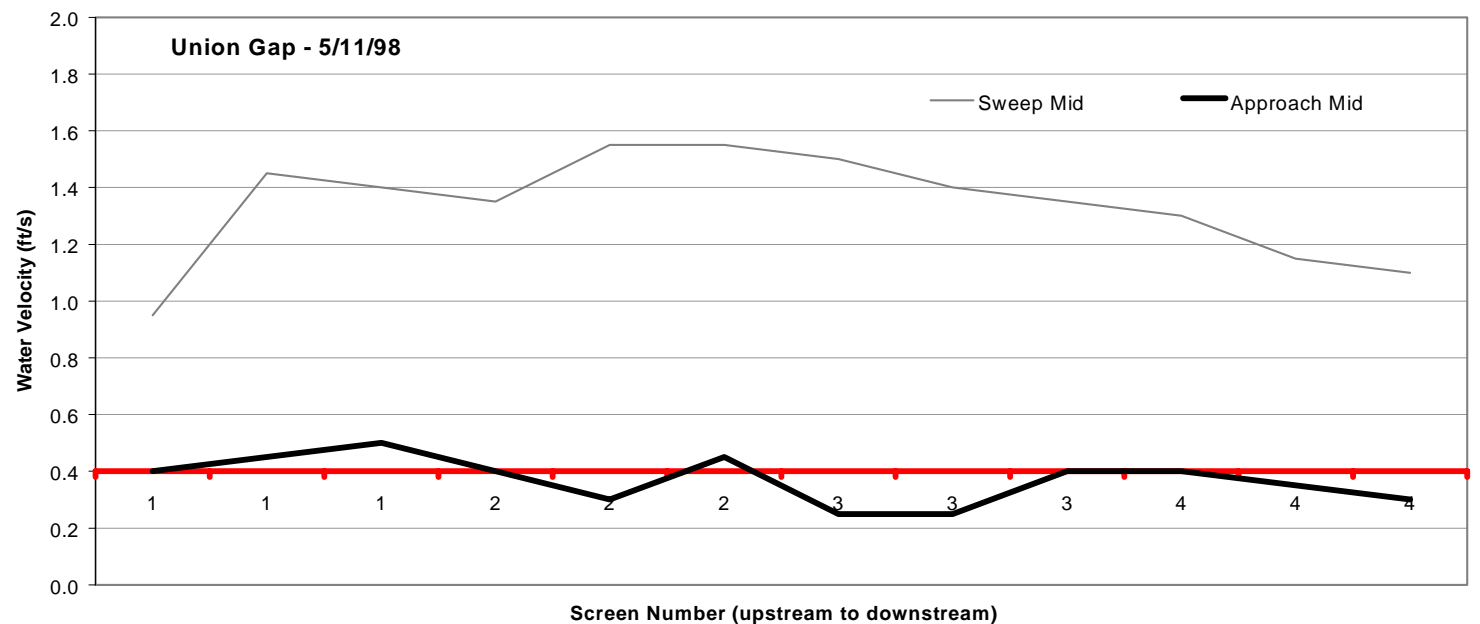

Figure 51. Water velocities at Union Gap, 5/11/98.

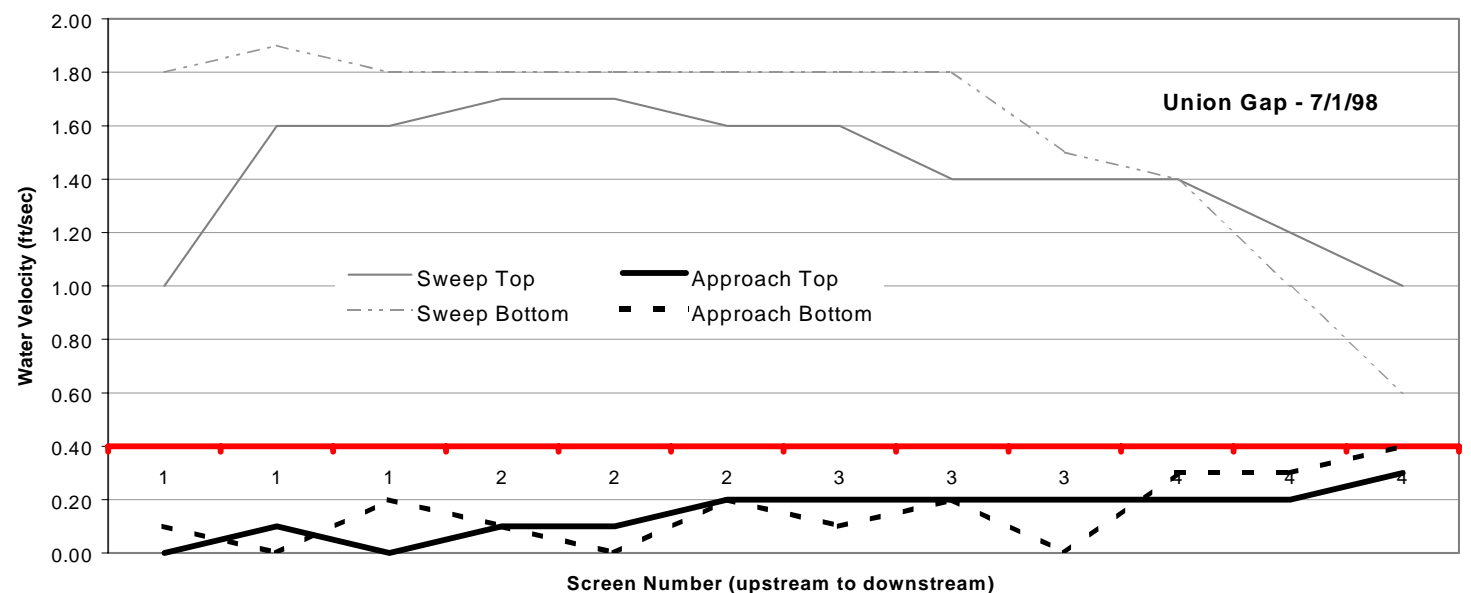

Figure 52. Water velocities at Union Gap, 7/1/98. 


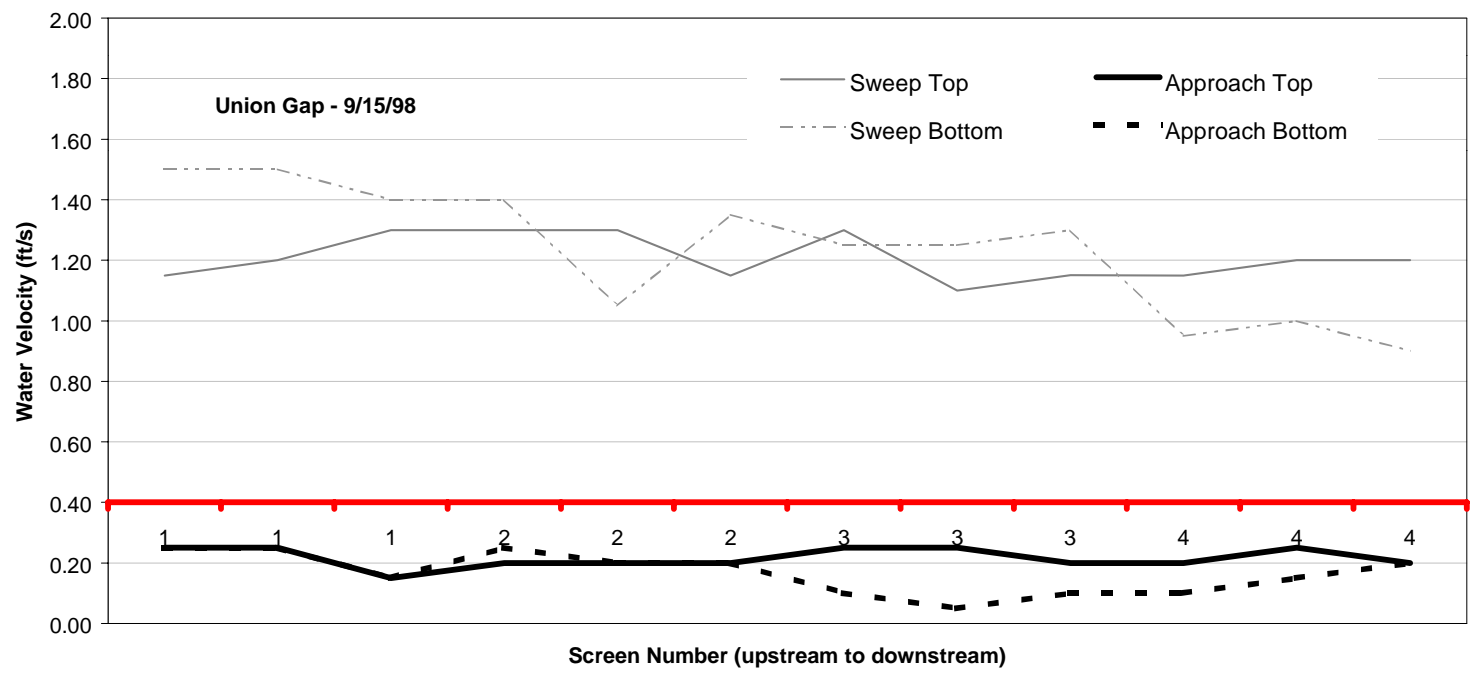

Figure 53. Water velocities at Union Gap, 9/15/98.

The screen and seals were in good condition. Adequate amounts of water always flowed over the bypass weir, and all other outfall conditions were good for fish passage.

Sediment and woody debris were not observed in front of the screens in May. During the July evaluation, there was approximately 3 in. of sediment near the bypass and less in all other locations. In September, there was little or no silt present in front of the screen. However, small twigs and leaves built up on the screens in September, probably because the interval set for brush operation (approximately 1 hour) was too long.

\section{$\underline{\text { Yakima Tieton }}$}

The Yakima-Tieton site was evaluated 5/12/98, 6/23/98, and 9/16/98.

Seventy percent of the recorded approach velocities were between 0 and 0.4 fps (Figure 54, Figure 55, and Figure 56). Twelve percent of the recorded velocities were zero, and 13\% were negative values. Only 5\% exceeded the NMFS limit of $0.4 \mathrm{fps}$. Most of the high approach velocities were recorded along the upstream half of the screen. There is a fast flow at this site, and sweep velocities were always much higher than their corresponding approach velocities. Sweep velocities did not increase toward the bypass, but sweep velocities were generally high 
enough to mitigate this condition. Screen submergence at Yakima Tieton was approximately 83.3, 95.2, and $92.9 \%$.

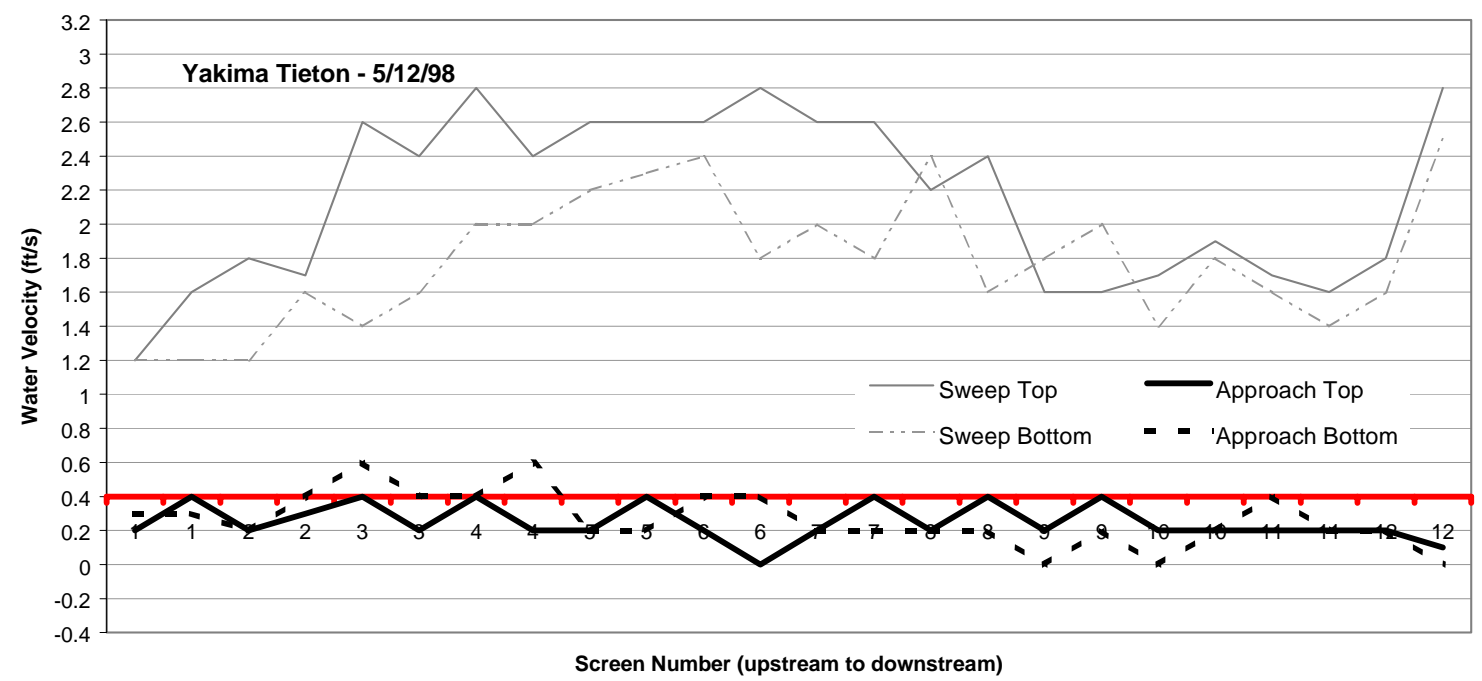

Figure 54. Water velocities at Yakima Tieton, 5/12/98.

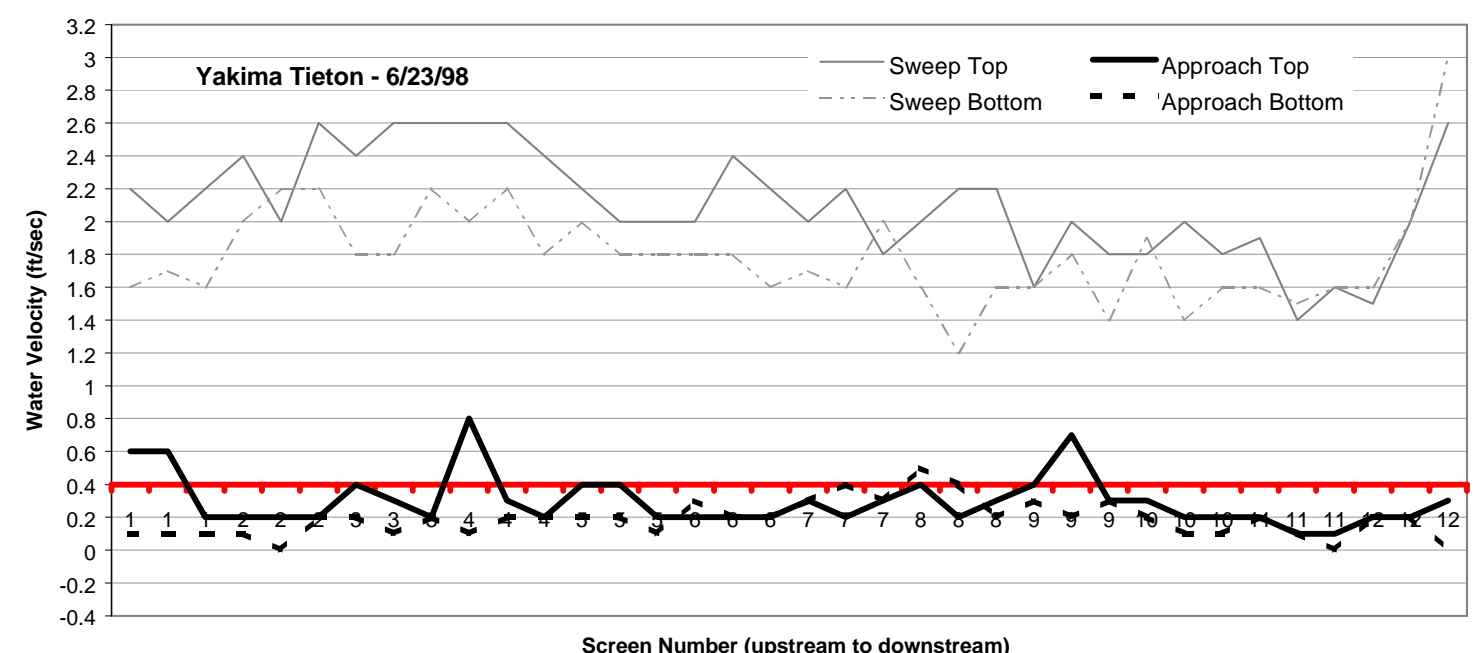

Figure 55. Water velocities at Yakima Tieton, 6/23/98. 


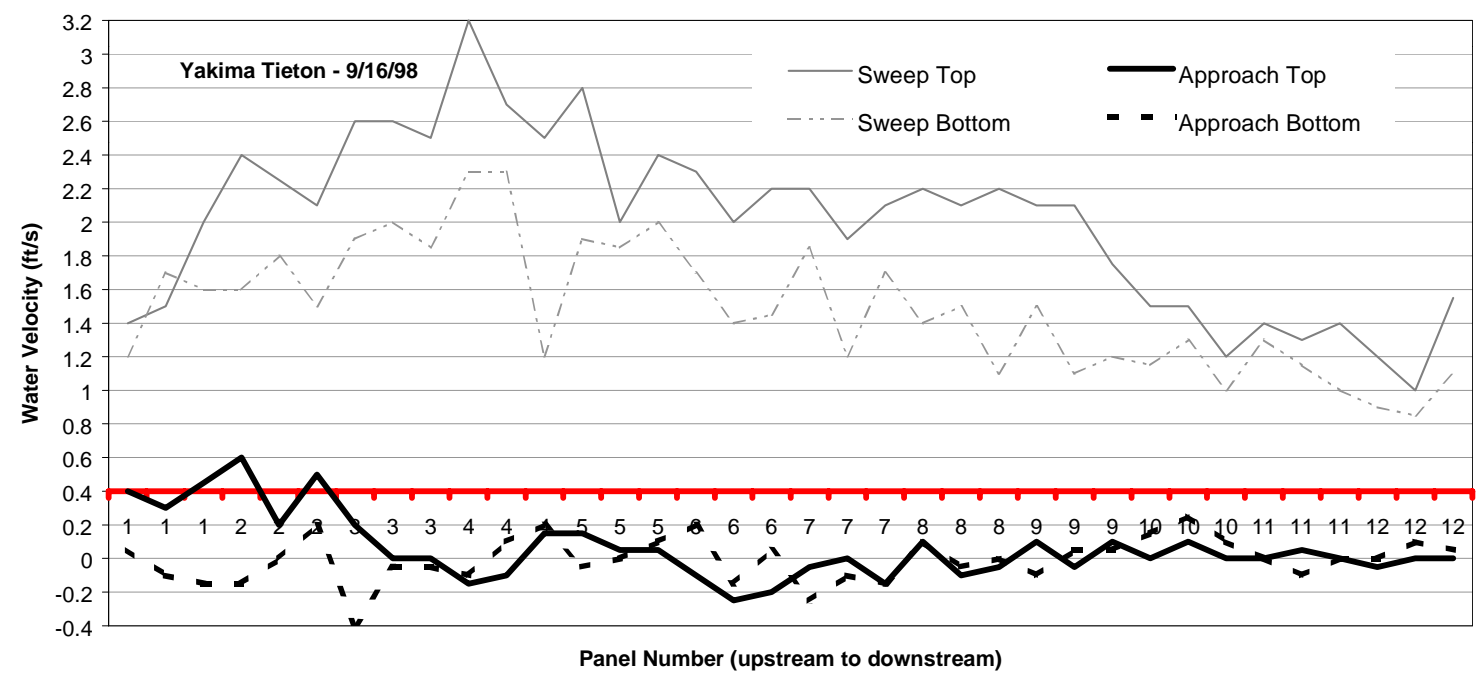

Figure 56. Water Velocities at Yakima Tieton, 9/16/98.

The screens were in good condition except for the continued build-up of algae along the bottom 6 in. of the screens where the brushes do not reach. Some loose caulking was observed on panels 3,9 , and 10 (numbering upstream to downstream).

Adequate amounts of water flowed over the weir in May and September, and water flowed under the top of the weir in June. Some sticks blocked the top of the opening in September. Outfall conditions were good for fish passage. A small mat of pulverized sticks and herbaceous material floated inside the wing walls in September.

Although there was never excessive sand, silt, or woody debris, there was a lot of leaf litter and small twigs that accumulated on the screens between brushings, especially in May. During that evaluation, the gang brushes could not keep up with the amount of debris and could not move past several large accumulations (Figure 57). We manually scraped enough debris off the screen for the brushes to operate again. In June, two brushes had been removed so that only two remained. By September, the brushes were splayed out, ineffective, and in need of replacement. Generally, silt accumulated along the downstream half of the screen, though it was rarely greater than 6 in. deep. No silt was observed in the bypass. 


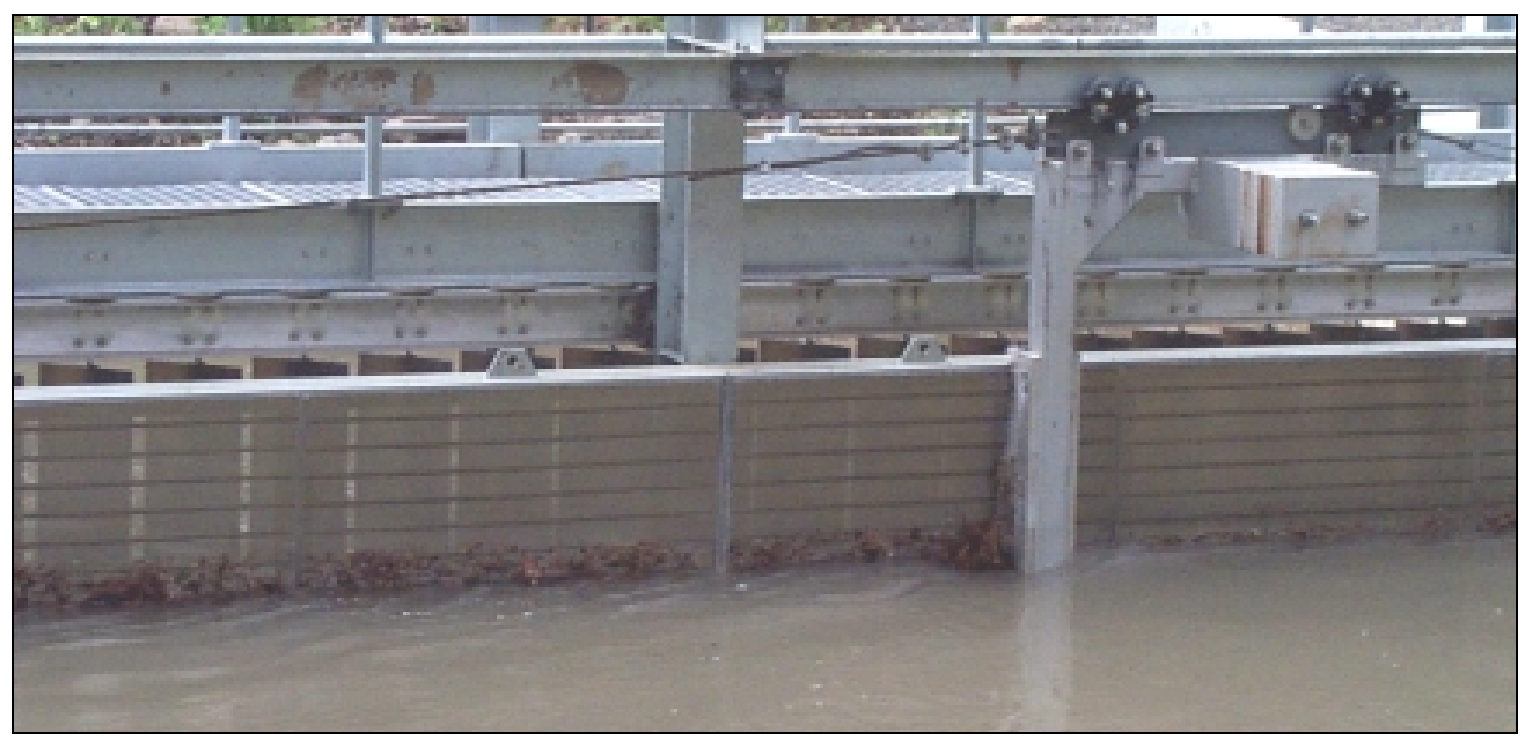

Figure 57. Leafy material accumulating on the Yakima Tieton screen, 5/12/98.

In September, we observed a dead kokanee caught in woody debris in the bypass (Figure 58). We assume the fish was dead before it got there because two other dead fish were observed floating down the canal while we were evaluating the site. It is assumed they did not survive the annual "flip-flop" event at the upstream reservoir.

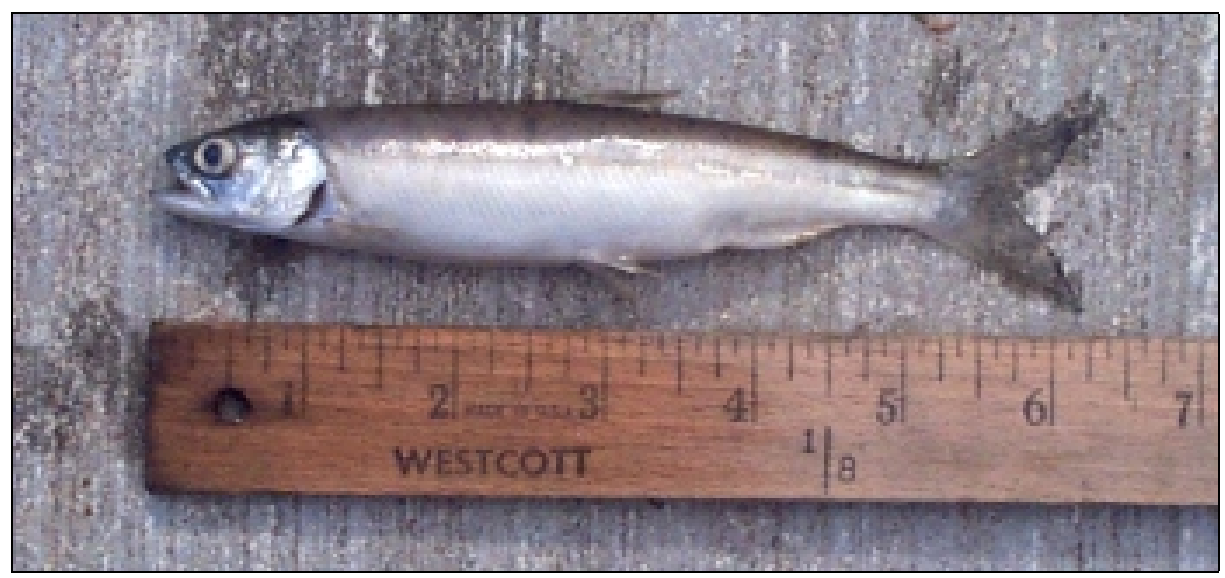

Figure 58. Kokanee retrieved from the bypass at Yakima Tieton, 5/12/98. 


\section{Vertical Traveling Screen}

\section{Gleed}

The Gleed site was evaluated 5/11/98, 7/7/98, and 9/21/98. Electrical interference prevented us from collecting any reliable water velocities.

Improvements to the site in 1998 included straightening the platform that was bent in 1997 and replacement of the metal panels across the trash rack.

In May, small 1- to 2-ft sections of 3/32-in. perforated plate were attached near the top of the screens to keep debris and fish out of the canal during high water conditions. They did not appear to be very effective, and some had already come unfastened. Also, the wire mesh screen still did not meet NMFS criteria for screen opening sizes; plastic screens with 3/32 openings had not been installed as planned.

Flow patterns were similar to those observed in 1997, where water flowed downstream in front of Screens 1 and 2 and upstream in front of Screens 3 and 4 (screens are numbered upstream to downstream). Although we cannot call our approach velocity recordings reliable because of the electrical interference, all were measured at less than $0.4 \mathrm{fps}$. Screen submergence values were approximately $62.5,61.7$, and $72.5 \%$.

Screen condition was good with the exception of a few bent wires. Several seals showed signs of wear.

At each evaluation, there were numerous sticks observed between the screens and the trash rack. Large logs had washed up during early flooding events near the diversion. Silt did not accumulate at this site. 


\section{References}

Abernethy, C.S., D.A. Neitzel, and W.V. Mavros. 1996. Movement and Injury Rates for Three Life Stages of Spring Chinook Salmon Oncorhynchus tshawytscha: A Comparison of Submerged Orifices and an Overflow Weir for Fish Bypass in a Modular Rotary Drum Fish Screen. Prepared by the Pacific Northwest National Laboratory for the Division of Fish and Wildlife, Bonneville Power Administration, Portland, Oregon.

Abernethy, C.S., D.A. Neitzel, and E.W. Lusty. 1990. Velocity Measurements at Three Fish Screen Facilities in the Yakima River Basin, Washington, Summer 1989. Prepared by the Pacific Northwest Laboratory for the Division of Fish and Wildlife, Bonneville Power Administration, Portland, Oregon.

Blanton, S.L., D.A. Neitzel, and C.S. Abernethy. 1998. Washington Phase II Fish Diversion Screen Evaluations in the Yakima River Basin, 1997. Prepared by the Pacific Northwest Laboratory for the Division of Fish and Wildlife, Bonneville Power Administration, Portland, Oregon.

Bryant, F.G., and Z.E. Parkhurst. 1950. Survey of the Columbia River and its tributaries; Part 4: Area III Washington streams from the Klickitat and Snake Rivers to Grand Coulee Dam, with notes on the Columbia and its tributaries above Grand Coulee Dam. U.S. Fish and Wildlife Service Special Scientific Report: Fisheries No. 37.

National Marine Fisheries Service (NMFS). 1995. Juvenile Fish Screen Criteria. National Marine Fisheries Service Environmental \& Technical Services Division, Portland, Oregon.

Neitzel, D.A., S.L. Blanton, C.S. Abernethy, and D.S. Daly. 1997. Movement of Fall Chinook Salmon Fry Oncorhynchus tshawytscha: A Comparison of Approach Angles for Fish Bypass in a Modular Rotary Drum Fish Screen. Prepared by the Pacific Northwest National Laboratory for the Environment, Fish and Wildlife Division, Bonneville Power Administration, Portland, Oregon. 
Neitzel, D.A., C.S. Abernethy, and E.W. Lusty. 1990a. A Fisheries Evaluation of the Toppenish Creek, Wapato, and Sunnyside Fish Screening Facilities, Spring 1988. Prepared by the Pacific Northwest Laboratory for the Division of Fish and Wildlife, Bonneville Power Administration, Portland, Oregon.

Neitzel, D.A., C.S. Abernethy, and E.W. Lusty. 1990b. A Fisheries Evaluation of the Westside Ditch and Wapato Canal Fish Screening Facilities, Spring 1989. Prepared by the Pacific Northwest Laboratory for the Division of Fish and Wildlife, Bonneville Power Administration, Portland, Oregon.

Neitzel, D.A., C.S. Abernethy, E.W. Lusty, and S.J. Wampler. 1988. A Fisheries Evaluation of the Richland and Wapato Canal Fish Screening Facilities, Spring 1987. Prepared by the Pacific Northwest Laboratory for the Division of Fish and Wildlife, Bonneville Power Administration, Portland, Oregon.

Neitzel, D.A., C.S. Abernethy, and E.W. Lusty. 1986. A Fisheries Evaluation of the Richland and Toppenish/Satus Fish Screening Facilities, Spring 1986. Prepared by the Pacific Northwest Laboratory for the Division of Fish and Wildlife, Bonneville Power Administration, Portland, Oregon.

Neitzel, D.A., C.S. Abernethy, E.W. Lusty, and L.A. Prohammer. 1985. A Fisheries Evaluation of the Sunnyside Canal Fish Screening Facility, Spring 1985. Prepared by the Pacific Northwest Laboratory for the Division of Fish and Wildlife, Bonneville Power Administration, Portland, Oregon.

Northwest Power Planning Council (NPPC). 1994. Fish and Wildlife Program: Measure 7.10. Northwest Power Planning Council, Portland, Oregon.

Northwest Power Planning Council (NPPC). 1987. Fish and Wildlife Program: 1403.4. Northwest Power Planning Council, Portland, Oregon.

Northwest Power Planning Council (NPPC). 1984. Fish and Wildlife Program: Measure 704(d). Northwest Power Planning Council, Portland, Oregon. 